\title{
INTERAÇÕES GENÓTIPOS X AMBIENTES E ESTABILIDADE FENOTÍPICA EM CANA-DE-AÇÚCAR NO ESTADO DE SÃO PAULO
}

\author{
ARNALDO JOSÉ RAIZER \\ Engenheiro Agrônomo
}

Orientador: Prof. Dr. ROLAND VENCOVSKY

\begin{abstract}
Dissertação apresentada à Escola Superior de Agricultura "Luiz de Queiroz", Universidade de São Paulo, para obtenção do título de Mestre em Agronomia, Área de Concentração: Genética e Melhoramento de Plantas.
\end{abstract}

$P \mid R A C I C A B A$

Estado de São Paulo - Brasil

Fevereiro - 1998 
Dados Internacionais de Catalogação na Publicação (CIP) DIVISÃo DE BIBLIOTECA E DOCUMENTAÇÃO - Campus "Luiz de Queiroz"/USP

\section{Raizer, Arnaldo José}

Interaçōes genótipos $x$ ambientes e estabilidade fenotípica em cana-de-açúcar no Estado de São Paulo / Arnaldo José Raizer. - Piracicaba, 1998.

$103 \mathrm{p}$.

Dissertação (mestrado) - Escola Superior de Agricultura Luiz de Queiroz, 1998. Bibliografia.

1. Clone cana-de-açúcar 2. Estabilidade 3. Fenótipo 4. Interaçăo genótipoambiente 5. Variedade I. Título 


\section{INTERAÇŌES GENÓTIPOS X AMBIENTES E ESTABILIDADE FENOTÍPICA EM CANA-DE-AÇÚCAR NO ESTADO DE SÃO PAULO}

ARNALDO JOSÉ RAIZER

Aprovado em: 08.04.98

Comissão Julgadora:

Prof. Dr. Roland Vencovsky ESALQ-USP

Prof. Dr. Natal Antonio Vello ESALQ-USP

Dr. William Lee Burnquist COPERSUCAR

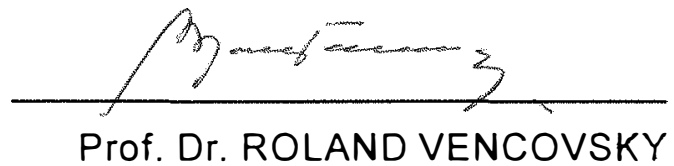

Orientador 
Agradeço a Deus, pelo amparo, permitindo o alcance de mais um degrau.

Dedico este trabalho aos meus pais e irmãos, pelo apoio, carinho e incentivo prestados durante toda a vida.

Às minhas queridas esposa Carla e filhas Mariana e Bruna, ofereço com amor. 
"O destino dos homens segue leis imutáveis que têm de ser cumpridas. Mas o homem tem o poder de moldar seu destino, na medida em que sua conduta o expõe à influência de forças benéficas ou destrutivas. Quando um homem está numa posição elevada e é modesto, ele brilha com a luz da sabedoria. Quando ele está numa posição inferior e é modesto, não pode ser ignorado ".

I Ching - O livro das Mutações (Antiga China) 


\section{AGRADECIMENTOS}

À Diretoria da Cooperativa dos Produtores de Cana, Açúcar e Álcool do Estado de São Paulo - Copersucar - pela oportunidade de aprofundar meus estudos no melhoramento genético da cana-de-açúcar. Espero que os conhecimentos obtidos sejam proveitosos e de grande utilidade nesta cultura.

Ao Prof. Dr. Roland Vencovsky, pela orientação e suporte prestados

durante o curso de pós-graduação. Agradeço as horas dedicadas, que contribuíram não apenas para a qualidade deste trabalho, mas também para minha formação acadêmica e profissional.

Aos Drs. William Lee Burnquist e Guilherme Rossi Machado Jr., da Gerência de Fitotecnia e da Divisão de Melhoramento da Copersucar, respectivamente, pela possibilidade de realizar meus estudos ao nivel de mestrado.

Especialmente ao $\mathrm{Eng}^{\circ} \mathrm{Agr}^{\circ}$ José Antonio Bressiani, da Copersucar, pela amizade, apoio e incentivo, além do auxilio na realização deste trabalho.

Aos Drs. Jorge Alberto Gonçalves da Silva, da Copersucar, e Marcelo de Almeida Silva, do Instituto Agronômico de Campinas, pela atenção e colaboração neste trabalho. Aos $\mathrm{Eng}^{\circ{ }^{\mathrm{s}}} \mathrm{Agr}^{{ }^{\circ} \mathrm{s}}$ René de Assis Sordi e Marcos Virgílio Casagrande, ao Estatístico Rubens Leite do Canto Braga Jr. e ao digitador Ronaldo Jorge Olegário, todos da Copersucar, pelas sugestões apresentadas e pelo auxílio na análise dos dados. 
Agradeço também aos técnicos agrícolas, que com eficiência vêm conduzindo os trabalhos de campo nos ensaios do programa de melhoramento da Copersucar, proporcionando a obtenção de informações confiáveis de novas variedades. Especialmente a Orlando Ferreira da Cruz, Hitler Magnoni de Grava, José Galdino Nobre, Rogério Jorge e José Leonel Pasqualinotto.

Aos membros da minha comissão julgadora, Drs. Roland Vencovsky, Natal Antonio Vello e William Lee Burnquist, que merecem minha gratidão pela amizade e por colaborar com minha formação na pesquisa científica.

Aos professores do Depto. de Genética, especialmente aos Drs. Cláudio Lopes de Souza Júnior, Gerhard Bandel e Isaias Olivio Geraldi. Às funcionárias Léia, Silvana e Bete, pela atenção dispensada.

Finalmente, gostaria de prestar meus agradecimentos a todos os colegas da pós-graduação, pela amizade e experiência obtidas durante o curso, especialmente aos $\mathrm{Eng}^{\circ \mathrm{s}} \mathrm{Agr}^{\mathrm{O}^{\mathrm{S}}}$ Antonio Augusto Franco Garcia, José Baldin Pinheiro e Rogério de Melo Costa Pinto. Agradeço também aos amigos e familiares, que de uma forma ou outra serviram de auxilio e estímulo na execução do presente trabalho. 


\section{SUMÁRIO}

Item

pág.

AGRADECIMENTOS

V

SUMÁRIO

VII

LISTA DE ANEXOS ..............................................................

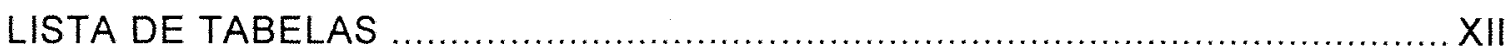

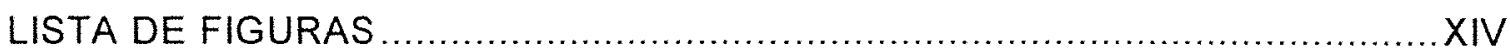

LISTA DE ABREVIATURAS E SIMBOLOS ............................................ XV

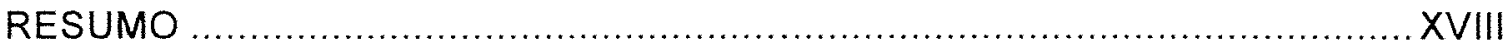

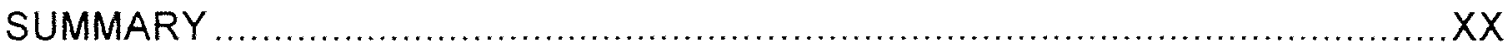

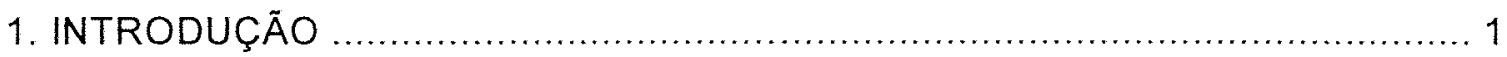

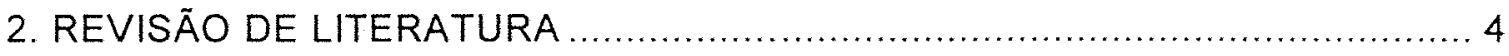

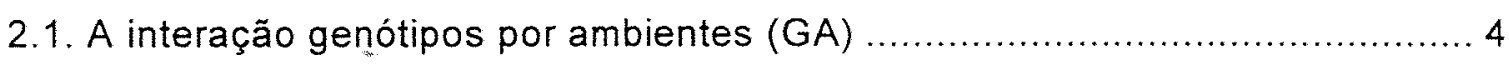

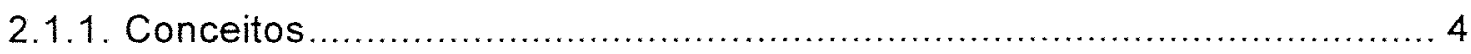

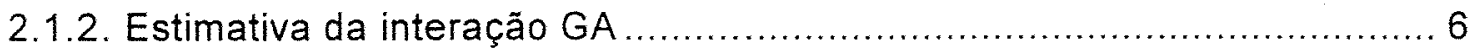

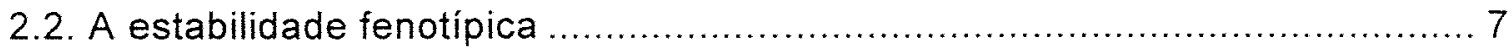

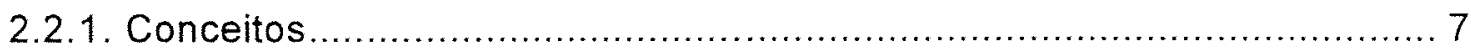

2.2.2. Métodos utilizados para estimar a estabilidade fenotípica.................... 9

2.3. Aplicações na cultura da cana-de-açúcar ......................................... 16

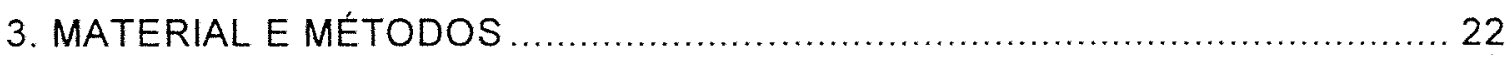

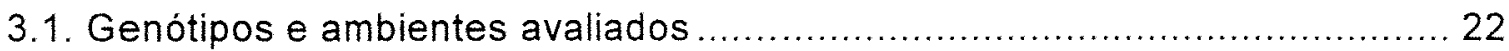

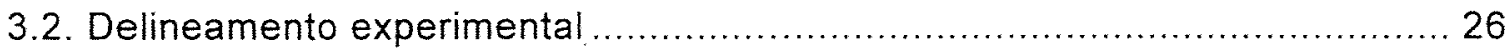

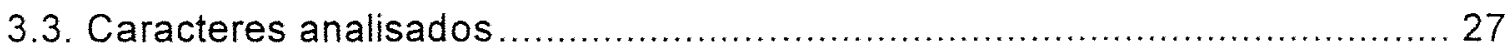

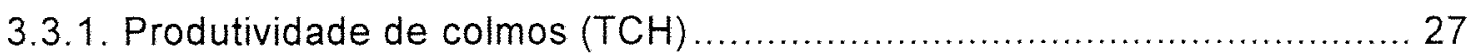




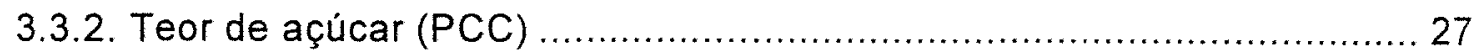

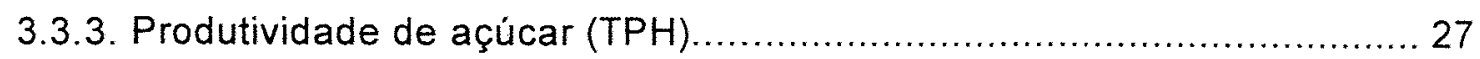

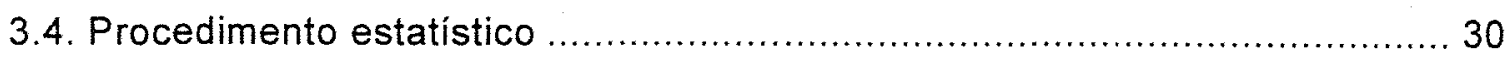

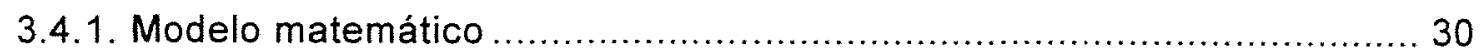

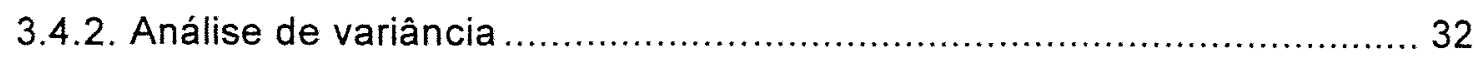

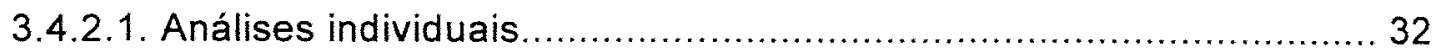

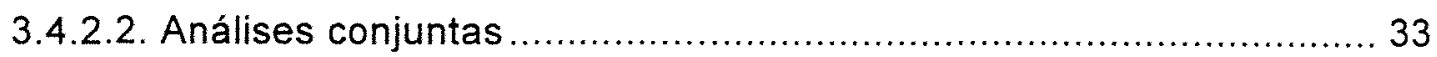

3.5. Parâmetros estimados em relação à produtividade de açúcar..................... 36

3.5.1. Estimativas da interação genótipos $X$ ambientes ................................ 36

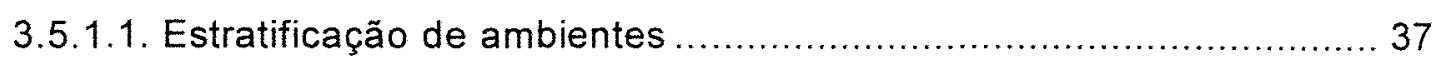

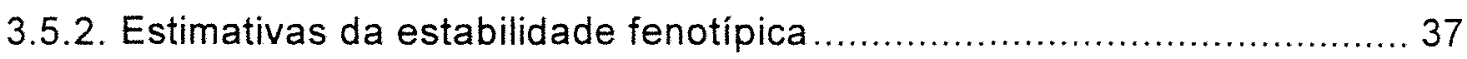

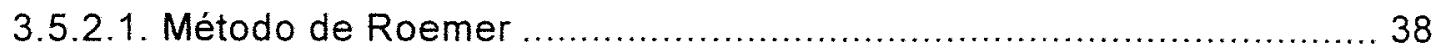

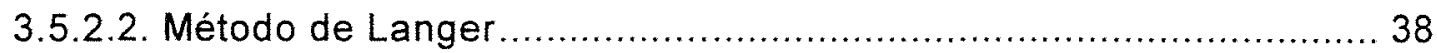

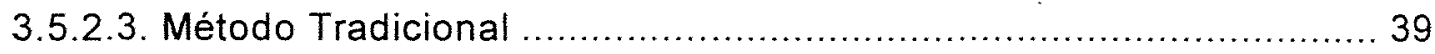

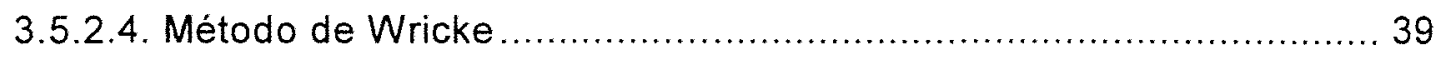

3.5.2.5. Método de Plaisted \& Peterson .................................................. 40

3.5.2.6. Método de Eberhart \& Russel .................................................... 40

3.5.2.7. Método de Silva \& Barreto ...................................................... 42

3.5.2.8. Método de Cruz, Torres \& Vencovsky ...................................... 42

3.5.3. Correlação ordinal entre os parâmetros de estabilidade fenotípica ........ 43

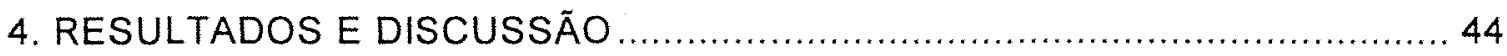

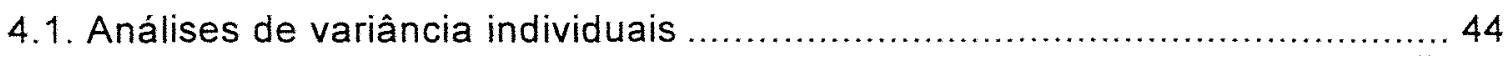

4.1.1. Grupo 1 - Ensaio de Caracterização/92 ............................................. 44

4.1.2. Grupo 2 - Ensaio de Caracterização/93 ….......................................... 45

4.1.3. Grupo 3 - Ensaio de Caracterização/94 …........................................ 45

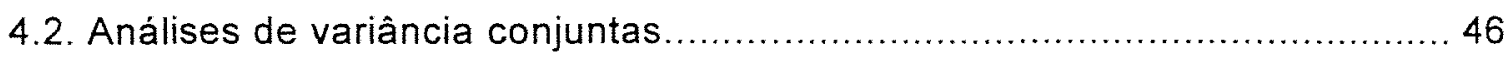

4.2.1. Grupo 1 - Ensaio de Caracterização/92 …......................................... 48

4.2.2. Grupo 2 - Ensaio de Caracterização/93 ….......................................... 48

4.2.3. Grupo 3 - Ensaio de Caracterização/94 ............................................ 49

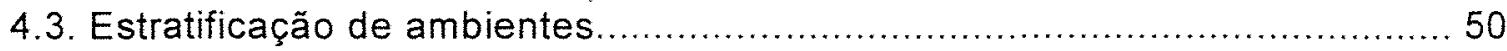

4.4. Comparação das médias obtidas para a estimativa de cinco cortes ............ 52 
4.4.1. Grupo 1 - Ensaio de Caracterização/92 ......................................... 54

4.4.2. Grupo 2 - Ensaio de Caracterização/93 ....................................... 55

4.4.3. Grupo 3 - Ensaio de Caracterização/94 .......................................... 56

4.5. Parâmetros de estabilidade fenotípica obtidos para a estimativa de cinco

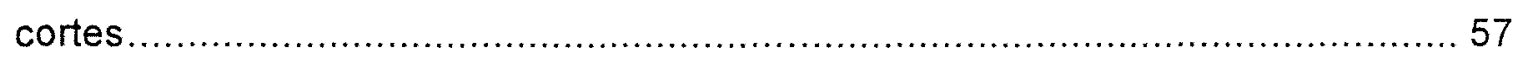

4.5.1. Estimativas dos parâmetros dos Grupos A e B ............................... 57

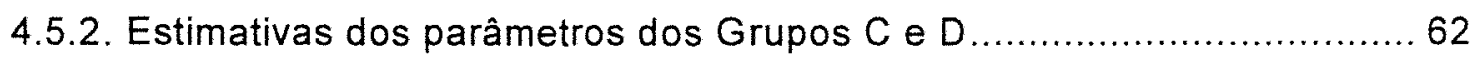

4.5.2.1. Método de Eberhart \& Russel.................................................. 62

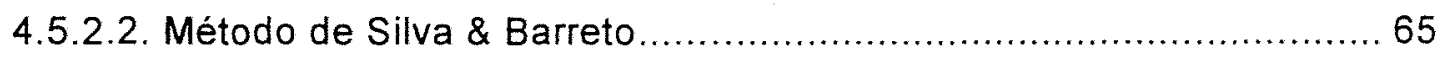

4.5.2.3. Método de Cruz, Torres \& Vencovsky ....................................67

4.6. Estimativas de correlação ordinal ( $r_{u u^{\prime}}$ de Spearman) entre os parâmetros de

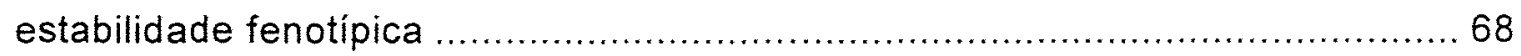

4.6.1. Parâmetros de estabilidade dos Grupos A e B.................................68 68

4.6.2. Parâmetros de estabilidade dos Grupos A, B, C e D ....................... 71

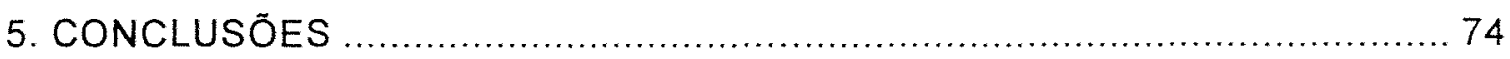

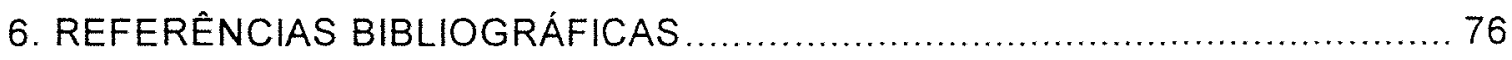

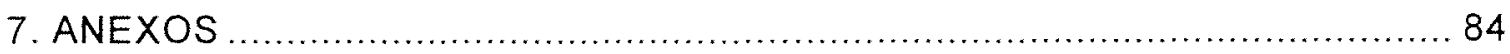




\section{LISTA DE ANEXOS}

Anexo

página

1. Resultados das análises de variância individuais e parâmetros genéticos em cada ambiente. Estimativas para a variável produtividade de colmos (TCH) no Ensaio de Caracterização/92. Média para 25 genótipos analisados, nos referidos cortes.

2. Resultados das análises de variância individuais e parâmetros genéticos em cada ambiente. Estimativas para a variável teor de sacarose (PCC) no Ensaio de Caracterização/92. Média para 25 genótipos analisados, nos referidos cortes

3. Resultados das análises de variância individuais e parâmetros genéticos em cada ambiente. Estimativas para a variável produtividade de açúcar (TPH) no Ensaio de Caracterização/92. Média para 25 genótipos analisados, nos referidos cortes

4. Resultados das análises de variância individuais e parâmetros genéticos em cada ambiente. Estimativas para a variável produtividade de colmos (TCH) no Ensaio de Caracterização/93. Média para 20 genótipos analisados, nos referidos cortes .88

5. Resultados das análises de variância individuais e parâmetros genéticos em cada ambiente. Estimativas para a variável teor de sacarose (PCC) no Ensaio de Caracterização/93. Média para 20 genótipos analisados, nos referidos cortes

6. Resultados das análises de variância individuais e parâmetros genéticos em cada ambiente. Estimativas para a variável produtividade de açúcar (TPH) no Ensaio de Caracterização/93. Média para 20 genótipos analisados, nos referidos cortes. 90

7. Resultados das análises de variância individuais e parâmetros genéticos em cada ambiente. Estimativas para a variável produtividade de colmos (TCH) no Ensaio de Caracterização/94. Média para 20 genótipos analisados, nos referidos 
cortes

8. Resultados das análises de variância individuais e parâmetros genéticos em cada ambiente. Estimativas para a variável teor de sacarose (PCC) no Ensaio de Caracterização/94. Média para 20 genótipos analisados, nos referidos cortes

9. Resultados das análises de variância individuais e parâmetros genéticos em cada ambiente. Estimativas para a variável produtividade de açúcar (TPH) no Ensaio de Caracterização/94. Média para 20 genótipos analisados, nos referidos cortes

10. Resultados das análises conjuntas de variância e parâmetros genéticos obtidos. Estimativas para as variáveis TCH, PCC e TPH no Ensaio de Caracterização/92, para os respectivos cortes. Estimativas para 25 genótipos analisados em 14 ambientes. .94

11. Resultados das análises conjuntas de variância e parâmetros genéticos obtidos. Estimativas para as variáveis $T C H, P C C$ e $T P H$ no Ensaio de Caracterização/93, para os respectivos cortes. Estimativas para 20 genótipos analisados em 16 ambientes .95

12. Resultados das análises conjuntas de variância e parâmetros genéticos obtidos. Estimativas para as variáveis TCH, PCC e TPH no Ensaio de Caracterização/94, para os respectivos cortes. Estimativas para 20 genótipos analisados em 13 ambientes. 96

13. Resultados médios de quatro repetições para os genótipos (GEN.) em cada local (amb.) para a variável produtividade de açúcar estimada para cinco cortes (TPH5), nos três grupos de ensaios avaliados 


\section{LISTA DE TABELAS}

Tabela

página

1. Clones e variedades de cana-de-açúcar estudadas e seus respectivos genitores.

2. Distribuição dos ensaios instalados com localização, características das áreas

e datas de plantio e colheitas 25

3. Participação porcentual das fontes de variação na soma de quadrados da análise conjunta, para as diferentes variáveis nos grupos de ensaios. 49

4. Grupos formados através da estratificação de ambientes para a variável teor de sacarose médio (PCCM).

5. Resultados dos genótipos (GEN.) para as variáveis estimatidas de cinco cortes. Médias para todos os locais (ambientes) avaliados... .53

6. Classificação entre as médias dos genótipos (GEN.) nos diversos locais avaliados. Variáveis estimadas para cinco cortes, Grupo 1, Ensaio de Caracterização/92. Comparação através do Teste de Tukey $(5 \%)$. .54

7. Classificação entre as médias dos genótipos (GEN.) nos diversos locais avaliados. Variáveis estimadas para cinco cortes, Grupo 2, Ensaio de Caracterização/93. Comparação através do Teste de Tukey $(5 \%)$. .55

8. Classificação entre as médias dos genótipos (GEN) nos diversos locais avaliados. Variáveis estimadas para cinco cortes, Grupo 3, Ensaio de Caracterização/94. Comparação através do Teste de Tukey $(5 \%)$. .56

9. Produtividade de açúcar e estimativas dos parâmetros de estabilidade calculados para a variável TPH5, para os genótipos (GEN.) do Ensaio de Caracterização/92 (Grupo 1). .59

10. Produtividade de açúcar e estimativas dos parâmetros de estabilidade calculados para a variável TPH5, para os genótipos (GEN.) do Ensaio de Caracterização/93 (Grupo 2). 
11. Produtividade de açúcar e estimativas dos parâmetros de estabilidade calculados para a variável TPH5, para os genótipos (GEN.) do Ensaio de Caracterização/94 (Grupo 3).

12. Estimativas dos parâmetros de estabilidade calculados para a regressão linear da variável TPH5 em relação ao índice ambiental ( lj ). Valores estimados para cada genótipo (GEN.) nos Ensaios de Caracterização 92, 93 e 94, segundo o método de Eberhart \& Russel 64

13. Estimativas dos parâmetros de estabilidade calculados para a regressão linear da variável TPH5 em relação aos índices ambientais ( lj ) e $T(\mathrm{lj})$. Valores estimados para cada genótipo (GEN.) nos Ensaios de Caracterização 92, 93 e 94 , segundo o método de Silva \& Barreto. 66

14. Estimativas dos parâmetros de estabilidade calculados para a regressão linear da variávelTPH5 em relação aos indices ambientais ( lj ) e $T($ lj $)$. Valores estimados para cada genótipo (GEN.) nos Ensaios de Caracterização 92, 93 e 94, segundo o método de Cruz, Torres e Vencovsky 68

15. Estimativas da correlação ordinal entre a produtividade de açúcar (TPH5) e os parâmetros de estabilidade dos grupos A e B, nos Ensaios de Caracterização 92, 93 e 94 .70

16. Estimativas da correlação ordinal entre a produtividade de açúcar (TPH5) e os principais parâmetros de estabilidade dos grupos $A, B, C$ e $D$, nos Ensaios de Caracterização 92, 93 e 94 


\section{LISTA DE FIGURAS}

Figura

página

1. Localização das principais regiões canavieiras do Estado de São Paulo, com subdivisão por tipos de solos e localização dos ensaios..................................24

2. Atividades realizadas nos ensaios de competição de clones de cana-deaçúcar. .29 


\section{LISTA DE ABREVIATURAS E SIMBOLOS}

NATT : Cooperativa Regional dos Produtores de Açúcar e Álcool de Alagoas;

SINDAÇÚCAR : Sindicato da Indústria do Açúcar e do Álcool no Estado de Pernambuco;

$\mathrm{TCH}$ : tonelada de cana por hectare, ou produtividade de colmos;

PCC : pol por cento cana, ou porcentagem de sacarose aparente nos colmos da cana-de-açúcar;

TPH : tonelada de pol por hectare, ou produtividade de açúcar;

Brix : porcentagem de sólidos solúveis aparente no caldo dos colmos da cana-deaçúcar;

seedling : em cana-de-açúcar, defini-se como a planta originária de semente sexuada;

$A Q$ : areia quartzosa;

LR : latossolo roxo;

LVA : latossolo vermelho-amarelo;

LVE : latossolo vermelho-escuro;

PVA : podzólico vermelho-amarelo;

PVE : podzólico vermelho-escuro;

TRE : terra roxa estruturada;

FV : fontes de variação;

GL : número de graus de liberdade;

$S Q$ : soma de quadrados;

QM : quadrado médio;

$E(Q M)$ : esperança do quadrado médio;

QMR : quadrado médio do resíduo; 
E : erro;

$M$ : média geral;

$B, b$ : número de repetições (blocos);

$\mathrm{G}, \mathrm{g}$ : número de tratamentos (genótipos);

$\mathrm{L}, \ell:$ número de locais (ambientes);

(GA), (GL) : interação de genótipos por ambientes ou locais;

i : relativo a genótipo;

$\mathrm{j}$ : relativo a local;

k: relativo a bloco;

$I_{j}$ e $T\left(I_{j}\right):$ medida dos índices do ambiente $j ;$

bou $_{\mathrm{i}}$ : coeficiente de regressão linear;

$\mathrm{R}^{2}$ : coeficiente de determinação da regressão linear;

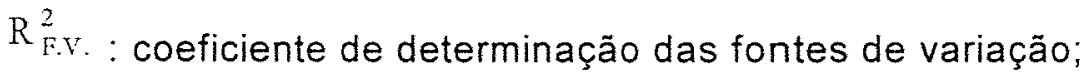

$\mathrm{CV}_{\mathrm{e}} \%$ : coeficiente de variação do erro (ambiental);

$\mathrm{CV}_{\mathrm{g}} \%$ : coeficiente de variação genético;

$\hat{\mathrm{h}}_{\mathrm{m}}^{2}$ : estimativa da herdabilidade ao nível de média;

$G_{s}$ : ganho na seleção;

$\hat{\sigma}_{\mathrm{g}}^{2}$ : estimativa da variância genética;

$\hat{\mathrm{V}}_{\mathrm{g}}$ : estimativa da diversidade genética; 
$\hat{\sigma_{\mathrm{e}}^{2}}, \hat{\sigma^{2}}$ : estimativa da variância do erro ou ambiental;

$\hat{\sigma_{\mathrm{f}}^{2}}$ : estimativa da variância fenotípica;

$\widehat{\sigma}_{\mathrm{d}}^{2}$ : estimativa da variância dos desvios da regressão;

$\hat{\sigma_{g \ell}^{2}}, \quad \hat{\sigma}_{g a}^{2}$ : estimativa da variância da interação genótiposxlocais ou genótiposxambientes;

$\sigma_{g(\ell)}^{\hat{2}}$ : estimativa da variância entre genótipos dentro de locais (ambientes). 


\title{
INTERAÇÕES GENÓTIPOS X AMBIENTES E ESTABILIDADE FENOTÍPICA EM CANA-DE-AÇÚCAR NO ESTADO DE SÃO PAULO
}

\author{
Autor: Arnaldo José Raizer \\ Orientador: Prof. Dr. Roland Vencovsky
}

\section{RESUMO}

No presente trabalho foram avaliados 48 clones experimentais de cana-de-açúcar (Saccharum spp.), em comparação com oito variedades de cultivo comercial. Três diferentes grupos de experimentos, conduzidos no período de 1992 a 1996, foram analisados em diferentes regiões do Estado de São Paulo, para as variáveis produtividade de colmos (TCH), teor de sacarose dos colmos (PCC) e produtividade de açúcar (TPH). Estes caracteres foram avaliados para os cortes 1, 2 e média estimada para cinco cortes.

$\mathrm{Na}$ análise conjunta foram avaliadas as fontes de variação de genótipos (clones ou variedades), ambientes (locais de experimentação) e da interação GA (genótiposxlocais). A variação total estimada para os caracteres em avaliação foi causada principalmente pela grande variabilidade existente entre os locais de experimentação. Variabilidade menor, mas também altamente significativa, foi proporcionada pela diversidade genética das variedades estudadas e pela interação destas com os ambientes. A existência de interação GA considerável justificou estudos de estratificação de ambientes e de estabilidade fenotípica. 
Para teor de sacarose (PCC) observou-se menor proporção da interação GA na variabilidade total do caráter. Desta forma foi possível estabelecer agrupamentos para esta característica, sendo que em diversos dos grupos formados houve indícios de padrões comuns de maturação entre os genótipos, o que ocorreu para ambientes localizados em regiões próximas ou com características de solo semelhantes.

Entre os cinco métodos avaliados para estimativa da estabilidade fenotipica, do tipo biológica, obteve-se maior facilidade de uso e independência dos parâmetros para as metodologias de Roemer e Langer, em relação ao método de Wricke. Estes métodos devem ser utilizados em conjunto com a produtividade de açúcar na seleção de novos clones.

Para a avaliação da estabilidade fenotipica, do tipo agronômica, foram correlacionadas três metodologias baseadas em regressão linear. Os dois métodos bi-segmentados forneceram informações mais detalhadas de adaptação e previsibilidade da resposta ambiental. Destes, o método de Cruz, Torres e Vencovsky (1989) deve ser preferido pois, além de discriminar melhor o comportamento adaptativo dos genótipos, não apresentou 0 inconveniente estatístico de correlação entre os coeficientes de regressão $b_{1} \in b_{2}$.

A produtividade de açúcar dos genótipos apresentou linearidade em relação a qualidade ambiental para diversas das variedades analisadas, sendo independente dos parâmetros de estabilidade e adaptabilidade. Desta forma há potencial para ganhos em produtividade com a melhoria ambiental e possibilidade de seleção simultânea de clones produtivos e com características desejáveis de estabilidade e adaptação ambiental.

As variedades SP83-5073, SP80-0185 e RB785148 destacaram-se em produtividade de açúcar, com níveis de estabilidade fenotípica favoráveis. Outros clones também apresentaram algumas características de estabilidade interessantes, devendo ser melhor avaliados para cultivo em condições específicas, ou empregados como padrões em futuros ensaios. 


\section{GENOTYPE-ENVIRONMENT INTERACTIONS AND PHENOTYPIC STABILITY IN SUGARCANE IN THE STATE OF SÃO PAULO}

Author: Arnaldo José Raizer

Adviser: Prof. Dr. Roland Vencovsky

\section{SUMMARY}

Forty eight sugarcane clones and eight commercial varieties were evaluated in the present study. Three different sets of trials, conducted from 1992 through 1996 in São Paulo state, were analysed for the variables stalk yield (TCH), sugar content (PCC) and sugar yield per hectare (TPH).

Analysis of Variance included genotypes (clones and varieties), sites and genotypes $x$ environment (GA) interaction as sources of variance. The total amount of variation for the variables was originated mainly from the great variability observed among the sites where the trials were conducted. A smaller variation, but still highly significant, was due to the genetic diversity of the varieties under study, besides the interaction between them with the environment. The observed GA interaction suggests that cluster analysis of environments and phenotypic stability studies are necessary.

A smaller proportion of the GA interaction, on the total variability for the trait, was observed for sugar content (PCC), which allowed the stablishiment of clusters for this trait. Within some clusters, a common sugar content standard, among genotypes, was observed for sites from nierby regions or with similar soil 
characteristics.

Among five methods for estimation of biological phenotipic stability, those from Roemer, Langer and Wricke showed greater easiness and parameter independence. These methods should be used togheter with sugar yield for clone selection.

For the investigation of agronomic stability for each genotype, three linear regression methods were correlated. The two way methods, Silva \& Barreto (1985) and Cruz, Torres e Vencovsky (1989), showed more detailed information on adaptability and prediction of the environment response. The method from Cruz, Torres e Vencovsky (1989) are prefered since allowed a better discrimination of genotypes for adaptability, besides this method did not show the statistic inconvenience of correlation between the regression coeficients $b_{1}$ and $b_{2}$.

The sugar yield for genotypes showed linearity with environmental quality for several varieties and independence from stability and adaptability parameters, suggesting the possibility of simultaneous selection of high yield clones with good environment adaptability and stability.

The varieties SP83-5073, SP80-0185 and RB785148 showed high yield and phenotypic stability. Other clones also showed favorable stability, requiring a more detailed study for specific conditions. These clones could also be used as checks in future competition trials. 


\section{INTRODUÇÃO}

A cana-de-açúcar (Saccharum spp.) ocupa atualmente cerca de 4,6 milhões de hectares no território brasileiro. Quase metade desta área se encontra no Estado de São Paulo, de onde provém aproximadamente $60 \%$ da produção nacional desta cultura, estimada em cerca de 300 milhões de toneladas (IBGE, 1996). A agro-indústria canavieira é responsável por milhões de empregos e geração de divisas pelo açúcar e o álcool, além do aproveitamento racional de biomassa vegetal, gerando energia elétrica e produtos para a indústria alcoolquímica e para a alimentação animal, entre outros.

Para manter toda a atividade econômica do setor deve-se produzir grande quantidade de matéria-prima, sendo necessário dispor de variedades adaptadas às diversas condições de solo, clima e práticas culturais encontradas no país.

Novas variedades de cana-de-açúcar são obtidas anualmente em programas de melhoramento existentes em instituiçōes de pesquisa no Brasil, ou mesmo por meio de seleções em algumas unidades produtoras. Procura-se indicar os melhores materiais para cada região produtora, possibilitando a utilização de variedades economicamente superiores. O objetivo é a melhoria da produtividade agrícola e das características industriais das variedades, que devem ser melhor adaptadas aos diferentes tipos de solos e técnicas de cultivo, além de apresentarem maior resistência a pragas e doenças.

Sabe-se que o fenótipo $(F)$ de um caráter é função do genótipo $(G)$, do ambiente (A) e da interação genótipos por ambientes (GA). Este último componente ocorre devido ao comportamento diferencial dos genótipos nos diferentes ambientes, devendo ser quantificado para determinar a sua importância 
na recomendação varietal e no programa de melhoramento genético. $O$ lançamento de novas variedades depende, portanto, da comprovação da superioridade do material genético em uma grande amplitude de condições ambientais, o que é denominado de estabilidade fenotípica.

Vários meios existem para atenuar o efeito da interação GA. Dentre eles, pelo menos três são considerados de maior importância: (a) identificação de variedades específicas para cada ambiente, o que muitas vezes é impraticável e envolve altos custos; (b) zoneamento ecológico, onde as variedades são agrupadas em ambientes semelhantes, cujo componente da interação é não significativo; e (c) identificação de variedades com maior estabilidade fenotípica.

No melhoramento de plantas existem dois conceitos de estabilidade fenotípica, estando intrinsicamente relacionados com os métodos de análise (Becker, 1981 e Becker \& Leon, 1988). No conceito estático, o genótipo deve possuir um nível de performance constante, independente de variações nas condições ambientais (estabilidade biológica ou homeostática). No conceito dinâmico, estabilidade agronômica, o genótipo deve possuir uma resposta previsivel à variação ambiental. Neste último caso, dentre os métodos biométricos utilizados destaca-se a regressão linear, que avalia a estabilidade agronômica, relacionando-a com a resposta produtiva das variedades entre os ambientes.

Entretanto existem limitações, tanto do ponto de vista estatístico como do ponto de vista biológico. As limitações estatísticas devem-se ao fato de as médias dos genótipos não serem independentes do indice ambiental, além da existência de relação linear, a qual nem sempre é verdadeira. O maior problema biológico ocorre quando alguns poucos ambientes de baixa ou de alta produtividade são incluídos na análise. Alguns métodos têm sido propostos para minimizar estas limitações, tais como: o uso de um índice ambiental independente, como por exemplo a média de cultivares testemunhas (Ferreira et al., 1992); a utilização de modelos de regressão bi-segmentados (Cruz et al., 1989; Silva \& Barreto, 1985 e Verma et al., 1978) e ainda a utilização de modelos não lineares, análises não paramétricas e análises multivariadas (Crossa, 1990 e Cruz, 1990). 
Para manter as metas de produção no país, torna-se necessária a expansão do cultivo da cana-de-açúcar para novas áreas, além do desenvolvimento de pesquisas para aumentar os índices de produtividade nas áreas tradicionais e garantir índices satisfatórios em áreas recém exploradas. Um programa de melhoramento deve, além de obter variedades adaptadas às condições específicas de determinados ambientes, buscar variedades com capacidade de explorar economicamente amplas faixas ambientais. Sendo assim, técnicas para avaliar a capacidade genética de adaptação ampla ou específica e o desempenho das variedades frente às variações ambientais devem fazer parte do programa de melhoramento.

O estudo da estabilidade fenotípica permite sintetizar, em poucos parâmetros, o enorme volume de informação obtido em um grande número de experimentos, distribuídos por locais e anos agrícolas diferentes. Estes parâmetros caracterizam a capacidade produtiva, a estabilidade fenotípica e o tipo de adaptação das variedades envolvidas nos experimentos, facilitando a recomendação das variedades e caracterizando-as para situações especificas de manejo.

Um dos objetivos do presente estudo é avaliar a variabilidade existente, tanto nos clones e variedades das fases finais do programa de melhoramento da Copersucar, como nos ambientes utilizados para experimentação. Espera-se estimar a magnitude da interação dos genótipos com os locais dos experimentos, verificando a possibilidade de agrupamento de ambientes para os caracteres avaliados. Além disso, verificar as características dos materiais promissores quanto à capacidade produtiva, tipo de adaptação aos ambientes avaliados e nivel de estabilidade fenotípica. Com o estudo da eficiência dos principais métodos de estabilidade, além do nível de associação entre estes, será avaliada a possibilidade da aplicação destes parâmetros no programa de melhoramento da cana-de-açúcar da Copersucar. 


\section{REVISÃO DE LITERATURA}

Nos programas de melhoramento da cana-de-açúcar, os melhoristas conduzem ensaios de competição com clones promissores de programas locais e de outras regiões, sendo que estes ensaios são normalmente realizados em vários anos e locais, comparando o desempenho de novas variedades com aquelas de amplo cultivo comercial. Tais estudos permitem avaliar a magnitude das interações de genótipos por ambientes e a estabilidade fenotípica de novos clones, mas, embora os dados assim obtidos possam auxiliar no processo de seleção de variedades, isso geralmente não ocorre.

Diversos autores têm apresentado considerações sobre a interação de genótipos por ambientes, sugerindo conceitos e indices de estabilidade, além de alguns métodos usados para estimar a estabilidade fenotípica em plantas.

\subsection{A interação genótipos por ambientes (GA)}

\subsubsection{Conceitos}

A interação de genótipos por ambientes, conhecida como GA, ocorre quando da constatação da expressão genotípica diferenciada entre ambientes, 0 que implica na redução da associação entre os valores genotípicos e fenotipicos. A seleção aplicada para determinado ambiente pode não ser eficiente em outro, diminuindo os ganhos de seleção. A interação entre genótipos e ambientes pode ser entendida de duas formas, a primeira quando a variância entre ambientes não é a mesma para todas as variedades, e a segunda, quando a ordem de classificação das variedades não é a mesma em todos os ambientes. 
O comportamento dos genótipos em relação ao ambiente tem merecido especial atenção por parte dos melhoristas. A interação entre genótipos e ambientes interfere na correta avaliação dos processos de seleção e nos resultados da mesma. Por esta razão, torna-se importante a estimativa da magnitude desta interação, bem como a utilização destes parâmetros na determinação da estabilidade fenotípica das diferentes variedades.

Comprovando tais dificuldades, Comstock \& Moll (1963) confirmaram que a interação de genótipos por ambientes tem constituído um importante problema nos programas de melhoramento vegetal, sendo que altas interações deste tipo têm reduzido os progressos na seleção.

Segundo Allard \& Bradshaw (1964) a variação ambiental pode ser classificada em duas categorias: previsivel e imprevisivel. A primeira refere-se às características permanentes do ambiente, como clima e solo, além de aspectos direcionados pela ação do homem nas práticas agricolas. A segunda corresponde às flutuações climáticas atípicas e variações pedológicas localizadas, também denominadas efeitos microambientais.

Para Tai (1971) o cultivo em larga escala de poucos genótipos, usual em diversas culturas, parece conflitante com a premissa de que as variedades respondem de modo diferenciado em ambientes distintos, além da maior vulnerabilidade a doenças e outros distúrbios bióticos. Segundo o autor, que trabalhou com a cultura da batata, pode-se minimizar os efeitos destas interações pela sub-divisão de uma região heterogênea em regiões mais homogêneas. Outra alternativa consiste na utilização de genótipos de alta estabilidade fenotípica. Salienta, ainda, que a primeira alternativa pode não ser muito eficiente em virtude de continuar havendo interações significativas dentro dos sub-grupos, como interações de genótipos por anos.

Segundo Lo (1987) situação similar levou os melhoristas a aumentar os esforços na seleção de variedades de cana-de-açúcar de ampla adaptação. Para minimizar o problema, os programas de melhoramento passaram a regionalizar os testes com clones nas fases finais de seleção. Em alguns casos, para aumentar a eficiência na obtenção de clones com maior adaptação local, 
pratica-se a seleção desde a fase de seedling em diversas estações experimentais distribuídas pela área canavieira.

\subsubsection{Estimativa da interação $G A$}

Segundo Vencovsky \& Barriga (1992) o processo tradicional de investigar as interações GA é a análise conjunta de variância, com grupos de experimentos, que pode ser visto em Pimentel Gomes (1990). Pelo desdobramento das somas de quadrados dos efeitos de ambientes e da interação $G A$, obtém-se as somas de quadrados para os efeitos de ambiente dentro de cada genótipo, que serve como estimativa da estabilidade do genótipo, sendo este mais estável quanto menor for tal estimativa. Os autores consideram que por esta análise, a magnitude de todos os tipos de interações, possiveis de serem estimadas, podem ser avaliadas conforme o propósito do melhorista. Os parâmetros estimados desta forma correspondem a estabilidade do tipo estática e, embora úteis, não fornecem uma indicação adequada da resposta dos genótipos nos diferentes ambientes onde são cultivados, sendo necessário o auxilio de análises complementares.

Ainda segundo Vencovsky \& Barriga (1992), fica demonstrado que a interação GA é de natureza genética, mas não no sentido usual, mas sim em decorrência da instabilidade das manifestações genotípicas entre ambientes. Em termos biométricos, a variância da interação GA pode ser dividida em duas partes. A primeira ocorre devido às diferenças na variabilidade genética, que ocorre dentro de ambientes (parte simples da interação). A segunda advém da falta de uma correlação linear perfeita entre os tratamentos genéticos, de um ambiente para outro (parte complexa da interação).

Segundo Fox et al. (1997) o fenômeno da interação GA é de extrema importância na determinação de aspectos em programas de melhoramento, como: (a) seleção para adaptação ampla ou específica; (b) escolha dos locais para seleção; (c) nivel de estresse nos ambientes escolhidos para as fases iniciais de seleção; (d) número ideal de ambientes e de genótipos a serem avaliados em cada fase de seleção. 
A extensa área cultivada com cana-de-açúcar no Brasil foi estratificada em regiões pelos programas de melhoramento então existentes. Inicialmente na região de Campos-RJ, com as variedades $C B$, no início deste século. Posteriormente pelo Instituto Agronômico de Campinas (variedades $(A C$ ), na década de 30 , e pelo Planalsucar e pela Copersucar, no final da década de 60 , com as variedades $R B$ e $S P$, respectivamente. Atualmente, a importância dos programas de melhoramento pode ser avaliada nos dados do censo varietal de cana-de-açúcar. Na safra de 1996 , cerca de $54 \%$ e $42 \%$ da área do Estado de São Paulo encontrava-se cultivada com variedades SP e RB (atualmente desenvolvidas por uma rede de Universidades Federais), respectivamente (COPERSUCAR, 1997). Programas locais de seleção de variedades também são desenvolvidos por algumas unidades produtoras, além de órgãos de pesquisa do nordeste, como o NATT e o SINDAÇÚCAR, que desenvolvem ensaios de competição com clones gerados nos programas de melhoramento citados anteriormente.

Apesar desta estratificação, ainda observa-se variação ambiental dentro de regiões, o que inviabiliza a obtenção de genótipos específicos para os diferentes ambientes. Considerando a fase atual do melhoramento da cana-deaçúcar no país, parece recomendável e de melhor aceitação comercial, a obtenção e cultivo de variedades estáveis, com adaptação satisfatória aos diferentes ambientes de uma região em particular.

\subsection{A estabilidade fenotípica}

\subsubsection{Conceitos}

Diversos autores têm definido o termo "estabilidade de produção" de plantas cultivadas de maneiras diferentes. Geralmente uma variedade é considerada estável se apresenta pequenas variações no seu comportamento geral, quando cultivada sob condições variadas de ambiente. Finlay \& Wilkinson (1963) definiram "estabilidade média" de uma forma dinâmica, para caracterizar 
uma variedade cuja produção varia de acordo com a capacidade dos ambientes em proporcionar altas ou baixas produtividades.

Segundo Becker (1981), um genótipo é considerado estável quando está consistentemente bem classificado. Se a estabilidade agronômica é demonstrada para uma grande amplitude de ambientes, então o genótipo é considerado de ampla adaptação. Se tal estabilidade estiver confinada a poucos locais, então o genótipo apresenta adaptação específica.

Lin et al. (1986) sugeriram três interpretações para os parâmetros de estabilidade, ou três tipos básicos de estabilidade fenotípica, sendo: Tipo 1 como estabilidade biológica, baseada na variância de ambientes dentro de genótipos, ou seja, $\hat{\sigma}_{\mathrm{g}(\ell)}^{2}$ igual a zero. Neste caso uma variedade é considerada estável se a sua variância entre ambientes for pequena; Tipo 2 - estabilidade agronômica, para resposta do genótipo aos ambientes paralela à resposta média de todos os genótipos testados, ou seja, $b_{i}$ igual a 1 (um); e Tipo 3 - alta confiabilidade na resposta estimada, ou seja, $\hat{\sigma}_{d}^{2}$ igual a 0 (zero). Os autores também identificaram quatro grupos de parâmetros estatísticos necessários para a avaliação destes tipos de estabilidade, sendo: Grupo A - estimativas a partir dos efeitos genotípicos; Grupo B - estimativas baseadas na variância da interação de genótipos por ambientes; Grupo C - baseado nos coeficientes de regressão; e Grupo D - baseado nos desvios de regressão. Na interpretação destes conceitos as estimativas dos grupos $\mathrm{A}$ e $\mathrm{B}$ avaliam a homeostase produtiva do genótipo ou estabilidade do tipo biológica, refletindo a uniformidade de produção entre os diversos ambientes, característica que logicamente será desejável em genótipos com boa produtividade média geral. As estimativas do grupo $\mathrm{C}$ explicam 0 comportamento do genótipo em termos de nível de resposta ao ambiente, indicando o tipo de adaptação, geral ou específica. As estimativas do grupo D expressam a confiabilidade no nível de resposta ao ambiente do genótipo, ou estabilidade do tipo agronômica.

Segundo Cruz \& Regazzi (1994), além das estimativas da interação 
GA, são necessárias avaliações de análises de adaptabilidade e estabilidade, pelas quais torna-se possível a identificação de cultivares de comportamento previsivel, que sejam responsivos às variações ambientais, em condições específicas ou amplas. Dos diversos métodos empregados com tal finalidade, a escolha de um deles depende dos dados experimentais, do número de ambientes disponiveis, da precisão requerida e do tipo de informação desejada. Consideram, também, que alguns métodos são alternativos, enquanto que outros são complementares, podendo ser usados conjuntamente.

Para o melhorista de plantas é de grande interesse o conceito de estabilidade da produção, no sentido de obter variedades que se comportem bem não apenas em um ambiente particular, mas também sob amplas faixas de cultivo, onde ocorrem diferentes condições ambientais. $O$ ambiente em questão pode ter várias interpretações, como locais (solo, clima, etc.), anos, épocas, sistemas de plantio ou colheita, técnicas de cultivo, etc. Sobre todos estes fatores pode, ainda, haver a interferência de condições bióticas e abióticas específicas.

A determinação de genótipos ideais é importante, por exemplo, para uma melhor caracterização das variedades aos produtores, escolha de testemunha para experimentos comparativos e escolha de genitores para cruzamentos, em programas de melhoramento.

\subsubsection{Métodos utilizados para estimar a estabilidade fenotípica}

Com o objetivo de transformar os dados biométricos obtidos em informações úteis ao melhoramento de plantas, avaliando conjuntamente o comportamento de genótipos e ambientes, diversos autores propuseram técnicas para estimação de parâmetros de estabilidade.

Numa das primeiras metodologias propostas para avaliar a estabilidade, baseada na interação GA, Roemert, citado por Duarte \& Zimmermann (1995), utilizou-se da variância fenotípica entre ambientes para

\footnotetext{
${ }^{1}$ ROEMER, T. Mitt. DLG. 32:87-89, 1917.
} 
caracterizar a estabilidade fenotípica de variedades. De forma similar, Francis \& Kannenberg (1978) sugeriram o uso do coeficiente de variação fenotípico. Nestes casos, avaliaram a chamada estabilidade biológica (estática).

Baseando-se em estimativas ambientais e fenotípicas extremas, StPierre et al. ${ }^{2}$ e, posteriormente, Langer et al. ${ }^{3}$, citados por Duarte \& Zimmermann (1995), obtiveram parâmetros de estabilidade em cevada e aveia, respectivamente.

Além de avaliar os efeitos genéticos, ambientais e suas interações, assim como as estimativas fenotípicas da estabilidade, a maioria dos autores passou a utilizar a regressão linear, como ferramenta para obter estimativas de parâmetros de estabilidade fenotípica.

Yates \& Cochran (1938) sugeriram a decomposição da interação variedades $x$ ambientes, determinando para cada variedade uma regressão linear da produtividade em relação à média da produtividade de todas as variedades em cada ambiente. Uma equação de regressão é ajustada para cada variedade que, representada em um gráfico de eixos cartesianos, mostra o comportamento individual de cada variedade sob o efeito dos diferentes ambientes.

Esta metodologia foi adaptada por Finlay \& Wilkinson (1963) para estudos de estabilidade em cultivares de cevada, considerando cada local ou ano como um ambiente. Inicialmente os autores estabeleceram indices ambientais $\left(I_{j}=X_{j}-X\right)$, onde:

$\mathrm{X}_{\mathrm{j}}$ corresponde à média aritmética de todos os I cultivares no ambiente $\mathrm{j}, \mathrm{com} \mathrm{j}=1,2, \ldots \mathrm{J}$;

$\mathrm{X}$ é a média geral do caráter, considerando todos os I cultivares e todos os $\mathrm{J}$ ambientes.

2 ST-PIERRE, C.A.; KLINCK, H.R. \& GAUTHIER, F.M. Can. J. Plant. Sci. 47:507-517, 1967.

${ }^{3}$ LANGER, I.; FREY, K.J. \& BAILEY, T. Euphytica. 28:17-24, 1979. 
Os autores transformaram previamente os dados para uma escala logarítmica, a fim de induzir um alto grau de linearização. A seguir, determinaram os coeficientes de regressão linear $b_{i}$ (com $i=1,2, \ldots l$, cultivares) entre a média do cultivar i em cada ambiente e os índices ambientais correspondentes. Para os autores um cultivar é considerado estável quando possuir b=0 (zero). Os cultivares seriam caracterizados por dois parâmetros: comportamento médio em todos os ambientes e o coeficiente de regressão (b). O cultivar ideal seria aquele que apresentasse produtividade média superior e $b=0$.

O método da regressão foi também utilizado por Eberhart \& Russel (1966), em milho, que introduziram um terceiro parâmetro para caracterizar os cultivares: a variância dos desvios da linearidade $\left(\hat{\sigma}_{d}^{2}\right)$. Para eles, a adaptabilidade refere-se à capacidade de os genótipos aproveitarem vantajosamente os estímulos do ambiente. A estabilidade diz respeito à capacidade de os genótipos mostrarem um comportamento altamente previsível, em função dos estímulos ambientais. A variedade ideal seria aquela que apresentasse produtividade média superior, $b=1$ e $\hat{\sigma}_{d}^{2}=0$.

Em relação ao método de Finlay \& Wilkinson (1963), o método de Eberhart \& Russel (1966) teria algumas vantagens. A primeira vantagem se refere ao coeficiente de regressão linear, pois cultivares com $b=1$ teriam potencial para responder à melhoria do ambiente, por exemplo através de insumo agricola ou irrigação, fato que não é esperado para cultivares com $b=0$. Esta vantagem assume importância maior quando se considera o fato de que normalmente $b=0$ está associado à produções inferiores, ou seja, adaptação a ambientes relativamente pobres. A segunda vantagem está relacionada à variância dos desvios da linearidade, pois um cultivar $\operatorname{com}{\hat{\sigma_{d}}}^{2}=0$ apresentaria padrão mais previsivel de resposta à melhoria ambiental. Ainda segundo alguns autores, a metodologia de Eberhart \& Russel (1966) deve ser preferida quando o número de ambientes for pequeno, até algo próximo de sete.

De acordo com Tai (1971), nas metodologias propostas por Finlay \& 
Wilkinson (1963) e Eberhart \& Russel (1966), a medida do indice ambiental $\left(I_{\mathrm{j}}\right)$, quantificada pelo desempenho dos próprios genótipos avaliados, está sujeita a erros. O autor propôs, então, um novo método, com parâmetros de adaptabilidade e estabilidade mais consistentes quando a variável independente $\left(I_{j}\right)$ estiver associada a erros.

Oliveira (1976), da mesma forma que outros autores, cita que o método mais simples para medir a estabilidade consiste na análise conjunta de variância de uma série de experimentos instalados em vários anos e locais. Além dos efeitos isolados de variedades, locais e anos, são estudados os efeitos das interações variedades $x$ locais, variedades $x$ anos, locais $x$ anos $e$ variedades $x$ locais $x$ anos, de modo a proporcionar estimativas das magnitudes de suas variâncias. Considerando as combinações de locais e anos por ambientes, a variação de ambientes dentro de cada variedade é uma medida da estabilidade da variedade. A variedade que apresentar a menor variação, estimada pelo quadrado médio dos desvios de ambientes dentro da variedade, é considerada a mais estável. Segundo Finlay \& Wilkinson (1963), este método é adequado para indicar a existência das interações, mas de baixa precisão, como medida básica de adaptabilidade, além de ser de difícil uso quando se avalia um grande número de genótipos.

Posteriormente, Verma et al. (1978), propuseram uma modificação nos métodos anteriores, dividindo os diversos ambientes de avaliação em dois sub-grupos, de acordo com o desvio em relação à média geral dos locais. Um grupo representaria os ambientes desfavoráveis (sob estresse ou baixa tecnologia) e o outro os favoráveis (de qualidade superior, sem estresse ou com alta tecnologia). Tal método foi o primeiro a usar o ajustamento de dois segmentos de reta, caracterizando uma regressão segmentada e bi-linear. Como deficiência, esta metodologia necessita de um grande número de locais de avaliação, pois são obtidas duas regressões lineares com menor número de pontos, o que prejudica os ajustes.

Para contornar este problema, Silva \& Barreto (1985) propuseram a 
utilização da regressão linear múltipla com dois segmentos de reta. Desta forma, com o uso de regressão bi-segmentada, os autores adotaram a idéia de Verma et al (1978), aprimorando-a do ponto de vista estatístico. Neste método a regressão passa a ser contínua, sendo que o ponto de inflexão das retas corresponde ao ambiente médio.

Outro passo foi dado por Cruz et al. (1989) que modificaram o método de Silva \& Barreto (1985), pela introdução de modelo de regressão descontínuo, com estimativas não correlacionadas dos coeficientes de regressão. Possiveis níveis de correlação entre os parâmetros $b$, neste novo método, serão decorrentes das propriedades genéticas dos materiais estudados, não mais devidos à existência de uma correlação residual ou intrínseca entre as estimativas de b. Nestas duas últimas técnicas, contudo, permanece a concepção original de Verma et al (1978), que permite a caracterização de cada genótipo por dois coeficientes de regressão, ao invés de um só, como em Finlay \& Wilkinson (1963) e Eberhart \& Russel (1966), além dos desvios de regressão.

Posteriormente, Storck (1989) extendeu o método de Cruz et al. (1989), com a finalidade de aprimorar a metodologia, incluindo mais um parâmetro de descontinuidade. $O$ autor testou um novo modelo para a relação entre a produção e a variação ambiental, sendo que para alguns cultivares de milho o modelo se ajustou bem à uma curva de Gompertz. Em tal modelo deve-se preferir um número de repetições que permitam uma boa estimativa da média, com o maior número possível de ambientes, sendo que os valores ambientais devem ser equidistantes e com a maior amplitude de variação possivel.

Em outras culturas, alguns autores basearam-se na regressão linear раra avaliar os efeitos genéticos, ambientais e as suas interações, em linhagens puras e nas gerações obtidas pelos seus intercruzamentos. Bucio Alanis (1966) utilizou um método que permite estimar os efeitos genéticos, ambientais e a interação entre eles, a partir de um par de linhagens puras de Nicotiana rustica. $O$ autor considerou o método de grande utilidade, pois permite estimar com maior precisão a herdabilidade e o ganho na seleção. Bucio Alanis \& Hill (1966) utilizaram o mesmo método considerando além das linhagens puras, a geração 
$F_{1}$.

Bilbro \& Ray (1976), estudando cultivares de algodão, propuseram o uso do coeficiente de regressão para medir a adaptabilidade e o coeficiente de determinação para medir a estabilidade. Os autores revelaram que estes dois parâmetros associados à produtividade são eficientes para avaliar o comportamento das variedades frente às variações ambientais.

Bhullar et al. (1977) aplicaram a técnica de regressão nas análises das gerações $F_{1}$ a $F_{5}$ obtidas pelos cruzamentos possiveis entre sete variedades de trigo. Os autores mostraram que a estabilidade fenotípica está associada com a constituição genética dos pais e com os níveis de heterozigosidade e heterogeneidade das populações. Apontaram ainda a possibilidade de combinar produtividades superiores com elevado grau de estabilidade.

Existem outros métodos propostos para o estudo da estabilidade fenotípica, não tendo como base a análise de regressão linear. Entre eles, Plaisted \& Peterson (1959), estudando variedades de batata, propuseram estimar um parâmetro de estabilidade para cada genótipo a partir das análises de grupos de experimentos. Consideraram inicialmente os resultados de um ano, realizando a análise conjunta da variância envolvendo todos os genótipos e locais. Se a interação por locais for significativa, realizam-se as análises conjuntas de variância para cada combinação dos genótipos dois a dois. O genótipo considerado mais estável será aquele que apresentar a menor média para a variância da interação de genótipos por ambientes.

Posteriormente, Plaisted (1960) propôs que fossem realizadas várias análises conjuntas de variância, omitindo um genótipo por vez. Em cada uma destas análises estima-se a interação de genótipos por ambientes, sendo que a magnitude desta interação indica a estabilidade do genótipo omitido. $O$ genótipo omitido será considerado tanto mais estável quanto maior for a magnitude desta interação. Esta modificação introduzida reduziu a quantidade de cálculos, mantendo a mesma interpretação do método anterior. 
Wricke ${ }^{4}$, citado por Oliveira (1976), desenvolveu um método para avaliação de genótipos, cujo parâmetro estimado é denominado "ecovalência". Tal estimativa também baseia-se na decomposição da interação $G A$, em componentes atribuidos a cada genótipo. A "ecovalência" avalia as oscilações de cada genótipo frente às variações ambientais, sendo a variedade tanto mais estável quanto menor for o valor deste parâmetro. Segundo o autor, a "ecovalência" e as médias de produtividade foram independentes para os grupos de ensaios avaliados.

Vários autores também compararam os diversos métodos usados para avaliar a estabilidade fenotípica. Para a cultura do sorgo, Jowett (1972) comparou os métodos de Finlay \& Wilkinson (1963), Wricke (1965) e Eberhart \& Russel (1966), concluindo que o método de Eberhart \& Russel (1966) deve ser preferido por ser mais explícito. Segundo o autor, o método de Finlay \& Wilkinson (1963) deve ser utilizado quando os genótipos usados tiverem produtividades bastante diferentes, em virtude de se trabalhar em escala logaritmica, fato que aumenta a homogeneidade dos desvios.

Oliveira (1976), utilizando dados de produtividade de milho, comparou os métodos de Plaisted \& Peterson (1959), Finlay \& Wilkinson (1963), Wricke (1965), Eberhart \& Russel (1966) e Tai (1971). O autor concluiu que, de uma maneira geral, houve concordância entre os resultados obtidos. No entanto, ressalta que os métodos de Finlay \& Wilkinson (1963) e Eberhart \& Russel (1966) fornecem maiores informações.

Crossa (1988) obteve dados de produtividade de milho de 27 variedades, testadas em 37 diferentes locais. As variáveis obtidas foram comparadas para estabilidade pelos métodos de Verma et al. (1978) e pelo método gráfico espacial, segundo Westcott (1987). O autor concluiu que o método gráfico espacial é mais eficiente quando se dispõe de poucos ambientes de experimentação ou ocorrem ambientes com distribuição descontínua dos indices

\footnotetext{
4 WRICKE, G. Z. Pflanzenzuchtg. 52:127-138, 1965.
} 
ambientais, com extremos de produtividade. Além disso, tal metodologia permite a avaliação de subgrupos com variedades de interesse.

Na cultura do feijoeiro, Duarte \& Zimmermann (1995) determinaram - grau de correlação entre 13 diferentes parâmetros estatísticos que estimam a estabilidade fenotípica, baseando-se em dados de produtividade obtidos em 12 diferentes localidades do Brasil. Os autores encontraram altas correlações entre diversos dos parâmetros de estabilidade estimados. A produtividade também apresentou alta corrrelação com vários indices de estabilidade. Desta forma, os autores recomendaram a utilização dos parâmetros mais independentes, como forma de caracterizar mais eficientemente os genótipos avaliados.

\subsection{Aplicações na cultura da cana-de-açúcar}

$\mathrm{Na}$ cultura da cana-de-açúcar diversos trabalhos constataram a importância da interação de genótipos por ambientes, explanando sobre sua importância nos processos de seleção de clones.

De acordo com Skinner (1971), as interações de genótipos por anos e locais têm importante influência no comportamento de variedades de cana-deaçúcar. Segundo este autor, a técnica da regressão se apresenta como um método promissor para avaliar variedades frente às variações ambientais. $O$ autor considerou que poucos trabalhos foram apresentados sobre o assunto até aquela época, principalmente quanto à comparação entre os métodos existentes e a determinação dos mais eficientes para utilização no melhoramento da cultura.

A existência de interação de genótipos por ambientes também foi relatada por Pires \& Costa (1980), com estudos de correlações entre componentes da produção em quatro locais da região canavieira de Pernambuco.

Considerando que diferentes ambientes, como épocas de plantio, idades de corte, anos e locais, afetam significativamente as médias, variâncias e o grau de determinação genética, Mariotti (1974 e 1980) sugere que os trabalhos de seleção sejam desenvolvidos em diferentes condições, no sentido de se obter genótipos adaptados a cada ambiente especifico. 
Kang \& Miller (1984) também relataram que interações de genótipos por locais influenciaram o comportamento de variedades de cana-de-açúcar, assim como as estratégias de melhoramento da cultura. Os autores compararam algumas metodologias para estimar a estabilidade fenotípica, observando relação entre alguns parâmetros.

Bassinello (1984) avaliou a interação genótipos $x$ ambientes em dez variedades de cana-de-açúcar nas regiões de Araras-SP e Bandeirantes-PR. O autor colheu os materiais em diferentes épocas de corte durante a safra, considerando a produtividade de colmos e o teor de sacarose, por três cortes consecutivos. Avaliando a análise conjunta de variância para todos os ambientes, a interação épocas de colheita $x$ variedades não acusou significância estatística para a média dos três estágios de corte em relação à produtividade. Essa tendência ocorreu em ambos os locais, indicando que não existe alteração no comportamento das variedades de uma época para outra. Assim, foi possivel escolher as épocas de colheita mais apropriadas a cada estágio de corte nos experimentos avaliados.

Bassinello (1991) também avaliou o desempenho de progênies oriundas de sete cruzamentos de cana-de-açúcar, nas regiões de Araras-SP e Uberlândia-MG. Para o caráter peso de colmos, a interação progênies $\times$ locais foi significativa, indicando a necessidade de programas específicos para ambientes contrastantes, como os avaliados. Os caracteres teor de sacarose (Brix) e número médio de colmos foram bem correlacionados nos dois ambientes, com destaque para a maior estabilidade do Brix. A progênie resultante do cruzamento entre SP70-1143 e RB72454, duas variedades de destaque comercial na época, foi a de melhor comportamento nos dois locais.

Numa revisão sobre os fatores que afetam a seleção em cana-deaçúcar, Skinner et al. (1987) citaram considerações de diversos autores sobre as interações que ocorrem entre progênies e clones. Segundo os autores a existência de interação GA reduz a eficiência da seleção, além de aumentar o tamanho e a complexidade dos programas de seleção, sendo que a importância destas interações difere entre países e mesmo em diferentes regiões do mesmo 
pais. A utilização de técnicas de regressão para medir a estabilidade não é rotineira em programas de melhoramento, sendo mais comum a classificação dos clones em termos da média geral, em comparação com os resultados obtidos por variedades padrão amplamente cultivadas. Tal procedimento é falho, na medida que não explora toda a informação disponivel obtida de ensaios realizados em diversos locais e anos, além de omitir informações sobre especificidade de adaptação dos genótipos. Além disso, os autores colocaram como maior dificuldade de exploração da metodologia, o número reduzido de diferentes ambientes onde a experimentação é conduzida.

A literatura em cana-de-açúcar é escassa sobre utilização ou comparação de metodologias de estabilidade fenotípica, tampouco compara parâmetros de diferentes grupos de análise. A determinação do grau de associação entre as estatísticas de estabilidade podem auxiliar aos melhoristas, permitindo a escolha de parâmetros ideais para discriminar clones em seleção, da maneira que melhor se encaixe nos conceitos de estabilidade desejados.

Fica evidente que, nos programas de melhoramento de cana-deaçúcar, é de extrema importância a utilização de variedades de alta estabilidade fenotípica, que normalmente são cultivadas em larga escala comercial, sendo, por isso, úteis como padrões em ensaios. É importante também que uma variedade padrão, além da alta produtividade, apresente boa estabilidade sob ampla região, a fim de que possa ser tomada como referência nos diversos estágios de seleção dos programas de melhoramento.

Para avaliar este comportamento, Pollock (1975) considerou locais, anos e cortes como ambientes contrastantes para estudos de estabilidade fenotípica de três variedades, utilizadas como padrão na Austrália. Pelos parâmetros de Eberhart \& Russel (1966), o autor concluiu que é preferível fazer seleção dos clones utilizando-se a média das três variedades padrão, já que é uma variável de maior estabilidade. Segundo Calheiros (1977), para as condições do Estado de Alagoas, as estimativas individuais de produtividade das variedades utilizadas como padrão (CB45-3 e Co331) também foram mais variáveis do que a média de ambas. Houve significativa interação variedades padrão $x$ ambientes, 
mostrando que a diferença entre ambas não é estável de um ambiente para outro. A escolha da média dos dois padrões, para a comparação com variedades ou clones a serem indicados para o plantio comercial, dará mais eficiência na seleção, já que esta mostrou menor interação por ambientes, ou seja, maior estabilidade na região canavieira de Alagoas. Baseado na estimativa do erro do contraste entre a média de um clone e a de um padrão, o autor sugeriu que, para maior segurança na seleção nas fases finais do programa de melhoramento, escolham-se clones com produtividade pelo menos $10 \%$ superior à média das variedades padrão.

Mariotti et al. (1976) estudaram a estabilidade na cana-de-açúcar na Argentina, utilizando os dados de cinco cortes de 17 experimentos instalados em um mesmo local, englobando um período de 15 anos. Os autores usaram o termo adaptabilidade para designar a capacidade potencial dos genótipos em assimilarem vantajosamente o estímulo ambiental (estabilidade agronômica, citada anteriormente por outros autores). A estabilidade, por sua vez, seria considerada como a capacidade dos genótipos exibirem um desempenho o mais constante possivel, em função das variações da qualidade ambiental (estabilidade biológica, anteriormente comentada). Os parâmetros utilizados neste estudo foram o coeficiente de regressão linear (b); a variação da linha de regressão $\left(\hat{\sigma}_{d}^{2}\right)$ e o coeficiente de determinação $\left(\mathrm{R}^{2}\right)$. Os autores afirmaram que a resposta aos estímulos ambientais para a maioria dos genótipos apresentou alta linearidade. Quando a análise de estabilidade foi feita para cada corte separadamente, 0 segundo corte apresentou maior estabilidade. Como não houve uma concordância geral de um corte para outro, os autores estabeleceram que a estabilidade nas condições da Argentina deve ser avaliada em função das médias dos diversos cortes.

Os métodos de Wricke (1965), Eberhart \& Russel (1966), Bilbro \& Ray (1976) foram comparados por Galvez (1980) em cana-de-açúcar. O autor determinou associação positiva entre a "ecovalência" e a variância dos desvios da linearidade, entre a "ecovalência" e o coeficiente de determinação e entre o 
coeficiente de determinação e a variância dos desvios da linearidade.

Singh \& Khan (1997) compararam os métodos de Eberhart \& Russel (1966) com a média relativa e o desvio padrão de ambientes dentro de genótipos. Os autores utilizaram dados de 22 variedades de cana-de-açúcar, obtidos em oito ensaios, em três ambientes contrastantes em regiões da India. Ambas as metodologias foram semelhantes na identificação dos genótipos mais produtivos e estáveis, sendo o segundo método de aplicação mais facilitada. Contudo, segundo os autores, este não consegue determinar a resposta dos genótipos a ambientes especificos, como no caso do primeiro método.

No Brasil, alguns trabalhos sobre estabilidade fenotipica em canade-açúcar foram publicados. Um deles, apresentado por Rushel (1977), utilizou dados de produtividade obtidos no primeiro corte de três grupos de experimentos. Estes foram instalados na Estação Experimental de Campos (RJ), do Ministério da Agricultura, nos anos 1956, 1957, 1964 e 1970. O autor considerou os parâmetros de Eberhart \& Russel (1966) estabelecendo que, apesar de a variedade CB45-3 apresentar um nível ótimo de estabilidade, é melhor utilizar a média das variedades CB45-3 e CB56-20 como padrão na seleção de clones, por tal estimativa apresentar melhor estabilidade.

Pires (1981) avaliou a estabilidade de seis variedades de cana-deaçúcar em 29 experimentos, em dois cortes realizados na região nordestina brasileira. O autor observou que as variedades responderam de forma predominantemente linear às variações ambientais, apresentando diferenças genéticas para produtividade, adaptação e estabilidade. Pelas análises de estabilidade de cada corte, verificou tendências mais estáveis das variedades no segundo corte. Estudos de repetibilidade indicaram que a seleção em cana-deaçúcar deve ser promissora no sentido de alterar tanto a produtividade, como também as respostas lineares e não-lineares às variações ambientais.

Peixoto et al. (1986) compararam os métodos de Eberhart \& Russel (1966), Verma et al. (1978) e Silva \& Barreto (1985). Os autores avaliaram com mais detalhes 6 variedades de cana-de-açúcar largamente cultivadas no Estado de São Paulo, concluindo que o método de Silva \& Barreto (1985) fornecia 
informações mais completas, facilitando a alocação destas variedades nos diversos ambientes estudados.

Nas condições do nordeste brasileiro, Barbosa (1992) avaliou nove variedades comerciais num total de 29 ambientes, com o método de Silva \& Barreto (1985). Utilizando dados de produtividade e os coeficientes de regressão, o autor determinou o nivel de resposta e o ambiente de cultivo mais adequado para cada variedade.

Em nove usinas do Estado de Alagoas, Barbosa (1993) avaliou oito variedades comerciais entre os anos de 1989 e 1992. Com a produtividade e os coeficientes de regressão, para a média dos ambientes desfavoráveis, médios e favoráveis, o autor destacou as variedades RB83102 e RB83160 como superiores em quaisquer das situações ambientais avaliadas, combinando estabilidade fenotípica com alta produtividade.

Utilizando dados de primeiro corte obtidos em 16 locais, Braga Júnior (1994a) utilizou o método de Silva \& Barreto (1985) para caracterizar o comportamento relativo de clones. O autor concluiu que a técnica foi adequada na análise e ajuste dos dados, possibilitando a indicaçăo de novas variedades para diferentes ambientes de produção.

Nas condições do Estado de Alagoas, Calheiros \& Barbosa (1996) avaliaram diversas variedades RB em diferentes cortes e épocas de colheita, usando a metodologia de Silva \& Barreto (1985). Os autores determinaram o coeficiente de variação entre ambientes, a produtividade, em toneladas de pol por hectare (TPH), e as regressões relativas aos indices ambientais. Assim, os diferentes genótipos puderam ser classificados quanto à produtividade e o nivel de resposta aos ambientes, com destaque para as variedades RB83594, RB83102 e RB72454.

Também em Alagoas, Lima \& Barbosa (1996), avaliaram variedades em diferentes cortes e épocas de colheita, usando a metodologia de Silva \& Barreto (1985). As variedades SP70-1143 e SP75-3046 foram as mais estáveis e de maior produtividade, adaptando-se aos ambientes desfavoráveis. 


\section{MATERIAL E MÉTODOS}

\subsection{Genótipos e ambientes avaliados}

Neste estudo foram utilizados dados de produtividade de colmos e de sacarose de 48 clones experimentais SP, comparados com oito variedades comerciais de cana-de-açúcar, obtidos em primeiro e segundo cortes, representando 56 diferentes genótipos $(G)$. Foram avaliados três grupos de experimentos plantados em anos consecutivos, a partir de 1992, num total de 43 ensaios, ou locais $(L)$, distribuídos pelas diversas regiões canavieiras do Estado de São Paulo. A denominação clone foi empregada para o material ainda em fase de experimentação, sendo o termo variedade utilizado quando a mesma já foi liberada para cultivo comercial, ou usada como padrão em experimentos. $O$ termo genótipo, mais abrangente, se referiu às duas situações anteriores.

Os ensaios analisados corresponderam à última fase de experimentação no Programa de Melhoramento da Copersucar, ou Ensaios de Caracterização. Foram denominados "Ensaios de Caracterização 92, 93 e 94" de acordo com o ano de plantio (1992 a 1994), constituídos por 25, 20 e 20 tratamentos, respectivamente. A relação dos grupos de ensaios, clones e variedades estudadas, com seus respectivos genitores, encontra-se na Tabela 1. A numeração à esquerda de cada variedade serviu como identificação do genótipo nas análises realizadas. Os genótipos originaram-se de cruzamentos biparentais, que produziram irmãos germanos, ou de policruzamentos, gerando meio irmãos. No primeiro caso são conhecidos os dois genitores, no segundo houve apenas o controle materno. 
Tabela 1 - Clones e variedades de cana-de-açúcar estudadas e seus respectivos genitores.

GRUPO 1

ENSAIO DE CARACTERIZAÇÃO/92

$\mathrm{N}^{1}$ VARIEDADE FEMEA ${ }^{3}$ MACHO

1 RB72454

2 RB765418

3 SP70-1143

4 SP71-1406

5 SP71-6163

$6 \mathrm{SP} 79-1011$

7 SP79-2312

8 SP79-2345

9 SP80-0147

10 SPBO-0185

11 SP80-1816

12 SP81-0274

13 SP $81-1763$

14 SP81-1949

15 SP81-2590

16 SP82-1432

17 SP82-2048

18 SP82-2077

19. SP82-3421

20 SP82-4010

21 SP82-6034

22 SP83-1006

23 SP83-1624

24 SP83-5073

25 SP83-5145

$P^{2}$ CP5376 ?

$P \mathrm{M} 25348$ ?

$P$ IAC4865?

P NA5679?

P NA5679 ?

P NA5679 Co775

P SP71-6106?

H574114?

Co798 ?

$\mathrm{BO} 77 \quad ?$

SP71-1088 H575028

$\mathrm{CB5253?}$

Co775 NA5679

SP70-1038?

TUC5619?

CB4077 CB52107

SP71-1088?

SP73-5037?

NA5679?

CB5253?

H682271?

SP71-6180 SP70-1423

SP70-5094 H61182O

SP71-1406 SP71-1088

Q76?
GRUPO 2

ENSAIO DE CARACTERIZAÇÃO/93

\begin{tabular}{lll}
\hline No VARIEDADE 3 & 4 \\
\hline RB72454 P CP5376 ?
\end{tabular}

1 = número referente ao genótipo (variedade ou clone)

2 = variedades-padrāo $(P)$

3 = genitor feminino

$4=$ genitor masculino

5 = policruzamento (macho desconhecido), meio-irmãos

$6=$ cruz. biparentais (genitores conhecidos) ou irmāos germanos

Os 43 ensaios foram conduzidos em 22 diferentes usinas cooperadas no Estado de São Paulo, entre os anos de 1992 e 1996. A experimentação foi realizada em diferentes regiões, com características particulares de clima e solo, abrangendo as principais zonas canavieiras do Estado de São Paulo (Figura 1). Os números em destaque representaram a localização das unidades cooperadas, correspondendo ao número de grupos de ensaios que foram instalados nas usinas. 


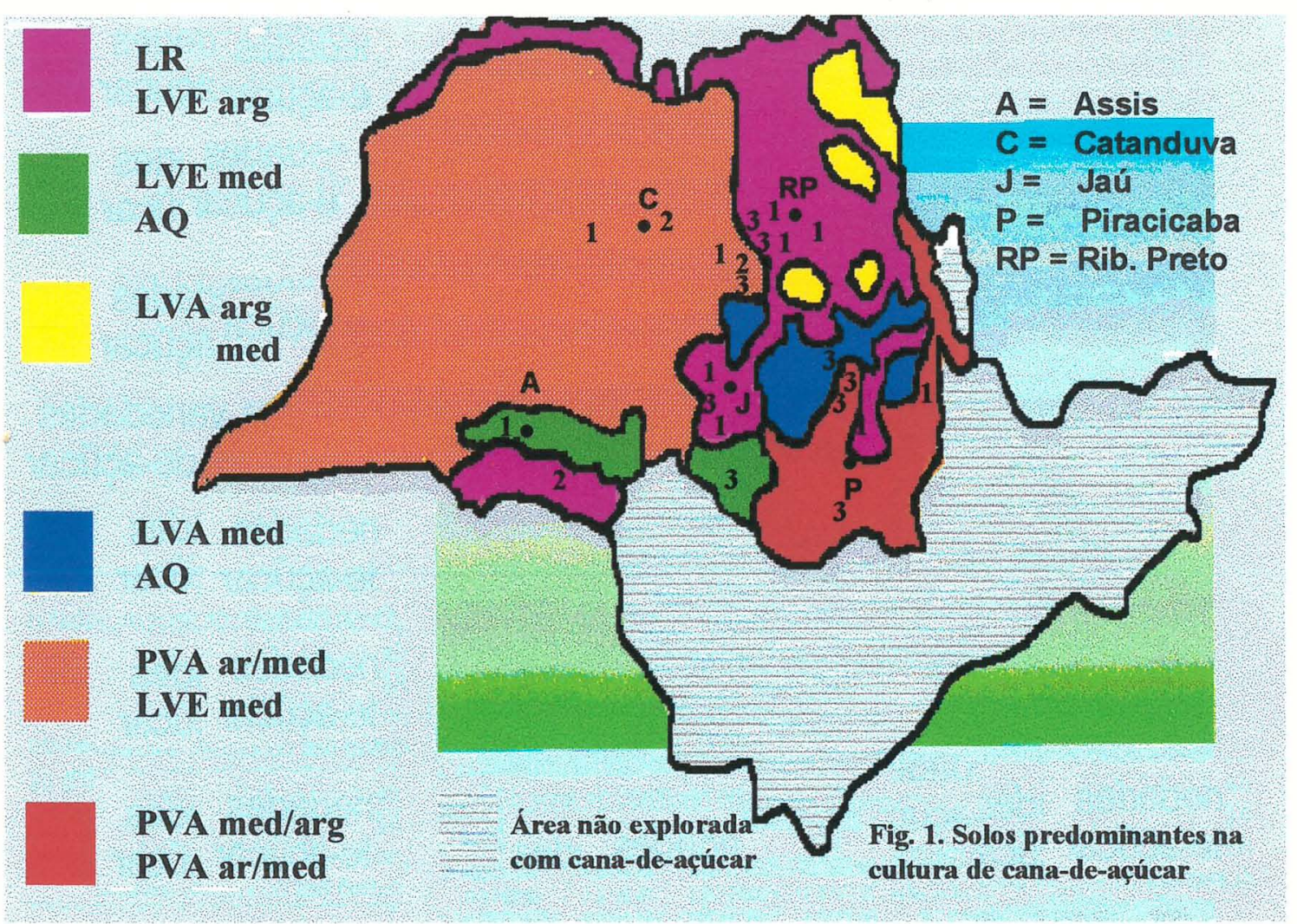

Adaptado de Landell et al. (1997)

Figura 1: Localização das principais regiões canavieiras do Estado de São Paulo, com subdivisão por tipos de solos e localização dos ensaios.

A distribuição dos três grupos de experimentos, suas características e respectivas datas de plantio e colheitas, encontra-se na Tabela 2. A numeração à esquerda de cada local serviu como identificação do ambiente nas análises realizadas.

Nos anos anteriores aos plantios dos ensaios, foram instalados viveiros com os clones e variedades objetos de avaliação, para servirem como posterior fonte de mudas com 12 meses de idade, com uniformidade e sanidade. 
Tabela 2 - Distribuição dos ensaios instalados com localização, características das áreas e datas de plantio e colheitas.

\begin{tabular}{|c|c|c|c|c|c|c|c|}
\hline & & & & DATA & DATA & & IPO DE \\
\hline$N^{0} 1$ & CÓDIGO & USINA & MUNICIPIO & PLANTIO & CORTE 1 CORTE 2 & FAZENDA & SOLO ${ }^{2}$ ESP $^{3}$ \\
\hline
\end{tabular}

GRUPO 1 - CARACTERLZAÇÄO/92

\begin{tabular}{|c|c|c|c|c|c|c|c|c|c|}
\hline 1 & 006 & BARRA GRANDE & LENÇOIS PAULISTA & $18 / 02 / 92$ & $06 / 07 / 93$ & $01 / 08 / 94$ & SAZO JOSÉ DO PASSINHO & AQ & 1,10 \\
\hline 2 & 007 & BELA VISTA & PONTAL & $17 / 02 / 92$ & $15 / 07 / 93$ & $11 / 08 / 94$ & BELA VISTA & LR & 1,40 \\
\hline 3 & 018 & CRESCIUMAL & LEME & $12 / 03 / 92$ & $08 / 07 / 93$ & $19 / 07 / 94$ & ALTO DA QUTTERIA & LVA-1 & 1,40 \\
\hline 4 & 029 & IRACEMA & IRACEMÁPOLIS & $19 / 02 / 92$ & $30 / 06 / 93$ & $10 / 08 / 94$ & COLONIA GRANDE & LR & 1,40 \\
\hline 5 & 045 & SANTA ADÉLIA & JABOTICABAL & $14 / 02 / 92$ & $08 / 07 / 93$ & $08108 / 94$ & SANTA MARIA & LVE-8 & 1,50 \\
\hline 6 & 055 & QUATÁ & QUATÁ & $13 / 02 / 92$ & $14 / 07 / 93$ & $26 / 08 / 94$ & POTRERINHO SAPEZAL. & LVE & 1,70 \\
\hline 7 & 058 & SANTA MARLA & CERQUILHO & $23 / 03 / 92$ & $21 / 07 / 93$ & $07 / 07 / 94$ & CAPUAVA & LVE & 1,40 \\
\hline 8 & 062 & SANTA TEREZINHA SA & ESPIRTTO SANTO DO PINHAL & $11 / 03 / 92$ & $12 / 07 / 93$ & $03 / 08 / 94$ & RANCISCO & PVA & 1,40 \\
\hline 9 & 070 & SẢO JOĀO & ARARAS & $13 / 02 / 92$ & $15 / 07 / 93$ & $17 / 08 / 94$ & TRES LAGOAS & LVA & 1,40 \\
\hline 10 & 075 & SAO LUL AA & PIRASSUNUNGA & $11 / 02 / 92$ & $\uparrow 3 / 07 / 93$ & $15 / 07 / 94$ & MORRO ALTO GROTẢO & LVA-12 & 1,40 \\
\hline 11 & 076 & SĀO LUIZ SA & OURINHOS & 13/02/92 & $12 / 07 / 93$ & $12 / 07 / 94$ & SANTANA VELHA & LR & 1,40 \\
\hline 12 & 077 & SÄO MANOEL & SĀO MANOEL & $26 / 02 / 92$ & 07/07/93 & $08 / 08 / 94$ & MONJOLINHO & LR & 1.40 \\
\hline 13 & 078 & SÁO MARTINHO & PRADOPOLIS & $14 / 03 / 92$ & $26 / 07 / 93$ & $24 / 08 / 94$ & BARRINHA & LR-3 & 1,50 \\
\hline & 083 & ANIN & RARAQUARA & $20 / 02 / 92$ & $08 / 07 / 93$ & $22 / 08 / 94$ & O BERNARDO & LVE & 1,30 \\
\hline
\end{tabular}

GRUPO 2 - CARACTERIZAÇĂO/93

\begin{tabular}{|c|c|c|c|}
\hline 1 & 006 & BARRA GRANDE & LENCOIS PAULISTA \\
\hline 2 & 013 & CATANDUVA & ARIRANHA \\
\hline 3 & 018 & CRESCIUMAL & LEME \\
\hline 4. & 020 & DA PEDRA & SERRANA \\
\hline 5 & 045 & SANTA ADÉLLA & JABOTICABAL. \\
\hline 5 & 057 & SANTA LULZA & ARARAQUARA \\
\hline 7 & 058 & SANTA MARIA & CERQUILHO \\
\hline 8 & 066 & SĀO CARLOS & JABOTICABAL \\
\hline 9 & 068 & SÄO FRANCISCOAB & SERTAOOZINHO \\
\hline 10 & 070 & SÃO JOÃO & ARARAS \\
\hline 11 & 072 & SĀO JOSÉ DA ESTIVA & NOVO HORIZONTE \\
\hline 12 & 074 & SẢO JOSÉ ZL & MACATUBA \\
\hline 13 & 075 & SĀO LUR AA & PIRASSUNUNGA \\
\hline 14 & 077 & SĀO MANOEL & SĀO MANOEL \\
\hline 15 & 078 & SÄO MARTINHO & PRADÓPOLIS \\
\hline 16 & 083 & ZANIN & ARARAQUARA \\
\hline \multicolumn{2}{|c|}{ GRUPO 3} & CARACTERIZAÇAO/94 & \\
\hline 1 & 006 & BARRA GRANDE & LENÇÓIS PAULISTA \\
\hline 2 & 013 & CATANDUVA & ARIRANHA \\
\hline 3 & 018 & CRESCIUMAL & LEME \\
\hline 4 & 022 & DLAMANTE & $J A U$ \\
\hline 5 & 045 & SANTA ADELIA & JABOTICABAL \\
\hline $\begin{array}{l}6 \\
7\end{array}$ & $\begin{array}{l}057 \\
058\end{array}$ & $\begin{array}{l}\text { SANTA LUIZA } \\
\text { SANTA MARLA }\end{array}$ & $\begin{array}{l}\text { ARARAQUARA } \\
\text { CERQUILHO }\end{array}$ \\
\hline 8 & 070 & SẢO JOÃO & ARARAS \\
\hline 9 & 075 & SĀO LUIZ AA & PIRASSUNUNGA \\
\hline 10 & 076 & SÄO LUIZ SA & OURINHOS \\
\hline 11 & 077 & SĀO MANOEL & SÄO MANOEL \\
\hline 12 & 078 & SĀO MARTINHO & PRADOPOLIS \\
\hline 13 & 083 & ZANIN & ARARAQUARA \\
\hline
\end{tabular}

\begin{tabular}{|c|c|c|c|c|c|}
\hline $02 / 03 / 93$ & $07 / 07 / 94$ & $23 / 08 / 95$ & SĀO JOSE DO PASSINHO & $A Q$ & 1,10 \\
\hline $10 / 03 / 93$ & $08 / 07 / 94$ & $24 / 08 / 95$ & SANTA JÚLLAVÁGUA LIMPA & PVA-12 & 1,10 \\
\hline $03 / 03 / 93$ & $14 / 07 / 94$ & $31 / 08 / 95$ & ALTO DA QUITEERIA & LVA-1 & 1,40 \\
\hline $09 / 02 / 93$ & $23 / 06 / 94$ & $29 / 08 / 95$ & SANTA EUGENIA & LVE & 1,50 \\
\hline $11 / 03 / 93$ & $20 / 07 / 94$ & $31 / 08 / 95$ & SAO ROSÁRIO & LVE & 1.50 \\
\hline $10 / 03 / 93$ & $26 / 07 / 94$ & $30 / 08 / 95$ & PONIE & LVA & 1.40 \\
\hline $17 / 03 / 93$ & $07 / 07 / 94$ & $15 / 08 / 95$ & CAPUAVA & LVE & 1,40 \\
\hline $02 / 03 / 93$ & $25 / 07 / 94$ & $15 / 08 / 95$ & COQUEFROS & TRE & 1,40 \\
\hline $16 / 02 / 93$ & $12 / 07 / 94$ & $01 / 09 / 95$ & BARRO PRETO & LVA-6 & 1,40 \\
\hline$\infty 9 / 03 / 93$ & $25 / 07 / 94$ & $21 / 08 / 95$ & TRES LAGOAS & LVA & 1,40 \\
\hline $16 / 03 / 93$ & $28107 / 94$ & 16 & IORGE & LVA-9 & $\$, 40$ \\
\hline $17 / 03 / 93$ & $12 / 07 / 94$ & $28 / 08 / 95$ & POUSO ALEGRE & LVE & 1,10 \\
\hline $23 / 03 / 93$ & $06 / 07 / 94$ & $30 / 08 / 95$ & TRÉS BARRAS & LVA-3 & 1.40 \\
\hline $17 / 03 / 93$ & $03 / 08 / 94$ & $29 / 08 / 95$ & PALMEIRAVARAQUÁ & LR-3 & 1,40 \\
\hline $12 / 02 / 93$ & $26 / 07 / 94$ & $15 / 08 / 95$ & BARRINHA & LR-3 & 1.50 \\
\hline $10 / 0$ & $28 / 07 / 9$ & $05 / 0$ & & LVE & 1,30 \\
\hline
\end{tabular}

GRUPO 3 - CARACTERIZAÇAOI94

\begin{tabular}{|c|c|c|c|c|c|}
\hline $24 / 02194$ & $17 / 07 / 95$ & $18107 / 96$ & SĀO JOSE DO PASSINHO & $\mathrm{AQ}$ & 1,10 \\
\hline 28/03/94 & $31 / 07 / 95$ & $24 / 07 / 96$ & TTÁPOLIS & LVA-B & 1,10 \\
\hline $02 / 02 / 94$ & $06 / 07 / 95$ & $11 / 07 / 96$ & ALTO DA QUTIERLA & LVA-1 & 1,40 \\
\hline $03 / 02 / 94$ & $10 / 08 / 95$ & $19 / 07 / 96$ & REDENÇĀO & LR & 9,40 \\
\hline $28 / 02 / 94$ & $27 / 07 / 95$ & $05107 / 96$ & SANTA MARIA & LVE-46 & 1,50 \\
\hline $\begin{array}{l}23 / 02 / 94 \\
02 / 02 / 94\end{array}$ & $\begin{array}{l}26 / 07 / 95 \\
10 / 07 / 95\end{array}$ & $\begin{array}{l}25107 / 96 \\
18 / 07 / 96\end{array}$ & $\begin{array}{l}\text { PONTE } \\
\text { CAPUAVA }\end{array}$ & $\begin{array}{l}\text { LVE } \\
\text { PVE-5 }\end{array}$ & $\begin{array}{l}1,40 \\
1,40\end{array}$ \\
\hline $09 / 03 / 94$ & $28 / 06 / 95$ & $23 / 07 / 96$ & TRESS LAGOAS & LVA & 1,40 \\
\hline 29/03/94 & $05 / 07 / 95$ & $03 / 07 / 96$ & TRES BARRAS & LVA & 1,40 \\
\hline $09 / 02 / 94$ & $18 / 07 / 95$ & $03 / 07 / 96$ & SANTANA VELHA & LR & 1,40 \\
\hline $14 / 04 / 94$ & $20107 / 95$ & $31 / 07 / 96$ & PALMEIRA/ARAQUÁ & LR-3 & 1,40 \\
\hline $22 / 02 / 94$ & $12 / 07 / 95$ & $30 / 07 / 96$ & BARRINHA & LR-3 & 1,50 \\
\hline $02 / 03 / 94$ & $19 / 07 / 95$ & $12 / 07 / 96$ & SÄO BERNARDO & LVE & 1,40 \\
\hline
\end{tabular}

$1=$ nümero referente ao ambiente (local)

2 = tipo de solo (grande grupo), ver lista de abreviaturas e simbolos

$3=$ espaçamento entre sulcos de plantio (metros) 


\subsection{Delineamento experimental}

Por ocasião da escolha das áreas experimentais as operações de preparo de solo, calagem, adubação e plantio foram realizadas de acordo com a recomendação e tipo de solo da área. Os tratos culturais de cana-planta e soca foram executados de acordo com o usual em cada usina. Foram obtidos e analisados os dados das colheitas de primeiro e segundo cortes (cana-planta e cana-soca). Na cana-planta (Corte 1) as variedades foram colhidas aproximadamente aos 16 meses de idade e, no ano seguinte, aos 13 meses para a cana-soca (Corte 2). Estes critérios foram seguidos em todos os locais, nos três grupos de ensaios.

Os ensaios foram instalados em usinas que adotam espaçamentos entre linhas de 1,10 a 1,50 metros, no delineamento de blocos ao acaso com quatro repetições (B). A parcela útil apresentava cinco sulcos de largura por dez metros de comprimento, mais carreadores de caminhamento de dois metros separando as parcelas. Portanto cada parcela era representada por 5 sulcos de 12 metros, sendo a área calculada de acordo com o espaçamento de cada local.

No dia anterior à colheita, foram cortados e despalhados 10 colmos seguidos, retirados da linha central de cada parcela, constituindo assim as amostras individuais por parcela. Estes colmos foram amarrados em um feixe e etiquetados, sendo então enviados para os laboratórios das Estações Experimentais da Copersucar, em Jaú e Piracicaba. As amostras foram desintegradas, preparadas e submetidas à analise tecnológica pelo método da prensa hidráulica (Tanimoto, 1969).

$\mathrm{Na}$ ocasião da colheita, após a queima dos ensaios, as parcelas foram cortadas manualmente, sendo os colmos amontoados e pesados com auxillio de garra hidráulica. A produção foi obtida com o uso de célula de carga, fornecendo os valores de peso de cada parcela. 


\subsection{Caracteres analisados}

\subsubsection{Produtividade de colmos (TCH)}

Com os dados da pesagem, obtidos na área experimental de cada parcela se obteve a variável TCH (toneladas de cana por hectare), representando o caráter produtividade de colmos de cada clone ou variedade.

Esta variável foi calculada para o corte $1(\mathrm{TCH} 1)$ e para o corte 2 ( $\mathrm{TCH} 2$ ). Com os resultados dos 2 cortes, estimou-se a produtividade para a média de cinco cortes ( $\mathrm{TCH} 5$ ), haja vista ser este o número médio de cortes mais explorado comercialmente na lavoura de cana-de-açúcar, para as condições do Estado de São Paulo. Tal estimativa foi obtida segundo Braga Júnior (1994b), sendo:

$$
\mathrm{TCH} 5=\frac{\left(\mathrm{TCH}_{2} * 3,5\right)+\mathrm{TCH} 1}{5}
$$

\subsubsection{Teor de açúcar (PCC)}

Da análise tecnológica dos colmos, segundo o método da prensa hidráulica, obteve-se o valor da PCC (pol \% cana) para cada genótipo avaliado. O caráter PCC representa a quantidade de sacarose ou açúcar aparente, em porcentagem, nos colmos da cana-de-açúcar.

Os teores de sacarose foram denominados pelas variáveis PCC1 e PCC2, para os cortes 1 e 2 , respectivamente. A média do teor de açúcar, para os dois cortes, foi denominada de PCCM, para cada clone ou variedade analisada.

\subsubsection{Produtividade de açúcar (TPH)}

A composição das duas variáveis anteriores (TCH e PCC) gerou um terceiro caráter, denominado TPH (tonelada de pol por hectare), para os 
respectivos cortes analisados. A TPH representa o rendimento em sacarose, ou produção de açúcar por unidade de área, para cada genótipo, e foi utilizada como medida de valor econômico neste estudo. Foram geradas as variáveis TPH1, TPH2 e TPH5, para os cortes 1, 2 e para a média estimada de cinco cortes, respectivamente, sendo calculadas por:

$$
\mathrm{TPH} 1=\frac{\mathrm{TCH} 1{ }^{*} \mathrm{PCC} 1}{100} ; \quad T P H 2=\frac{\mathrm{TCH}_{2}{ }^{*} \mathrm{PCC} 2}{100} ; \quad T P H 5=\frac{\mathrm{TCH} 5{ }^{*} \mathrm{PCCM}}{100}
$$

Um resumo das atividades realizadas durante os anos de 1992 a 1997 pode ser visto na Figura 2. 


\begin{tabular}{|c|c|c|}
\hline Ano & Mês & Atividades \\
\hline 1992 & Março & Plantio Caracterização/92 \\
\hline \multirow[t]{2}{*}{1993} & Março & Plantio Caracterização/93 \\
\hline & Julho & Corte 1 Caracterização/92 \\
\hline \multirow[t]{2}{*}{1994} & Março & Plantio Caracterização/94 \\
\hline & $\begin{array}{l}\text { Julho } \\
\text { Agosto }\end{array}$ & $\begin{array}{l}\text { Corte } 1 \text { Caracterização/93 } \\
\text { Corte } 2 \text { Caracterização/92 }\end{array}$ \\
\hline 1995 & $\begin{array}{l}\text { Julho } \\
\text { Agosto }\end{array}$ & $\begin{array}{l}\text { Corte } 1 \text { Caracterização/94 } \\
\text { Corte } 2 \text { Caracterização/93 }\end{array}$ \\
\hline 1996 & $\begin{array}{l}\text { Agosto } \\
\text { Novembro }\end{array}$ & $\begin{array}{l}\text { Corte } 2 \text { Caracterização/94 } \\
\text { Análises individuais dos ensaios }\end{array}$ \\
\hline 1997 & & $\begin{array}{l}\text { Agrupamento dos dados } \\
\text { Análises conjuntas } \\
\text { Estudo das metodologias de } \\
\quad \text { Estabilidade Fenotipica }\end{array}$ \\
\hline
\end{tabular}

Figura 2 - Atividades realizadas nos ensaios de competição de clones de cana-de-açúcar.

Tem-se pois, em resumo, três grupos de ensaios, cada um deles com três caracteres de avaliação, analisados para o corte 1, corte 2 e para a estimativa de cinco cortes. Isto resultou em nove variáveis por grupo de ensaios, sendo:

TCH1, TCH2 E TCH5 - produtividade de colmos para o corte 1, corte 2 e para a estimativa de cinco cortes, respectivamente;

PCC1, PCC2 E PCCM - teor de sacarose para o corte 1, corte 2 e para a média dos dois cortes;

TPH1, TPH2 E TPH5 - produtividade de açúcar para o corte 1, corte 2 e 
para a estimativa de cinco cortes, respectivamente.

\subsection{Procedimento estatístico}

As análises estatísticas foram realizadas individualmente por ensaio e corte, de acordo com o delineamento de blocos ao acaso. Em seguida foram obtidas as análises conjuntas dentro de cada grupo de experimento, para cada corte separadamente e para a estimativa de cinco cortes, em relação aos três caracteres analisados. Antes de avaliar as fontes de variação para cada variável, através das análises conjuntas, observou-se a homogeneidade das variâncias residuais. Para tal utilizou-se o valor 7,00 como máximo tolerável para o quociente entre o maior e menor quadrado médio residual, entre os ensaios de cada grupo (Pimentel Gomes, 1990).

As análises de variância, sejam individuais ou conjuntas, assim como os parâmetros delas estimados e as análises de estabilidade, foram todas obtidas com o auxílio do Programa Genes (Cruz, 1997). Com estas análises se avaliou a precisão de cada ensaio e a variabilidade existente entre os diferentes genótipos e locais. Também obtiveram-se as estimativas das variâncias das interações (genótipos $X$ locais).

As estimativas dos parâmetros de estabilidade foram obtidas apenas para o valor predito de cinco cortes, avaliando-se o caráter TPH5, haja vista ser este empregado na seleção de clones, assim como na escolha de variedades comerciais dentro do Programa de Melhoramento da Copersucar. Tais parâmetros, estimados por diferentes métodos de análise da estabilidade fenotípica, foram correlacionados para obtenção do grau de associação entre eles.

\subsubsection{Modelo matemático}

As análises individuais foram realizadas, para as variáveis descritas 
anteriormente, segundo o modelo:

$$
\begin{aligned}
& Y_{i k}=M+G_{i}+B_{k}+E_{i k}, \text { onde: } \\
& M=\text { média geral; } \\
& G_{i}=\text { efeito fixo do i-ésimo genótipo }(i=1,2, \ldots, g) ; \\
& B_{k}=\text { efeito aleatório do k-ésimo bloco }(k=1,2, \ldots, b) ; \\
& E_{i k}=\text { erro aleatório. }
\end{aligned}
$$

$\mathrm{Na}$ análise conjunta dos ensaios foi utilizado o modelo matemático abaixo, considerado como misto, tendo como efeito fixos a média (M) e os genótipos $(G)$, sendo os demais efeitos aleatórios.

$$
\text { O modelo } Y_{i j k}=M+G_{i}+L_{j}+(G L)_{i j}+B_{k(j)}+E_{i j k} \text {, }
$$

foi utilizado para representar a observação feita do caráter $Y$, no tratamento $i$, no local j e no bloco k do local j, onde:

$$
\begin{aligned}
& M=\text { média geral; } \\
& G_{i}=\text { efeito do i-ésimo genótipo, que corresponde a variedades e }
\end{aligned}
$$
clones $(i=1,2, \ldots, g)$;

$L_{j}=$ efeito do j-ésimo local, corresponde a ambientes $(j=1,2, \ldots, \ell)$;

$(G L)_{i j}=$ efeito da interação do i-ésimo genótipo com o j-ésimo local;

$B_{k(j)}=$ efeito do k-ésimo bloco dentro do j-ésimo local $(k=1,2, \ldots, b)$;

$E_{i j k}=$ erro aleatório. 


\subsubsection{Análise de variância}

\subsubsection{Análises individuais}

Os procedimentos das análises individuais, para as três variáveis mencionadas anteriormente, nos três grupos de ensaios e para todos os cortes, seguiram o recomendado por Cruz \& Regazzi (1994). Segue o quadro da análise de variância:

\begin{tabular}{lllll}
\hline FV & GL & QM & E(QM) & $F$ \\
\hline Blocos (B) & $b-1$ & QM1 & $\sigma_{b}^{2}$ & \\
Genótipos (G) & $g-1$ & QM2 & $\sigma^{2}+b V_{g}$ & QM2/QM3 \\
Erro (E) & $(b-1)(g-1)$ & QM3 & $\sigma^{2}$ & \\
\hline Total & $\mathrm{gb}-1$ & & & \\
\hline
\end{tabular}

Os parâmetros estimados, ao nivel de média das parcelas foram,

diversidade genética:

$$
\hat{V}_{g}=\frac{Q M 2-Q M 3}{b}
$$

variância residual:

$$
\hat{\sigma}^{2}=\frac{Q M 3}{b}
$$

variância fenotipica:

$$
\hat{\sigma}_{\mathrm{f}}^{2}=\frac{\mathrm{QM2}}{\mathrm{b}}
$$

herdabilidade ao nível de média de clones:

$$
\hat{h}_{m}^{2}=\frac{\hat{\sigma}_{g}^{2}}{\hat{\sigma}_{f}^{2}}
$$


coeficiente de variação residual:

$$
\hat{\mathrm{CV}}_{\mathrm{e}}(\%)=\frac{100 \sqrt{\mathrm{QM} 3}}{\hat{\mathrm{M}}}
$$

coeficiente de variação genético:

$$
\hat{C V} g(\%)=\frac{100 \sqrt{\hat{\sigma}_{g}^{2}}}{\hat{M}}
$$

relação entre os coeficientes:

$$
\underline{\mathrm{CV}} \mathrm{g}(\%)
$$$$
\hat{C V}_{e}(\%)
$$

$$
\hat{G}_{\mathrm{s}}=\mathrm{K} \frac{\hat{\sigma_{\mathrm{g}}^{2}}}{\hat{\sigma}_{\mathrm{f}}}(\mathrm{K}=1,40 ; 20 \% \text { clones sel. })
$$

ganho na seleção:

$$
\hat{G}_{s}(\%)=\frac{\hat{G}_{s} 100}{\hat{M}}
$$

\subsubsection{Análises conjuntas}

Os procedimentos das análises conjuntas, para as três variáveis mencionadas anteriormente, nos três grupos de ensaios e para todos os cortes, seguiram o recomendado por Cruz \& Regazzi (1994). Segue o quadro de análise de variância conjunta, com as esperanças dos quadrados médios para cada fonte de variação, para o modelo misto ( $G$ fixo) e com interação de primeira ordem. 


\begin{tabular}{lllll}
\hline FV & GL & QM & E(QM) & $F$ \\
\hline Blocos/Locais & $\ell(b-1)$ & QM1 & $\sigma^{2}+g \sigma_{b}^{2}$ & \\
Genótipos (G) & $g-1$ & QM2 & $\sigma^{2}+b \frac{g}{g-1} \sigma_{g}^{2}+b 1 V_{g}$ & QM2/QM4 \\
Locais (L) & $\ell-1$ & & & QM3/QM1 \\
GXL & $(g-1)(\ell-1)$ & QM4 & $\sigma^{2}+b \frac{g}{g-1} \sigma_{g \ell}^{2}$ & QM4/QM5 \\
& & & & \\
Erro (E) & $\ell(b-1)(g-1)$ & QM5 & $\sigma^{2}$ & \\
\hline Total & $g b \ell-1$ & & & \\
\hline
\end{tabular}

Conhecidas as esperanças dos quadrados médios, os componentes de variância associados aos efeitos aleatórios e os componentes quadráticos associados aos efeitos fixos foram estimados, obtendo-se os seguintes parâmetros genéticos,

diversidade genética:

$$
\hat{V_{g}}=\frac{Q M 2-Q M 4}{b l}
$$

variância de locais:

$$
\hat{\sigma}^{2}=\frac{Q M 3-Q M 1}{b g}
$$

variância da int. genótipos $x$ locais:

$$
\hat{\sigma}_{g_{p}}^{2}=\frac{Q M 4-Q M 5}{b} \frac{g-1}{g}
$$

variância residual:

$$
\hat{\sigma}^{2}=\mathrm{QM} 5
$$

variância fenotípica:

$$
\hat{\sigma_{\mathrm{f}}^{2}}=\hat{V}_{\mathrm{g}}+\frac{\hat{\sigma_{\mathrm{g} \ell}^{2}}}{\ell}+\frac{\hat{\sigma^{2}}}{\mathrm{~b} \ell}
$$


herdabilidade ao nível de média de clones:

$$
\hat{\mathrm{h}}_{\mathrm{m}}^{2}=\frac{\hat{\mathrm{V}}_{\mathrm{g}}}{\frac{\mathrm{QM} 2}{\mathrm{~b} \ell}}
$$

coeficiente de variação residual:

$$
\hat{C V}_{\mathrm{e}}(\%)=\frac{100 \sqrt{\mathrm{QM} 3}}{\hat{\mathrm{M}}}
$$

coeficiente de variação genético:

$$
\hat{C V}_{g}(\%)=\frac{100 \sqrt{\hat{V}_{g}}}{\hat{M}}
$$

relação entre os coeficientes:

$$
\frac{\hat{C V}_{\mathrm{g}}(\%)}{\hat{C V_{\mathrm{e}}}(\%)}
$$

$$
\hat{G}_{s}=K \frac{\hat{\sigma}_{g}^{2}}{\hat{\sigma}_{f}}(K=1,40 ; 20 \% \text { clones sel. })
$$

ganho na seleção:

$$
\hat{G}_{s}(\%)=\frac{\hat{G}_{s} 100}{\hat{M}}
$$

Cabe salientar que, sendo $G$ um parâmetro de efeito fixo, tem-se que $\mathrm{V}_{\mathrm{g}}$ é uma medida de diversidade genética interpopulacional. Neste caso, deve-se considerar com cuidado as estimativas de herdabilidade ou progresso devido à seleção. É mais interessante identificar os materiais mais promissores pela média geral, comparando-os entre si, além de avaliar o comportamento dos genótipos nos diferentes ambientes.

Para computar a influência relativa de cada fonte de variação, sobre a diversidade total dos dados, foram calculados coeficientes de determinação $\left(R^{2}\right)$ a partir das somas de quadrados, procedimento este recomendado em 
modelos fixos ou mistos (Vencovsky \& Barriga, 1992), como é o caso:

$$
\hat{\mathrm{R}}_{\mathrm{F} . \mathrm{V} .}^{2}=\frac{S Q_{\mathrm{F} . \mathrm{V}}}{S \mathrm{Q}_{\text {Toral }}}
$$

\subsection{Parâmetros estimados em relação à produtividade de açúcar}

As estimativas dos parâmetros obtidos nas análises conjuntas $e$ usadas na avaliação da interação $G A$, na estratificação de ambientes e nos diversos métodos de estabilidade, para cada grupo de experimentos, consideraram apenas as variáveis estimadas para a média de 5 cortes, especificamente a TPH5, já que este é o caráter de maior importância na seleção de variedades de cana-de-açúcar.

Tais estimativas basearam-se nas análises conjuntas de variância e nos dados médios dos genótipos nos vários ambientes. Os resultados foram obtidos com o uso do Programa Genes, sendo que detalhes das metodologias, como a obtenção dos graus de liberdade, somas de quadrados e quadrados médios encontram-se descritos em Cruz (1997).

Neste item estão descritos apenas as estimativas dos parâmetros que quantificam o nivel e o tipo de adaptação de cada genótipo, conforme a metodologia empregada. As deduções teóricas e derivações matemáticas, assim como ilustrações e emprego das fórmulas geradas, podem ser observadas em Cruz \& Regazzi (1994).

\subsubsection{Estimativas da interação genótipos $X$ ambientes}

O comportamento da variação atribuído aos efeitos da interação $G A$, representado por $\sigma_{\mathrm{ga}}^{2}$, é quantificado por meio de um sistema no qual se igualam os quadrados médios, obtidos da análise de variância conjunta, aos respectivos estimadores dos componentes de suas esperanças matemáticas. 
Uma vez constatada a presença da interação $G A$, para algum caráter em avaliação, pôde-se verificar o comportamento dessa fonte de variação num determinado conjunto de ambientes, agrupando-os ou verificando a semelhança entre estes.

\subsubsection{Estratificação de ambientes}

A estratificação dos ambientes foi feita com base no algoritmo de $\operatorname{Lin}^{5}$, que consiste em estimar o quadrado médio para a interação entre genótipos e pares de ambientes e, posteriormente, agrupar aqueles ambientes cuja interação é não-significativa. O método prossegue com a estimação da interação para grupos de três ambientes, sendo empregado o Teste $F(5 \%)$ para se avaliar a possibilidade da formação de cada grupo.

A soma de quadrados da interação GA para cada par de ambiente foi obtida por:

$$
\begin{aligned}
& S Q(G A)_{i j^{\prime}}=\frac{1}{2}\left[d_{i j^{\prime}}^{2}-\frac{1}{g}\left(Y_{j}-Y_{. j^{\prime}}\right)^{2}\right] \text {, onde } \\
& d_{i j^{\prime}}^{2}=\sum_{i}\left(Y_{i j}-Y_{i j^{\prime}}\right)^{2}
\end{aligned}
$$

sendo que este expressa o quadrado da distância Euclidiana entre os ambientes j e j', com base no comportamento médio de g genótipos.

\subsubsection{Estimativas da estabilidade fenotípica}

As metodologias de análise da estabilidade e adaptabilidade destinam-se à avaliação de um grupo de genótipos, testados em vários ambientes. Tais metodologias são fundamentadas na existência da interação GA. Assim, este procedimento é complementar ao da análise de variância individual e

${ }^{5}$ LIN. C.S. Theor. Appl. Genet. 62:277-280, 1982 
conjunta, com dados experimentais resultantes de ensaios realizados em uma série de ambientes.

Para a interpretação das metodologias utilizadas, assim como do grau de associação entre elas, seguiu-se a classificação dos métodos em grupos, conforme Lin et al. (1986).

\subsubsection{Método de Roemer}

É baseado na variância fenotípica entre ambientes, ou seja, na variabilidade da média de determinado genótipo nos diversos ambientes de estudo. Tal estimativa foi calculada por:

$$
\operatorname{Ro\sigma }_{i}^{2}=\frac{\left[\sum_{j} Y_{i j}^{2}-\frac{\left(Y_{i}\right)^{2}}{\ell}\right]}{\ell-1} \text {, para o genótipo i, }
$$

onde $\ell$ é o número de locais ou ambientes de avaliação. Quanto menores as estimativas obtidas para este parâmetro, maior a estabilidade do genótipo.

\subsubsection{Método de Langer}

Baseia-se na amplitude das médias obtidas por cada genótipo, nos diferentes ambientes, e no desempenho do genótipo nos ambientes extremos. Foram estimados dois parâmetros, a saber:

$$
\mathrm{L}_{\mathrm{i}}=\mathrm{Y}_{\mathrm{ih}}-\mathrm{Y}_{\mathrm{il}} \quad \text { e } \quad \mathrm{L} 2_{\mathrm{i}}=\mathrm{Y}_{\mathrm{ib}}-\mathrm{Y}_{\mathrm{iw}} \quad \text {, onde }
$$

$Y_{\text {ih }}$ representa o maior e $Y_{i l} \circ$ menor valor médio obtido para o genótipo i entre os diversos ambientes; $Y_{i b}$ e $Y_{i w}$ equivalem à média do genótipo i nos ambientes de melhor e pior produtividade, respectivamente. 


\subsubsection{Método Tradicional}

Este método consiste em fazer a análise conjunta dos ensaios, considerando todos os ambientes, e desdobrar a soma de quadrados dos efeitos de ambientes mais a interação GA na soma de quadrados dos efeitos de ambientes dentro de cada genótipo.

A variação de ambientes dentro de cada genótipo é usada como estimativa da estabilidade, de tal forma que o genótipo que proporcionar o menor quadrado médio, nos vários ambientes, será considerado o mais estável.

As somas de quadrados de ambientes dentro de genótipos foi obtida por meio de:

$$
\mathrm{SQA} / \mathrm{G}=\mathrm{SQA}+\mathrm{SQGA}, \text { ou, ainda }
$$$$
\text { SQA } / G_{i}=b\left[\sum_{j} Y_{i j}^{2}-\frac{\left(\sum_{j} Y_{i j}\right)^{2}}{\ell}\right] \text {, onde }
$$

b representa o número de blocos ou repetições, $\ell$ é o número de locais ou ambientes de avaliação.

\subsubsection{Método de Wricke}

Neste método o parâmetro de estabilidade, denominado "ecovalência", também é estimado por uma partição da soma de quadrados da interação GA. Tal partição é dada por:

$$
\begin{aligned}
& \omega_{i}=\sum_{j} \hat{G}_{i j}^{2} \\
& \text { sendo } \\
& \hat{\mathrm{GA}_{i j}}=\mathrm{Y}_{\mathrm{ij}}-\overline{Y_{\mathrm{i} .}}-\overline{Y_{. j}}+\overline{Y_{.}}
\end{aligned}
$$

Também neste caso serão mais estáveis os genótipos associados às menores estimativas de $\omega_{\mathrm{i}}$. 


\subsubsection{Método de Plaisted \& Peterson}

Neste caso a estabilidade, quantificada por $\mathrm{pp}_{\mathrm{i}}$, é estimada pela média aritmética dos componentes de variância da interação entre pares de genótipos $x$ ambientes que envolve um determinado genótipo. Esta estimativa é obtida por meio da média de $(\mathrm{g}-1)$ análises de cada genótipo, num total de $\mathrm{g}(\mathrm{g}-1) / 2$ análises para os pares de genótipos. Assim, tem-se:

$$
\mathrm{pp}_{i}=\frac{\sum_{i^{\prime}} \hat{\sigma}_{\text {gaii' }}^{2}}{\mathrm{~g}-1}
$$

em que

$$
\hat{\sigma}_{\text {gaii' }}^{2}=\frac{Q M(G A)_{i^{\prime}}-Q M R}{b}
$$

Os genótipos mais estáveis serão aqueles que apresentarem as menores estimativas de $\mathrm{pp}_{\mathrm{i}} \mathrm{e}$, consequentemente, contribuírem menos para a interação GA.

\subsubsection{Método de Eberhart \& Russel}

Esta metodologia utiliza-se da regressão linear, sendo que são obtidas estimativas da estabilidade e da adaptabilidade, através da média, da resposta linear à variação ambiental e do desvio da regressão de cada genótipo. O seguinte modelo foi usado:

$$
Y_{i j}=\beta_{o i}+\beta_{1 i} I_{j}+\delta_{i j}+\overline{\varepsilon_{i j}},
$$

em que:

$$
\begin{aligned}
& \beta_{0 i}=\text { média geral do genótipo i }(i=1,2, \ldots, g) ; \\
& \beta_{1 i}=\text { resposta linear do genótipo i à variação ambiental; }
\end{aligned}
$$


$I_{j}=$ indice ambiental para o local $j(j=1,2, \ldots, \ell)$, sendo

$$
I_{j}=\frac{Y_{j}}{g}-\frac{Y}{g \ell} ;
$$

$\delta_{\mathfrak{i}}=$ desvio da regressão;

$\overline{\varepsilon_{i j}}=$ erro experimental médio.

As estimativas dos parâmetros obtidos da análise de variância, pelo modelo deste método (ver Cruz, 1997), são dados por:

- média do genótipo

$$
\hat{\beta_{\mathrm{oi}}}=\frac{Y_{\mathrm{i}}}{\ell}
$$

- medida da adaptabilidade

$$
\hat{\beta_{1 i}}=\frac{\sum_{j} Y_{i j} I_{j}}{\sum_{j} I_{j}^{2}} \text {, sendo que }
$$

a estimativa deste parâmetro é avaliada por meio da estatística $t$, conforme expressão apresentada a seguir:

$$
t=\frac{\hat{\beta_{1 i}-1}}{\sqrt{\hat{V}\left(\hat{\beta_{1 i}}\right)}}
$$

- medida da estabilidade ou previsibilidade do comportamento linear

$$
R_{i}^{2}=\frac{S Q_{i}}{S Q L / C_{i}}
$$




$$
\text { e } \quad \hat{\sigma}_{\mathrm{di}}^{2}=\frac{\mathrm{QMD}_{\mathrm{i}}-\mathrm{QMR}}{\mathrm{b}} \text {, sendo que }
$$

a estimativa deste parâmetro é avaliada pela estatística $F$, comparando-se o valor calculado $\left(F=Q_{1} / Q M R\right)$ com o valor de $F$ tabelado $\left(F_{\alpha, \ell-2, m}\right)$, sendo $\alpha \circ$ nível de significância, $\ell$ o número de ambientes e $\mathrm{m}$ ○ número de graus de liberdade do resíduo.

\subsubsection{Método de Silva \& Barreto}

O método é baseado na regressão linear múltipla, bi-segmentada, sendo que $O$ indice ambiental é originalmente calculado conforme Eberhart \& Russel (1966). O modelo utilizado é o seguinte:

$$
Y_{i j}=\beta_{o i}+\beta_{1 i} I_{j}+\beta_{2 i} T\left(I_{j}\right)+\delta_{i j}+\overline{\varepsilon_{i j}}
$$

em que

$$
\begin{aligned}
& T\left(I_{j}\right)=0 \text { se } I_{j} \leq 0 \\
& T\left(I_{j}\right)=I_{j} \text { se } I_{j}>0 .
\end{aligned}
$$

Os estimadores das somas de quadrados e dos parâmetros de estabilidade, além dos testes de significância, são semelhantes aos empregados no método anterior. Nas discussões sobre o método, B1i e B2i são referidos como coeficientes de regressão do método, ou simplesmente b1 e b2, respectivamente.

\subsubsection{Método de Cruz, Torres \& Vencovsky}

Este método, que consiste numa alteração da proposta anterior, também utiliza a regressão linear múltipla, bi-segmentada. O modelo utilizado é o seguinte: 


$$
Y_{i j}=\beta_{o i}+\beta_{1 i} I_{j}+\beta_{2 i} T\left(I_{j}\right)+\delta_{i j}+\overline{\varepsilon_{i j}}
$$

em que

$$
\begin{aligned}
& T\left(I_{j}\right)=0 \text { se } I_{j} \leq 0 \\
& T\left(I_{j}\right)=I_{j}-\bar{I}_{+} \text {se } I_{j}>0 \text {, sendo } \bar{I}_{+} \text {a média dos índices } I_{j} \text { positivos. }
\end{aligned}
$$

Os estimadores das somas de quadrados e dos parâmetros de estabilidade, assim como as variâncias associadas e os testes de hipóteses, foram calculados de modo semelhante aos dois métodos anteriores. Da mesma forma que no método anterior, B1i e B2i também são referidos como coeficientes de regressão do método, ou simplesmente b1 e b2, respectivamente.

\subsubsection{Correlação ordinal entre os parâmetros de estabilidade} fenotípica

O grau de associação entre as estimativas dos diversos parâmetros de estabilidade, ou correlação fenotípica, foi medido pelo coeficiente de correlação ordinal de Spearman. Tal coeficiente, obtido para cada par de estimativa de dois parâmetros u e u', é dado por:

$$
r_{s} u^{\prime}=1-\frac{6 \sum_{i} d_{i}^{2}}{n^{3}-n}
$$

onde $d_{i}$ é a diferença entre a ordem de classificação do genótipo i, para as estimativas dos parâmetros $u$ e $u^{\prime}$ e $n$ é o número de pares de valores das estimativas uu'. $O$ teste $t$, para o referido coeficiente de correlação, foi obtido por:

$$
t=r_{s} u u^{\prime} \sqrt{\frac{n-2}{1-r_{s} u u^{\prime 2}}}
$$

com $(n-2)$ graus de liberdade. 


\section{RESULTADOS E DISCUSSÃO}

\subsection{Análises de variância individuais}

Foram avaliados os dados referentes aos três grupos de ensaios, separadamente para cada grupo, variável e corte em estudo. Seguem as observações mais importantes, comparando-se a variabilidade dos dados obtidos.

\subsubsection{Grupo 1 - Ensaio de Caracterização/92}

A produtividade de colmos variou bastante entre os locais dos ensaios, principalmente no primeiro corte (TCH1). A variabilidade das médias dos locais permitiu o uso de índices ambientais de grande diversidade, favorecendo as análises de estabilidade. O nível de precisão obtido para os ensaios foi alto, já que os coeficientes de variação ambiental $\left(\mathrm{CV}_{\mathrm{e}} \%\right.$ ) foram sempre baixos, em todos os cortes. Isto confirma a qualidade na condução dos experimentos e a consequente confiabilidade nos dados gerados. Em todos os casos a variabilidade genética foi superior à ambiental, indicando a presença de diversidade genética passível de seleção. Com as ressalvas anteriormente comentadas, observa-se que foram altas as estimativas de variabilidade genética $e$, consequentemente, as estimativas de herdabilidade e de ganho de seleção porcentual, para todos os locais e cortes avaliados (Anexo 1)

A variável teor de sacarose dos colmos (PCC) apresentou médias muito semelhantes nos cortes avaliados, indicando menor variabilidade deste caráter $e$, consequentemente, índices ambientais muito próximos. Os reduzidos valores das estimativas do $\mathrm{CV}_{\mathrm{e}} \%$ confirmam a qualidade dos experimentos. Da 
mesma forma que para a produtividade de colmos $(\mathrm{TCH})$, as estimativas de herdabilidade e ganho de seleção porcentual foram elevadas (Anexo 2).

Os indices ambientais para a produtividade de açúcar, estimada para cinco cortes (TPH5), variaram de $-2 \mathrm{t}$ açúcar/ha a $+4 \mathrm{t}$ açúcar/ha, com boa precisão dos ensaios. Na maioria dos locais, a variabilidade genética foi superior à variância ambiental, e as estimativas de herdabilidade, em cada local e corte, foram sempre superiores a 0,75 (Anexo 3).

\subsubsection{Grupo 2 - Ensaio de Caracterização/93}

Da mesma forma, obteve-se grande amplitude para os indices ambientais da variável $\mathrm{TCH}$, com bom nível de precisão dos ensaios, para ambos os cortes e para a maioria dos locais. Observa-se que foram altas as estimativas individuais para a variabilidade genética $e$, consequentemente, também para a herdabilidade e ganhos de seleção, principalmente para a soqueira, TCH2 e TCH5 (Anexo 4).

Novamente, o caráter PCC apresentou pequena variabilidade nos índices ambientais e ótimo nivel de precisão nos ensaios. As estimativas de herdabilidade e ganho de seleção também foram elevadas na maioria dos locais e cortes estudados (Anexo 5).

Para a variável TPH, assim como para $T C H$, houve maior variação dos indices ambientais no corte 1. Para TPH5 a amplitude dos índices foi menor em relação aos ensaios do grupo anterior, ficando na faixa de $-3 \mathrm{t}$ açúcar/ha a $+2 \mathrm{t}$ açúcar/ha (Anexo 6).

\subsubsection{Grupo 3 - Ensaio de Caracterização/94}

O nível de precisão dos ensaios foi muito bom para todas as variáveis e cortes analisados, em todos os casos a variação genética foi superior à ambiental.

Para a produtividade de colmos as estimativas de diversidade 
genética, herdabilidade e ganho de seleção, para todos os locais e cortes avaliados, foram elevadas (Anexo 7).

Na média dos ambientes o caráter PCC foi bem semelhante nos cortes avaliados. Aqui também os índices ambientais apresentaram pequena amplitude (Anexo 8).

Apesar deste grupo de ensaios ter sido conduzido em menor número de ambientes, 13 locais, a variável TPH5 apresentou boa amplitude, com valores dos indices ambientais entre $-3 t$ açúcar/ha a +3 t açúcar/ha (Anexo 9).

De modo geral, as análises individuais permitiram quantificar a magnitude da diversidade genética expressa em cada local, além das discrepâncias existentes entre as variâncias residuais de cada ambiente. Observa-se que, em todos os locais e cortes, o Teste $F$ para variação de genótipos foi altamente significativo, para as nove variáveis analisadas, nos três grupos de ensaios (Anexos 1 a 9). Esta significância atesta a alta diversidade existente entre as variedades e clones avaliados, expressa em cada ambiente de experimentação (locais e cortes). Isto indica que no conjunto dos 56 genótipos avaliados, alguns diferenciaram-se na produtividade de colmos, teor de sacarose elou produtividade de açúcar.

Considera-se que os parâmetros genéticos estimados, para as diferentes variáveis em cada local, devem ser observados com ressalva, já que neste caso a variabilidade genética está superestimada, pois engloba as variâncias de locais e anos, bem como suas interações. Consequentemente, o mesmo diz respeito aos coeficientes de variação genética e de herdabilidade, e aos ganhos de seleção.

\subsection{Análises de variância conjuntas}

Apenas no primeiro grupo de ensaios (Caracterização/92), para a variável teor de sacarose no corte 2 (PCC2), verificou-se relação maior que o mínimo estabelecido para o teste de homogeneidade das variâncais residuais. Neste grupo de ensaios se obteve o valor de 9,38 , devido à maior variância do 
erro no ambiente 4, ligeiramente superior aos demais ambientes. Mesmo assim este ambiente foi incorporado na análise conjunta, já que os coeficientes de variação ambiental, neste caso, foram baixos, sempre inferiores a $10 \%$, conforme observado nas análises individuais (Anexo 2).

Dentro de cada um dos três grupos de ensaios, embora se trate dos mesmos genótipos e locais, a comparação de determinada variável para os dados obtidos no corte 1 , corte 2 e para a estimativa de cinco cortes, devem observar certas ressalvas. Entre os cortes 1 e 2 confundem-se os efeitos de ano agrícola e de estádio de cultivo, cana planta e cana soca, respectivamente. Para comparações destes cortes com os dados obtidos para a média de cinco cortes, deve-se lembrar que esta última variável é uma estimativa obtida pelos valores dos cortes 1 e 2, com maior peso para o dado da soqueira (Braga Júnior , 1994b).

Avaliando-se as análises conjuntas, para todas as variáveis e cortes, observa-se que predominam os efeitos das fontes de variação de Locais e de Genótipos, e em menor grau o da interação genótiposXlocais, sendo todos altamente significativos ao nivel de $1 \%$ de probabilidade. Os coeficientes de variação residual foram sempre muito baixos, menores que $10 \%$, confirmando 0 elevado nivel de eficiência na condução dos ensaios. Isto indica que a região abrangida pelos ensaios foi ampla e variada, houve boa diversidade de clones para seleção e a precisão dos experimentos foi muito boa (Anexos 10 a 12).

A diversidade genética encontrada, de grande magnitude, proporcionou estimativas de herdabilidade, ao nível de média de clones, sempre maiores que 0,90, valor considerado alto. Da mesma forma, quase em todos os casos, o coeficiente de variação genético $\left(\mathrm{CV}_{\mathrm{g}} \%\right)$ foi maior que o residual $\left(\mathrm{CV}_{\mathrm{e}} \%\right)$

Para computar a influência relativa de cada fonte de variação sobre a diversidade total dos dados, foram calculados coeficientes de determinação $\left(R_{\text {F.V. }}^{2}\right.$ ) a partir das somas de quadrados, para as variáveis de cada grupo de ensaio. Os dados obtidos na Tabela 3 são discutidos a seguir, as 
observações mais importantes estão em destaque.

\subsubsection{Grupo 1 - Ensaio de Caracterização/92}

A variância de locais (LOC) foi maior na cana-planta para a produtividade de colmos e, por consequência, para a produtividade estimada de açúcar (TCH1 e TPH1, respectivamente). Em relação aos cortes, a diversidade genética (GEN) foi, proporcionalmente, mais importante na cana-soca para a produtividade de colmos e de açúcar, TCH2 e TPH2, respectivamente. Também para o teor de sacarose, a variação entre os locais foi a causa principal das diferenças obtidas entre os clones, principalmente no corte 2 (PCC2). A variável TPH seguiu o mesmo comportamento da produtividade de colmos (TCH).

Em função destes resultados verifica-se que, no primeiro corte, a grande variabilidade existente entre os locais avaliados foi a causa predominante da variação da produtividade das variedades e clones. Já no segundo corte, a variação de locais foi menor e a diversidade genética entre os clones passou a ser importante para a produtividade de colmos e de açúcar (Anexo 10).

\subsubsection{Grupo 2 - Ensaio de Caracterização/93}

A proporção existente, entre os cortes, para as fontes de variação foi muito semelhante para a produtividade de colmos ( $\mathrm{TCH})$, com predominância dos efeitos de locais na variabilidade do caráter. Pelos resultados, verifica-se que a grande variabilidade existente entre os locais avaliados foi a causa predominante da variação na produtividade dos genótipos.

Da mesma forma ocorrida para os ensaios do grupo anterior, para - teor de sacarose, a variação entre os locais foi a causa principal das diferenças obtidas entre os clones, principalmente no corte 2 (PCC2).

A variância de locais foi maior na cana-planta para a produtividade de açúcar (TPH1). Para este caráter, em relação aos cortes, a diversidade genética foi mais importante na cana-soca, TPH2 (Anexo11). 
Tabela 3 - Participação percentual das fontes de variação na soma de quadrados da análise conjunta, para as diferentes variáveis nos grupos de ensaios.

\begin{tabular}{|c|c|c|c|c|c|c|c|c|c|c|c|c|}
\hline \multirow{2}{*}{$\begin{array}{l}\text { Ensaio } \\
\text { FV } \\
\text { Var. } 1\end{array}$} & \multicolumn{4}{|c|}{ Caracterização/92 } & \multicolumn{4}{|c|}{ Caracterização/93 } & \multicolumn{4}{|c|}{ Caracterização/94 } \\
\hline & $G N^{2}$ & LOC & $G \times L$ & ERR & GEN & LOC & GXL & ERR & GEN & LOC & GXL & ERR \\
\hline $\mathrm{TCH} 1$ & $22 \%$ & $53 \%$ & $15 \%$ & $8 \%$ & $29 \%$ & $45 \%$ & $15 \%$ & $9 \%$ & $24 \%$ & $55 \%$ & $10 \%$ & $8 \%$ \\
\hline $\mathrm{TCH} 2$ & $35 \%$ & $34 \%$ & $18 \%$ & $11 \%$ & $29 \%$ & $46 \%$ & $15 \%$ & $7 \%$ & $28 \%$ & $48 \%$ & $13 \%$ & $8 \%$ \\
\hline $\mathrm{TCH} 5$ & $32 \%$ & $41 \%$ & $17 \%$ & $8 \%$ & $29 \%$ & $46 \%$ & $15 \%$ & $7 \%$ & $29 \%$ & $48 \%$ & $12 \%$ & $8 \%$ \\
\hline PCC1 & $30 \%$ & $34 \%$ & $17 \%$ & $19 \%$ & $25 \%$ & $43 \%$ & $15 \%$ & $17 \%$ & $31 \%$ & $48 \%$ & $9 \%$ & $10 \%$ \\
\hline $\mathrm{PCC} 2$ & $27 \%$ & $50 \%$ & $13 \%$ & $10 \%$ & $21 \%$ & $46 \%$ & $16 \%$ & $15 \%$ & $33 \%$ & $50 \%$ & $9 \%$ & $7 \%$ \\
\hline PCCM & $34 \%$ & $45 \%$ & $12 \%$ & $9 \%$ & $27 \%$ & $49 \%$ & $13 \%$ & $11 \%$ & $40 \%$ & $45 \%$ & $7 \%$ & $7 \%$ \\
\hline TPH1 & $16 \%$ & $50 \%$ & $20 \%$ & $12 \%$ & $21 \%$ & $46 \%$ & $18 \%$ & $12 \%$ & $27 \%$ & $37 \%$ & $18 \%$ & $14 \%$ \\
\hline TPH2 & $29 \%$ & $30 \%$ & $25 \%$ & $13 \%$ & $30 \%$ & $35 \%$ & $21 \%$ & $10 \%$ & $21 \%$ & $55 \%$ & $15 \%$ & $8 \%$ \\
\hline TPH5 & $26 \%$ & $38 \%$ & $24 \%$ & $11 \%$ & $29 \%$ & $36 \%$ & $22 \%$ & $10 \%$ & $22 \%$ & $52 \%$ & $16 \%$ & $9 \%$ \\
\hline
\end{tabular}

1 = FV (fontes de variação), Var. (variáveis analisadas)

2 = as fontes de variação GEN, LOC, GXL e ERR referem-se às variações genéticas, de locais, da interação genótiposxlocais e do erro, respectivamente

\subsubsection{Grupo 3 - Ensaio de Caracterização/94}

Novamente a grande variabilidade existente entre os locais avaliados foi a causa predominante da variação na produtividade de colmos (TCH) e no teor de sacarose (PCC), tanto no corte 1 como no corte 2. Para a produtividade de açúcar a variância de locais (LOC) foi mais expressiva na canasoca (TPH2), enquanto que a diversidade genética (GEN) foi mais importante na cana-planta (Anexo 12).

De forma geral, embora a interação genótiposXlocais $\left(\sigma_{\mathrm{g} \ell}^{2}\right)$ seja proporcionalmente menor, em comparação com a a variação de locais $\left(\sigma_{\ell}^{2}\right)$ e a diversidade genética $\left(\mathrm{V}_{\mathrm{g}}\right)$, aquela foi altamente significativa, indicando a possibilidade de estudos de estratificação de ambientes. Este resultado pode ser decorrente de uma maior adaptabilidade geral dos clones destes grupos de ensaios, diminuindo a participação relativa da interação na variação total dos dados. Deve-se lembrar que se trata da última fase de seleção clonal do programa de melhoramento da Copersucar, e que estes clones já passaram por 
seis fases de avaliação, até chegarem ao Ensaio de Caracterização.

A proporção da variabilidade total dos dados referentes à interação GXL foi menor para a variável teor de sacarose (PCC), em relação à produtividade de colmos e de açúcar (TCH e TPH, respectivamente) Também pode ser observado pelos dados da Tabela 3 , nos destaques em negrito, que para a variável de seleção (TPH5) a variação devido a diversidade genética $\left(\mathrm{V}_{\mathrm{g}}\right)$ e a devida a interação $\left(\sigma_{g \ell}^{2}\right)$ foram proporcionalmente próximas. Desta forma, a interação de clones com locais, ainda bem ampla e atuante, justifica a realização de estudos de estabilidade fenotípica.

\subsection{Estratificação de ambientes}

Confirmada a presença da interação genótipos $X$ locais, assim como sua importância nos ensaios analisados, procurou-se contornar os inconvenientes resultantes desta interação através da estratificação de ambientes. Dessa forma, avaliou-se a possibilidade da formação de grupos ou sub-regiões mais homogêneas. O agrupamento de ambientes semelhantes visa a minimização da interação dentro dos grupos e maximização entre os grupos. Com esta técnica pode-se escolher um grupo de ambientes para um determinado grupo de variedades, ou um grupo de variedades para um dado grupo de ambientes.

Foram avaliadas as variáveis obtidas para a estimativa de cinco cortes, TCH5, PCCM e TPH5, que correspondem à produtividade de colmos, teor médio de sacarose e produtividade de açúcar, respectivamente, em cada grupo de ensaio.

Após gerada a matriz com todas as combinações de ambientes, avaliando-se a significância da interação entre cada par de ambiente, constatouse a formação de grupos apenas para o teor médio de sacarose (PCCM). Este agrupamento só ocorreu para os ensaios de Caracterização 92 e 93 (Tabela 4). Para a produtividade de colmos (TCH5) e de açúcar (TPH5) a interação genótipos por locais foi mais expressiva, sendo que nenhum par de ambientes proporcionou a mesma classificação entre os genótipos testados. A localização dos ensaios, 
com características e tipo de solo de cada ambiente encontram-se na Tabela 2.

Tabela 4 - Grupos formados através da estratificação de ambientes para a variável teor de sacarose médio (PCCM).

Ensaio de Caracterização/92

\begin{tabular}{c|rr|rr|l|l}
\hline Interação & \multicolumn{2}{|c|}{ Teste F } & GRUPOS $^{3}$ & \multicolumn{1}{|c|}{ Usinas } & Fator comum \\
\hline QMI $^{1}$ & Fcal & Ftab $^{2}$ & Ambientes & & & \\
\hline 0,044 & 0,96 & 1,52 & 8 & 10 & Santa Ter. SA São Luiz AA & Regiões próximas \\
0,056 & 1,23 & 1,52 & 1 & 8 & Barra Gde. Santa Ter. SA & nenhum \\
0,063 & 1,39 & 1,52 & 5 & 6 & Sta. Adélia $\quad$ Quatá & nenhum \\
0,067 & 1,47 & 1,52 & 10 & 13 & São Luiz AA São Martinho & nenhum \\
\hline
\end{tabular}

Ensaio de Caracterização/93

\begin{tabular}{c|rr|rr|ll|l}
\hline Interação & \multicolumn{2}{|c|}{ Teste F } & GRUPOS & \multicolumn{1}{|c|}{ Usinas } & \multicolumn{1}{c}{ Fator comum } \\
\hline QMI & Fcal & Ftab & Ambientes & & & \\
\hline 0,059 & 1,22 & 1,59 & 1 & 13 & Barra Gde. & São Luiz AA & Solos de baixa fertilidade \\
0,061 & 1,25 & 1,59 & 5 & 6 & Sta. Adélia & Sta. Luiza & Regióes próximas \\
0,069 & 1,43 & 1,59 & 1 & 2 & Barra Gde. & Catanduva & Solos de baixa fertilidade \\
0,071 & 1,46 & 1,59 & 1 & 4 & Barra Gde. & da Pedra & Solos de baixa fertilidade \\
0,075 & 1,55 & 1,59 & 6 & 15 & Sta. Luiza & São Martinho & Regiões próximas \\
\hline
\end{tabular}

Ensaio de Caracterização/94

\begin{tabular}{c|c|c|c|c}
\hline Interação & Teste F & GRUPOS & Usinas & Fator comum \\
\hline QMI & Fcal Ftab & Ambientes & & \\
\hline
\end{tabular}

Sem formação de grupo

1 = quadrado médio da interação genótiposXlocais, para os grupos de ambientes

2 = valores de $F$, calculado e tabelado, ao nivel de $5 \%$ de probabilidade

3 = grupos de ambientes com interação não significativa ( $\mathrm{Fcal}<\mathrm{F}$ tab)

No ensaio de Caracterização/92 quatro grupos de ambientes foram formados, com destaque para o agrupamento 8 e 10 , de menor interação $(F=0,96)$. Os ambientes 8 e 10 participaram ainda de mais dois grupos, o que indica que há boa associação entre a classificação das variedades nestes dois locais em relação a outros ambientes para o teor de açúcar, quando comparados com os locais 1 e 13, respectivamente. 
Como sugestão de algum fator comum entre os grupos formados, apenas se observou que os ensaios das usinas 8 (Santa Terezinha SA, município de Espírito Santo do Pinhal) e 10 (Usina São Luiz AA, em Pirassununga) situamse em regiões mais próximas, em relação aos outros agrupamentos.

No ensaio de Caracterização/93 foi possivel a formação de cinco grupos de ambientes, destacando-se os grupos com os pares 1 e 13 (Barra Grande com São Luiz AA) e 5 e 6 (Santa Adélia com Santa Luiza), onde se detectou pequena variância para a interação $G A$. Os ambientes 1 e 6 participaram ainda de outros grupos, o que indica que há boa associação entre a classificação das variedades nestes ensaios em relação a outros locais de experimentação.

Observa-se que os dois agrupamentos que envolvem as usinas número 5 (Santa Adélia, município de Jaboticabal), 6 (Santa Luiza, Araraquara) e 15 (São Martinho, Pradópolis) abrangem uma região geográfica bem próxima.

Cabe salientar, ainda, que nos outros três agrupamentos (1 e 13; 1 e $2 ; 1$ e 4) há em comum a presença de solos arenosos de baixa fertilidade nas áreas de experimentação, embora se trate de quatro regiões bem disitintas do Estado de São Paulo (Usinas Barra Grande, em Lençóis Paulista; Catanduva, em Ariranha; da Pedra, em Serrana e São Luiz AA, no município de Pirassununga).

Geralmente, em solos de menor fertilidade e de textura mais grossa, é comum ocorrer uma antecipação na maturação dos colmos da cana-de-açúcar, com maior uniformidade no teor de sacarose das variedades, devido ao estresse hídrico mais acentuado apresentado nestas áreas. Este comportamento pode justificar a menor interação observada nestes agrupamentos para o teor de sacarose médio nos dois cortes (PCCM). Pelos dados do Anexo 5, nota-se que os ambientes 2,4 e 13 realmente classificaram-se entre os de maior PCCM, apresentando indices ambientais positivos para o caráter.

\subsection{Comparação das médias obtidas para a estimativa de cinco cortes}

Os resultados médios obtidos para as variedades e clones 
avaliados, em cada grupo de ensaio, se encontram na Tabela 5. Tratam-se dos valores obtidos para a estimativa de cinco cortes, para a produtividade de colmos (TCH5), o teor de sacarose médio (PCCM) e a produtividade de açúcar (TPH5).

A análise das médias em cada grupo de ensaio, pelo Teste de Tukey, classificou os genótipos, separando-os estatisticamente.

Tabela 5 - Resultados dos genótipos (GEN.) para as variáveis estimadas de cinco cortes. Média para todos os locais (ambientes) avaliados.

GRUPO 1 - CARACTERZZAÇĀCY92 14 ANBIENTES

\begin{tabular}{rrrr}
\hline GEN & TCH5 & PCCM TPH5 \\
\hline 1 & 115,27 & 14,60 & 16,78 \\
2 & 85,70 & 15,72 & 13,46 \\
3 & 93,32 & 14,73 & 13,70 \\
4 & 79,36 & 14,85 & 11,79 \\
5 & 76,30 & 15,44 & 11,79 \\
6 & 92,32 & 15,43 & 14,18 \\
7 & 90,73 & 15,89 & 14,36 \\
8 & 101,64 & 14,06 & 14,26 \\
9 & 107,86 & 14,48 & 15,57 \\
10 & 107,02 & 14,97 & 15,96 \\
11 & 105,84 & 15,59 & 16,41 \\
12 & 103,68 & 14,93 & 15,40 \\
13 & 94,38 & 16,08 & 15,14 \\
14 & 109,32 & 13,81 & 15,04 \\
15 & 103,95 & 15,23 & 15,78 \\
16 & 97,82 & 14,96 & 14,63 \\
17 & 91,48 & 15,56 & 14,18 \\
18 & 99,71 & 13,97 & 13,94 \\
19 & 100,43 & 15,38 & 15,40 \\
20 & 101,79 & 15,73 & 15,97 \\
21 & 109,54 & 14,99 & 16,37 \\
22 & 115,21 & 14,12 & 16,26 \\
23 & 108,75 & 14,05 & 15,22 \\
24 & 96,98 & 16,29 & 15,74 \\
25 & 109,45 & 13,96 & 15,25 \\
\hline & & &
\end{tabular}

GRUPO 2 - CARACTERZAÇÃOY93 16 AMBIENTES

\begin{tabular}{rrrr}
\hline GEN & TCH5 & PCCM & TPH5 \\
\hline 1 & 90,67 & 15,65 & 14,08 \\
2 & 94,78 & 14,79 & 13,94 \\
3 & 83,25 & 15,44 & 12,78 \\
4 & 53,48 & 15,72 & 8,40 \\
5 & 81,17 & 16,21 & 13,07 \\
6 & 83,48 & 15,74 & 13,05 \\
7 & 102,38 & 14,73 & 15,02 \\
8 & 83,94 & 16,53 & 13,83 \\
9 & 69,59 & 16,72 & 11,59 \\
10 & 81,56 & 16,54 & 13,41 \\
11 & 83,31 & 16,60 & 13,73 \\
12 & 78,59 & 16,73 & 13,11 \\
13 & 81,27 & 15,73 & 12,69 \\
14 & 80,19 & 15,88 & 12,70 \\
15 & 94,48 & 15,52 & 14,60 \\
16 & 77,02 & 16,68 & 12,76 \\
17 & 87,58 & 15,63 & 13,62 \\
18 & 88,52 & 15,31 & 13,43 \\
19 & 83,52 & 15,68 & 13,00 \\
20 & 9280 & 16,16 & 14,90 \\
\hline
\end{tabular}

GRUPO 3 - CARACTERIZAÇÃOY94 13 AMBIENTES

\begin{tabular}{rrrr}
\hline GEN & TCH5 PCCM TP15 \\
\hline 1 & 94,17 & 14,89 & 14,04 \\
2 & 81,42 & 14,35 & 11,69 \\
3 & 73,73 & 15,22 & 11,22 \\
4 & 82,17 & 15,70 & 12,87 \\
5 & 78,88 & 16,01 & 12,62 \\
6 & 80,85 & 16,13 & 13,04 \\
7 & 71,08 & 16,96 & 12,04 \\
8 & 96,29 & 13,83 & 13,28 \\
9 & 93,77 & 15,71 & 14,69 \\
10 & 87,73 & 16,34 & 14,33 \\
11 & 73,83 & 16,35 & 12,11 \\
12 & 91,08 & 15,26 & 13,90 \\
13 & 93,98 & 15,27 & 14,35 \\
14 & 73,77 & 16,40 & 12,09 \\
15 & 77,25 & 15,48 & 11,97 \\
16 & 68,06 & 16,08 & 10,89 \\
17 & 82,19 & 15,88 & 13,07 \\
18 & 74,15 & 14,99 & 11,09 \\
19 & 79,40 & 15,53 & 12,32 \\
20 & 82,62 & 15,63 & 1292 \\
\hline
\end{tabular}




\subsubsection{Grupo 1 - Ensaio de Caracterização/92}

Neste grupo as 15 primeiras classificadas em produtividade de colmos (TCH5) foram semelhantes, com destaque para os genótipos 1 (RB72454, padrão) e 22 (SP83-1006). Em termos de teor de sacarose médio os 11 genótipos melhor classificados foram semelhantes, com destaque para o genótipo 24 (SP835073). A variável de interesse na seleção de clones, produtividade de açúcar (TPH5), foi similar para as 17 variedades melhor classificadas, destacando-se o genótipo 1, a variedade-padrão RB72454 (Tabela 6).

Tabela 6 - Classificação entre as médias dos genótipos (GEN.) nos diversos locais avaliados. Variáveis estimadas para 5 cortes, Grupo 1, Ensaio de Caracterização/92. Comparação através do Teste de Tukey ( $5 \%$ ).

\begin{tabular}{ll}
\hline GEN. & \multicolumn{1}{c}{ TCH5 } \\
\hline 1 & $115,26 \mathrm{a}$ \\
22 & $115,21 \mathrm{a}$ \\
21 & $109,53 \mathrm{ab}$ \\
25 & $109,44 \mathrm{ab}$ \\
14 & $109,32 \mathrm{ab}$ \\
23 & $108,75 \mathrm{abc}$ \\
9 & 107,85 abcd \\
10 & 107,01 abcde \\
11 & 105,83 abcdef \\
15 & 103,94 abcdef \\
12 & 103,67 abcdef \\
20 & 101,78 abcdef \\
8 & 101,64 abcdef \\
19 & 100,42 abcdefg \\
18 & 99,71 abcdefg \\
16 & 97,82 bcdefg \\
24 & 96,98 bcdefg \\
13 & 94,37 bcdefgh \\
3 & 93,32 cdefgh \\
6 & 92,32 defgh \\
17 & 91,48 efghi \\
7 & 90,73 fghi \\
2 & 85,69 ghi \\
4 & 79,35 hi \\
5 & $76,30 \mathrm{i}$ \\
\hline
\end{tabular}

\begin{tabular}{ll}
\hline GEN & \multicolumn{1}{c}{ PCCM } \\
\hline 24 & $16,28 \mathrm{a}$ \\
13 & $16,08 \mathrm{ab}$ \\
7 & $15,88 \mathrm{abc}$ \\
20 & $15,73 \mathrm{abcd}$ \\
2 & $15,71 \mathrm{abcd}$ \\
11 & 15,59 abcde \\
17 & 15,56 abcdef \\
5 & 15,43 abcdef \\
6 & 15,43 abcdef \\
19 & 15,37 abcdef \\
15 & 15,22 abcdef \\
21 & $14,98 \mathrm{bcdefg}$ \\
10 & $14,96 \mathrm{cdefg}$ \\
16 & $14,95 \mathrm{cdefg}$ \\
12 & $14,92 \mathrm{cdefg}$ \\
4 & $14,84 \mathrm{cdefgh}$ \\
3 & $14,72 \mathrm{defgh}$ \\
1 & $14,60 \mathrm{efgh}$ \\
9 & $14,47 \mathrm{fgh}$ \\
22 & $14,12 \mathrm{gh}$ \\
8 & $14,05 \mathrm{gh}$ \\
23 & $14,04 \mathrm{gh}$ \\
18 & $13,96 \mathrm{gh}$ \\
25 & $13,95 \mathrm{gh}$ \\
14 & $13,80 \mathrm{~h}$ \\
\hline
\end{tabular}

\begin{tabular}{ll}
\hline GEN & \multicolumn{1}{c}{ TPH5 } \\
\hline 1 & $16,78 \mathrm{a}$ \\
11 & $16,40 \mathrm{ab}$ \\
21 & $16,36 \mathrm{ab}$ \\
22 & $16,25 \mathrm{ab}$ \\
20 & $15,96 \mathrm{abc}$ \\
10 & $15,95 \mathrm{abcd}$ \\
15 & $15,78 \mathrm{abcd}$ \\
24 & $15,74 \mathrm{abcd}$ \\
9 & $15,57 \mathrm{abcd}$ \\
19 & $15,39 \mathrm{abcd}$ \\
12 & $15,39 \mathrm{abcd}$ \\
25 & $15,25 \mathrm{abcd}$ \\
23 & $15,22 \mathrm{abcd}$ \\
13 & $15,14 \mathrm{abcd}$ \\
14 & $15,03 \mathrm{abcd}$ \\
16 & $14,63 \mathrm{abcd}$ \\
7 & $14,36 \mathrm{abcd}$ \\
8 & $14,25 \mathrm{bcde}$ \\
17 & $14,18 \mathrm{bcde}$ \\
6 & $14,18 \mathrm{bcde}$ \\
18 & $13,94 \mathrm{bcde}$ \\
3 & $13,70 \mathrm{cde}$ \\
2 & $13,46 \mathrm{de}$ \\
4 & $11,79 \mathrm{e}$ \\
5 & $11,78 \mathrm{e}$ \\
\hline
\end{tabular}

$\mathrm{QMR}^{1}: 36,6095$

QMR: 0,1814

QMR: 0,9347

$\mathrm{DMS}^{2}: 15,64$

DMS : 1,10

DMS : 2,49

1 = quadrado médio do resíduo da análise conjunta

2 = diferença minima significativa 


\subsubsection{Grupo 2 - Ensaio de Caracterização/93}

Os seis primeiros clones classificados em produtividade de colmos (TCH5) foram semelhantes, com destaque para o genótipo 7 (SP77-3331). Em termos de teor de sacarose não se encontrou valores médios muito diferentes, sendo que os 20 primeiros genótipos foram semelhantes, com destaque para os genótipos 12, 9 e 16 (SP80-1468, SP79-2312 e SP81-1747, respectivamente). Para a variável de interesse na seleção de clones, TPH5, o grupo de genótipos mostrou-se bem homogêneo. Apenas as quatro primeiras variedades, genótipos 7 , 20, 15 e 1 (SP77-3331, SP82-3721, SP80-3480 e RB72454) foram superiores às duas piores classificadas (Tabela 7 ).

Tabela 7 - Classificação entre as médias dos genótipos (GEN.) nos diversos locais avaliados. Variáveis estimadas para 5 cortes, Grupo 2, Ensaio de Caracterização/93. Comparação através do Teste de Tukey $(5 \%)$.

\begin{tabular}{|c|c|c|c|c|c|}
\hline GEN. & $\mathrm{TCH} 5$ & GEN. & PCCM & GEN. & TPH5 \\
\hline 7 & $102,37 \mathrm{a}$ & 12 & $16,73 \mathrm{a}$ & 7 & $15,01 \mathrm{a}$ \\
\hline 2 & $94,78 \mathrm{ab}$ & 9 & $16,72 \mathrm{a}$ & 20 & $14,90 \mathrm{a}$ \\
\hline 15 & $94,48 a b$ & 16 & $16,68 \mathrm{a}$ & 15 & $14,60 \mathrm{a}$ \\
\hline 20 & $92,79 a b c$ & 11 & $16,60 \mathrm{ab}$ & 1 & 14,08 a \\
\hline 1 & $90,67 \mathrm{abcd}$ & 10 & $16,53 a b c$ & 2 & $13,94 a b$ \\
\hline 18 & $88,51 \mathrm{abcd}$ & 8 & $16,53 \mathrm{abc}$ & 8 & $13,82 a b$ \\
\hline 17 & $87,57 \mathrm{bcd}$ & 5 & $16,20 \mathrm{abcd}$ & 11 & $13,73 a b$ \\
\hline 8 & 83,93 bcde & 20 & 16,16 abcd & 17 & $13,61 \mathrm{ab}$ \\
\hline 19 & $83,51 \mathrm{bcde}$ & 14 & 15,88 abcde & 18 & 13,42 ab \\
\hline 6 & $83,48 \mathrm{bcde}$ & 6 & 15,73 abcdef & 10 & $13,41 \mathrm{ab}$ \\
\hline 11 & 83,31 bcde & 13 & 15,73 abcdef & 12 & $13,10 \mathrm{ab}$ \\
\hline 3 & 83,25 bcde & 4 & 15,71 abcdef & 5 & $13,06 \mathrm{ab}$ \\
\hline 10 & 81,56 bcde & 19 & 15,67 abcdef & 6 & 13,05 ab \\
\hline 13 & 81,26 bcde & 1 & 15,64 abcdef & 19 & $12,99 a b$ \\
\hline 5 & 81,17 bcde & 17 & 15,63 abcdef & 3 & $12,78 a b$ \\
\hline 14 & 80,18 bcde & 15 & 15,51 bcdef & 16 & 12,76 ab \\
\hline 12 & $78,59 \mathrm{cde}$ & 3 & 15,44 cdef & 14 & $12,70 \mathrm{ab}$ \\
\hline 16 & $77,01 \mathrm{de}$ & 18 & $15,31 \mathrm{def}$ & 13 & $12,68 \mathrm{ab}$ \\
\hline 9 & $69,59 \mathrm{e}$ & 2 & 14,78 ef & 9 & $11,58 \mathrm{~b}$ \\
\hline 4 & $53,48 \mathrm{f}$ & 7 & $14,72 f$ & 4 & $8,39 \mathrm{c}$ \\
\hline QMR ${ }^{1}:$ & $: 34,1936$ & QMR: & 0.1944 & QMR: & 0,9352 \\
\hline DMS $^{2}:$ & $: 14,64$ & DMS & 1,10 & DMS & 2,42 \\
\hline
\end{tabular}

1 = quadrado médio do residuo da análise conjunta

2 = diferença minima significativa 


\subsubsection{Grupo 3 - Ensaio de Caracterização/94}

Em virtude da menor variância residual, obtida na análise conjunta deste grupo de ensaio, os genótipos puderam ser separados com maior facilidade, já que foram menores os valores de DMS (Diferença Mínima Significativa) utilizados na comparação entre as médias.

Seis genótipos melhor classificados em produtividade de colmos (TCH5) foram semelhantes, com destaque para o número 8 (SP80-0180). Em termos de teor de sacarose médio (PCCM) seis genótipos foram os melhores, com destaque para o genótipo 7 (SP80-0144).

A produtividade de açúcar, TPH5, foi similar para as 11 variedades melhor classificadas, separando-se estatisticamente apenas as cinco primeiras das quatro últimas. O melhor genótipo foi o número 9, SP80-3280 (Tabela 8 ).

Tabela 8 - Classificação entre as médias dos genótipos (GEN.) nos diversos locais avaliados. Variáveis estimadas para 5 cortes, Grupo 3, Ensaio de Caracterização/94. Comparação através do Teste de Tukey $(5 \%)$.

\begin{tabular}{|c|c|c|c|c|c|}
\hline GEN. & $\mathrm{TCH} 5$ & \multicolumn{2}{|c|}{ GEN. PCCM } & GEN. & TPH5 \\
\hline 8 & $96,28 \mathrm{a}$ & 7 & $16,95 \mathrm{a}$ & 9 & $14,69 \mathrm{a}$ \\
\hline 1 & $94,17 a b$ & 14 & $16,40 a b$ & 13 & $14,35 a b$ \\
\hline 13 & $93,98 a b$ & 11 & $16,34 \mathrm{abc}$ & 10 & $14,32 a b$ \\
\hline 9 & $93,76 a b$ & 10 & $16,34 a b c$ & 1 & $14,04 a b c$ \\
\hline 12 & $91,07 \mathrm{abc}$ & 6 & $16,13 \mathrm{abcd}$ & 12 & $13,90 \mathrm{abc}$ \\
\hline 10 & $87,73 \mathrm{abcd}$ & 16 & 16,08 abcde & 8 & $13,28 \mathrm{abcd}$ \\
\hline 20 & 82,61 bcde & 5 & 16,00 bcde & 17 & 13,07 abcde \\
\hline 17 & 82,19 bcde & 17 & 15,88 bcde & 6 & 13,03 abcde \\
\hline 4 & 82,17 bcde & 9 & 15,70 bcdef & 20 & 12,91 abcdef \\
\hline 2 & 81,42 bcde & 4 & $15,70 \mathrm{bcdef}$ & 4 & 12,86 abcdef \\
\hline 6 & 80,84 cdef & 20 & $15,63 \mathrm{bcdef}$ & 5 & 12,62 abcdef \\
\hline 19 & 79,40 cdef & 19 & 15,53 bcdef & 19 & 12,32 bcdef \\
\hline 5 & 78,88 cdef & 15 & $15,48 \mathrm{cdef}$ & 11 & $12,11 \mathrm{cdef}$ \\
\hline 15 & $77,25 \mathrm{def}$ & 13 & $15,26 \mathrm{def}$ & 14 & $12,08 \mathrm{cdef}$ \\
\hline 18 & 74,15 ef & 12 & 15,26 def & 7 & $12,03 \mathrm{cdef}$ \\
\hline 11 & 73,82 ef & 3 & $15,21 \mathrm{efg}$ & 15 & 11,96 cdef \\
\hline 14 & 73,76 ef & 18 & $14,98 \mathrm{fg}$ & 2 & $11,68 \mathrm{def}$ \\
\hline 3 & $73,73 \mathrm{ef}$ & 1 & $14,88 \mathrm{fg}$ & 3 & 11,22 def \\
\hline 7 & 71,07 ef & 2 & $14,34 \mathrm{gh}$ & 18 & 11,09 ef \\
\hline 16 & $68,05 \mathrm{f}$ & 8 & $13,82 \mathrm{~h}$ & 16 & $10,88 \mathrm{f}$ \\
\hline \multicolumn{2}{|c|}{ QMR $^{1}: \quad 26,2674$} & \multicolumn{2}{|c|}{ QMR: 0,1258} & \multicolumn{2}{|c|}{ QMR: 0,6988} \\
\hline \multicolumn{2}{|c|}{ DMS $^{2}: 12,83$} & \multicolumn{2}{|c|}{ DMS : 0,88} & \multicolumn{2}{|c|}{ DMS : 2,09} \\
\hline
\end{tabular}

1 = quadrado médio do resíduo da análise conjunta

2 = diferença minima significativa 


\subsection{Parâmetros de estabilidade fenotípica obtidos para a estimativa de cinco cortes}

Foram estimados os parâmetros utilizados para a determinação da estabilidade fenotípica, empregados de acordo com a metodologia a que se referem. As estimativas foram agrupadas de acordo com a clasificação de Lin (1986), usando-se os dados de produtividade de açúcar estimada para cinco cortes (TPH5). Os dados médios de TPH5 dos genótipos para cada um dos locais avaliados, podem ser visualizados no Anexo 13.

\subsubsection{Estimativas dos parâmetros dos Grupos A e B}

Os parâmetros baseados nos efeitos genotípicos (grupo A) e nas estimativas oriundas da interação de genótipos por ambientes (grupo B) encontram-se nas Tabelas 9 a 11, para os Ensaios de Caracterização 92, 93 e 94, respectivamente. Estas estimativas relacionam-se com a estabilidade estática dos genótipos ou, no caso, indicam a estabilidade biológica frente às variações encontradas nos ambientes de experimentação.

Dentro do grupo A, as estimativas obtidas pelos métodos Tradicional e de Roemer resultaram na mesma classificação dos genótipos, nos três grupos de ensaios. Esta relação, já esperada, deve-se à forma de determinação destes parâmetros. O modelo Tradicional utiliza o desdobramento da soma de quadrados, resultando na estimativa dos efeitos de ambientes dentro de cada genótipo. A metodologia proposta por Roemer utiliza-se dos dados médios das variedades nos diferentes ambientes, obtidos em tabela de dupla entrada, estimando também a variância fenotípica de ambientes dentro de cada genótipo. Pela nítida equivalência destes dois parâmetros, deve-se optar pela utilização da metodologia proposta por Roemer, já que é de mais fácil aplicação. Os parâmetros $L 1_{i} \in L 2_{i}$, obtidos pelo método de Langer, estimam as amplitudes de produtividade obtidas por cada genótipo, sendo também de fácil aplicação.

Para o grupo $B$, as estimativas dos métodos de Plaisted \& Peterson e de Wricke classificaram os genótipos na mesma posição, apresentando 
basicamente as mesmas vantagens e estando, também, de certa forma interrelacionadas. No primeiro método as estimativas são obtidas pela decomposição da variância da interação $G A$, enquanto que no segundo utiliza-se a decomposição da soma de quadrados da interação GA. Concordância entre estas duas estimativas também foi relatada nos trabalhos de Kang \& Miller (1984) e Oliveira (1976). Pela facilidade de obtenção, a metodologia de Wricke deve ser preferida.

Analisando inicialmente os dados da Tabela 9 (Caracterização/92), observa-se que as quatro variedades melhor classificadas em produtividade de açúcar (genótipos 1, RB72454; 11, SP80-1816; 21, SP82-6034 e 22, SP83-1006), apresentaram altas estimativas para a maioria dos parâmetros, ou seja, também foram mais instáveis e com maior amplitude de produtividade entre os ambientes, interagindo mais com os mesmos. Como destaque, o genótipo número 20 (SP824010), quinto colocado em produtividade de açúcar, foi um dos mais estáveis, já que obteve índices baixos para diversos parâmetros que avaliam a estabilidade do tipo biológica. Também os genótipos números 15, 24 e 9 apresentaram bons rendimentos e menor sensibilidade a variação ambiental. Por outro lado, os genótipos 20 e 5 foram ruins tanto em produtividade de açúcar quanto em nível de estabilidade biológica. 
Tabela 9 - Produtividade de açúcar e estimativas dos parâmetros de estabilidade calculados para a variável TPH5, para os genótipos (GEN.) do Ensaio de Caracterização/92 (Grupo 1).

\begin{tabular}{|c|c|c|c|c|c|c|c|c|c|c|c|c|c|c|}
\hline \multirow[b]{2}{*}{ GEN. } & \multicolumn{2}{|c|}{ Média } & \multicolumn{12}{|c|}{ Parâmetros ${ }^{2}$} \\
\hline & TPH5 & cl. 1 & $\operatorname{Ro\sigma }_{3}^{2}$ & $\mathrm{cl}$. & $\mathrm{Ll}_{4}$ & cl. & $\begin{array}{l}\mathrm{L} 2 \mathrm{i}_{4} \\
\end{array}$ & cl. & $\begin{array}{r}I_{1} \\
5 \\
\end{array}$ & $\mathrm{cl}$. & 6 & cl. & $\omega_{i}$, & \\
\hline 1 & 16,78 & & 6,02 & 5 & 9,54 & 3 & 6,66 & 11 & 24,07 & 5 & 1,56 & 10 & 95,75 & 10 \\
\hline 2 & 13,46 & 23 & 6,41 & 3 & 10,47 & 1 & 10,47 & 1 & 25,65 & 3 & 1,66 & 6 & 105,21 & 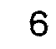 \\
\hline 3 & 13,70 & 22 & 1,35 & 25 & 4,62 & 25 & 3,02 & 25 & 5,41 & 25 & 1,13 & 19 & 52,70 & 19 \\
\hline 4 & 11,79 & 24 & 4,59 & 13 & 7,90 & 13 & 6,03 & 14 & 18,36 & 13 & 1,95 & 3 & 134,42 & 3 \\
\hline 5 & 11,79 & 25 & 5,07 & 7 & 8,19 & 11 & 8,19 & 7 & 20,26 & 7 & 1,81 & 4 & 120,30 & 4 \\
\hline 6 & 14,18 & 20 & 1,77 & 22 & 5,00 & 23 & 3,37 & 22 & 7,07 & 22 & 1,31 & 15 & 70,49 & 15 \\
\hline 7 & 14,36 & 17 & 4,74 & 11 & 8,59 & 9 & 8,59 & 6 & 18,97 & 11 & 1,46 & 13 & 84,92 & 13 \\
\hline 8 & 14,26 & 18 & 2,41 & 21 & 5,38 & 21 & 3,05 & 24 & 9,62 & 21 & 1,03 & 22 & 42,07 & 22 \\
\hline 9 & 15,57 & 9 & 5,01 & 9 & 7,64 & 14 & 7,64 & 9 & 20,03 & 9 & 1,07 & 21 & 46,07 & 21 \\
\hline 10 & 15,96 & 6 & 6,19 & 4 & 9,07 & 6 & 9,07 & 3 & 24,74 & 4 & 1,28 & 16 & 67,89 & 16 \\
\hline 11 & 16,41 & 2 & 7,59 & 1 & 10,15 & 2 & 7,75 & 8 & 30,36 & 1 & 1,77 & 5 & 116,76 & 5 \\
\hline 12 & 15,40 & 11 & 2,73 & 19 & 5,68 & 20 & 3,42 & 21 & 10,92 & 19 & 1,51 & 11 & 0,41 & 11 \\
\hline 13 & 15,14 & 14 & 1,66 & 23 & 5,14 & 22 & 5,14 & 16 & 6,63 & 23 & 1,13 & 20 & 52,47 & 20 \\
\hline 14 & 15,04 & 15 & 1,55 & 24 & 4,93 & 24 & 3,06 & 23 & 6,20 & 24 & 1,60 & 9 & 99,24 & 9 \\
\hline 15 & 15,78 & 7) & 4,88 & 10 & 7,46 & 15 & 6,68 & 10 & 19,52 & 10 & 1,25 & 17 & 64,87 & 17 \\
\hline 16 & 14,63 & 16 & 4,59 & 12 & 8,00 & 12 & 4,62 & 17 & 18,38 & 12 & 1,48 & 12 & 87,64 & 12 \\
\hline 17 & 14,18 & 19 & 4,48 & 14 & 9,53 & 4 & 6,65 & 12 & 17,91 & 14 & 1,18 & 18 & 57,23 & 18 \\
\hline 18 & 13,94 & 21 & 3,74 & 16 & 8,36 & 10 & 3,79 & 20 & 14,96 & 16 & 2,19 & 2 & 158,09 & 2 \\
\hline 19 & 15,40 & 10 & 3,83 & 15 & 6,59 & 17 & 5,21 & 15 & 15,30 & 15 & 2,27 & 1 & 166,78 & 1 \\
\hline 20 & 15,97 & 5 & 2,75 & 18 & 6,02 & 18 & 4,29 & 19 & 11,02 & 18 & 1,02 & 23 & 41,09 & 23 \\
\hline 21 & 16,37 & 3 & 6,86 & 2 & 9,30 & 5 & 9,22 & 2 & 27,43 & 2 & 1,62 & 8 & 101,00 & 8 \\
\hline 22 & 16,26 & 4 & 5,43 & 6 & 8,62 & 8 & 8,62 & 5 & 21,71 & 6 & 1,63 & 7 & 102,80 & 7 \\
\hline 23 & 15,22 & 13 & 5,02 & 8 & 9,07 & 7 & 9,07 & 4 & 20,09 & 8 & 1,32 & 14 & 71,23 & 14 \\
\hline 24 & 15,74 & 8 & 3,07 & 17 & 7,23 & 16 & 6,47 & 13 & 12,28 & 17 & 0,88 & 25 & 27,27 & 25 \\
\hline 25 & 15,25 & 12 & 2,55 & 20 & 5,97 & 19 & 4,45 & 18 & 10,21 & 20 & 0,96 & 24 & 35,17 & 24 \\
\hline
\end{tabular}

$1=$ classificação dos genótipos

$2=$ parâmetros dos grupos $A$ e $B$, segundo Lin et al (1986)

$3=$ método de Roemer

$4=$ método de Langer

$5=$ método Tradicional

$6=$ método de Plaisted \& Peterson

7 = método de Wricke

No Ensaio de Caracterização/93 o melhor genótipo em produtividade, SP77-3331 (número 7), também foi um dos mais instáveis. Da segunda a quinta classificação em TPH5, os niveis de estabilidade já foram melhores, com destaque para a variedade número 2 (RB785148), quinta colocada, que se mostrou estável e alcançou alta produtividade (Tabela 10). Por 
outro lado, os genótipos 4, 9 e 13 apresentaram baixa TPH5 e alta variabilidade.

Tabela 10 - Produtividade de açúcar e estimativas dos parâmetros de estabilidade calculados para a variável TPH5, para os genótipos (GEN.) do Ensaio de Caracterização/93 (Grupo 2).

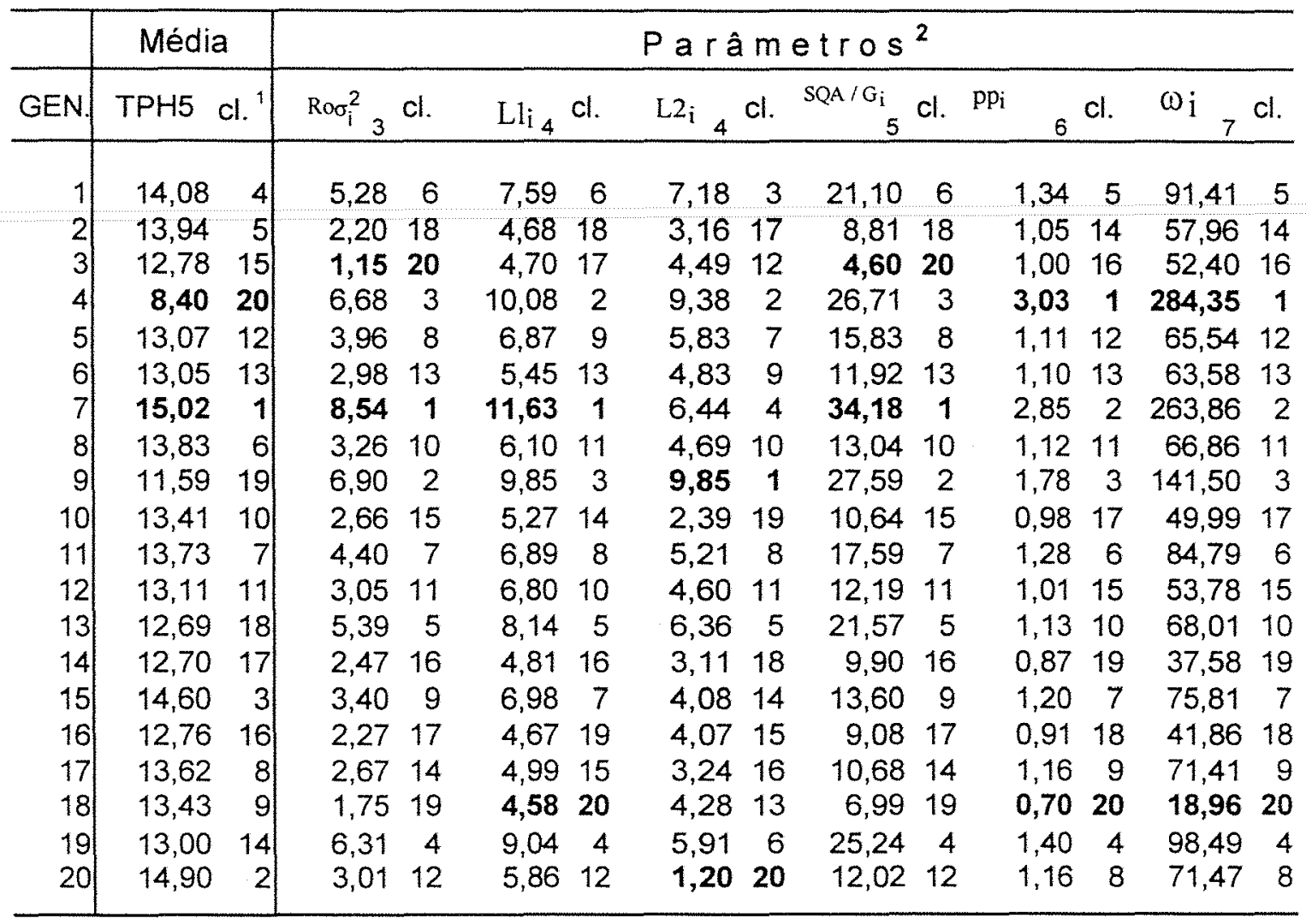

1 = classificação dos genótipos

2 = parâmetros dos grupos $A$ e $B$, segundo Lin et al (1986)

$3=$ método de Roemer

$4=$ método de Langer

$5=$ método Tradicional

$6=$ método de Plaisted \& Peterson

$7=$ método de Wricke

No Ensaio de Caracterização/94, também o melhor genótipo em produtividade, SP80-3280, foi um dos mais instáveis. Os genótipos menos produtivos também tenderam a ser os mais estáveis. Os clones SP80-3390 e SP80-4445, números 10 e 13, respectivamente, foram bem equilibrados, reunindo alta produtividade e bons niveis de estabilidade fenotípica (Tabela 11). Os piores genótipos, aqueles com baixa produtividade e alta variabilidade, foram os 
números 4,9 e 13.

Tabela 11 - Produtividade de açúcar e estimativas dos parâmetros de estabilidade calculados para a variável TPH5, para os genótipos (GEN.) do Ensaio de Caracterização/94 (Grupo 3).

\begin{tabular}{|c|c|c|c|c|c|c|c|c|c|c|c|c|c|c|}
\hline \multirow[b]{2}{*}{ GEN } & \multicolumn{2}{|l|}{ Média } & \multicolumn{12}{|c|}{ Parâmetros ${ }^{2}$} \\
\hline & TPH5 cl & & $\mathrm{Ro \sigma}_{\mathrm{i}}^{2}{ }_{3}$ & & $\mathrm{Ll}_{4}$ & & $\mathrm{~L} \mathrm{i}_{4} \mathrm{C}$ & cl. & $\begin{array}{r}\mathrm{SQA} / \mathrm{G}_{\mathrm{i}} \\
\quad 5 \\
\end{array}$ & cl. & & $\mathrm{cl}$. & $\omega_{\mathrm{i}}$ & cl. \\
\hline 1 & 14,04 & 4 & 5,15 & 4 & 9,43 & 1 & 6,35 & 11 & 20,59 & 4 & 1,45 & 1 & 102,65 & 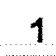 \\
\hline 2 & 11,69 & 17 & 2,77 & 18 & 5,77 & 17 & 4,63 & 17 & 11,08 & 18 & 0,62 & 17 & 7,73 & 17 \\
\hline 3 & 11,22 & 18 & 5,09 & 5 & 7,08 & 9 & 7,02 & 6 & 20,36 & 5 & 1,03 & 3 & 64,75 & 3 \\
\hline 4 & 12,87 & 10 & 3,61 & 14 & 5,63 & 18 & 5,02 & 15 & 14,44 & 14 & 0,67 & 15 & 31,65 & 15 \\
\hline 5 & 12,62 & 11 & 3,38 & 17 & 5,91 & 16 & 5,91 & 13 & 13,50 & 17 &, 62 & 18 & 28 & 18 \\
\hline 6 & 13,04 & 8 & 4,49 & 8 & 7,62 & 6 & 7,62 & 4 & 97 & 8 & 0 & 10 & 07 & 10 \\
\hline 7 & 12,04 & 15 & 3,76 & 13 & & 12 & 6,61 & 7 & 15,05 & 13 & 66 & 6 & 10 & 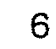 \\
\hline 8 & 13,28 & 6 & 1,86 & 20 & 4,49 & 20 & 4,44 & 18 & 7,44 & 20 & 1,27 & 2 & 36,21 & 2 \\
\hline 9 & 14,69 & & 5,61 & 1 & 8,14 & 2 & 7,81 & 2 & 22,45 & 1 & 1,00 & 4 & 2,06 & 4 \\
\hline 10 & 14,33 & 3 & 4,40 & 9 & 35 & 8 & 7 & 5 & 17,59 & 9 & 0,61 & 19 & 26,76 & 19 \\
\hline 11 & 12,11 & 13 & 5,46 & 2 & 7,76 & 4 & 6,60 & 8 & 21,82 & 2 & 0,80 & 8 & 44,18 & 8 \\
\hline 12 & 13,90 & 5 & 3,97 & 12 & 9 & 13 & 4,64 & 16 & 15,88 & 12 & 0,70 & 11 & 34,98 & 11 \\
\hline 13 & 14,35 & 2 & 4,53 & 7 & 6,93 & 10 & 6,47 & 9 & 18,13 & 7 & 0,69 & 12 & 34,16 & 12 \\
\hline 14 & 09 & 14 & 4,56 & 6 & 7,74 & 5 & 7,74 & 3 & 18,24 & 6 & 0,69 & 13 & 34,00 & 13 \\
\hline 15 & 11,97 & 16 & 4,04 & 11 & 6,42 & 14 & 5,84 & 14 & 16,16 & 11 & 0,57 & 20 & 22,81 & 20 \\
\hline 16 & 10,89 & 20 & 3,50 & 15 & 6,11 & 15 & 4,32 & 19 & 14,01 & 15 & 0,99 & 5 & 61,01 & 5 \\
\hline 17 & 13,07 & 7 & 3,44 & 16 & 7,39 & 7 & 6,08 & 12 & 13,78 & 16 & 0,65 & 16 & 30,08 & 16 \\
\hline 18 & 11,09 & 19 & 2,35 & 19 & 5,19 & 19 & 4,08 & 20 & 9,41 & 19 & 0,68 & 14 & 32,70 & 14 \\
\hline 19 & 12,32 & 12 & 5,18 & 3 & 7,89 & 3 & 7,89 & 1 & 20,73 & 3 & 0,73 & 9 & 37,32 & 9 \\
\hline 20 & 12,92 & 9 & 4,19 & 10 & 6,70 & 11 & 6,35 & 10 & 16,75 & 10 & 0,85 & 7 & 48,31 & 7 \\
\hline
\end{tabular}

1 = classificação dos genótipos

2 = parâmetros dos grupos $A$ e $B$, segundo Lin et al (1986)

3 = método de Roemer

$4=$ método de Langer

$5=$ método Tradicional

$6=$ método de Plaisted \& Peterson

$7=$ método de Wricke

De forma geral, entre as variedades-padrão a SP70-1143, apesar de pouco produtiva, foi sempre a que obteve as menores estimativas dos parâmetros de estabilidade biológica, nos três grupos de ensaios, mostrando-se bastante estável. Tal caracteristica demonstra a rusticidade deste material, que foi amplamente explorado em cultivos no Estado de São Paulo, principalmente em solos de menor fertilidade. O genótipo SP71-6163 também foi pouco produtivo, porém foi um dos mais instáveis nos ensaios de 1992 e 1993. Este 
comportamento deve ser associado a maior exigência ambiental e, principalmente, devido a problemas fitossanitários que prejudicaram esta variedade nos últimos anos. A SP79-1011 apresentou boa estabilidade, obtendo valores intermediários de produtividade de açúcar, nos três grupos de ensaios avaliados. Para a RB72454, de alta produtividade de açúcar, os dados quase sempre indicaram baixo nivel de estabilidade, o que não ocorreu para a variedade RB785148 que, como comentado anteriormente, foi uma das mais produtivas e estáveis (ver números das variedades-padrão na Tabela 1).

Dentre as variedades comerciais liberadas recentemente se destacou, em termos de estabilidade, a SP83-5073 (genótipo 24, Ensaio de Caracterização/92). Para esta variedade, oitava classificada em produtividade de açúcar, as estimativas de todos os parâmetros de estabilidade foram baixas, indicando que os valores de TPH5 pouco variaram entre os ambientes. $O$ mesmo ocorreu para o genótipo número 20 do Ensaio de Caracterização/92 (SP82-4010), quinto colocado em produtividade de açúcar.

\subsubsection{Estimativas dos parâmetros dos Grupos C e D}

Nestes grupos encontram-se os parâmetros estimados com base nas análises de regressões lineares, entre a produtividade de açúcar estimada para 5 cotes e os índices ambientais para cada genótipo. Desta forma avalia-se o nível de estabilidade agronômica das variedades, ou seja, o tipo de resposta, a adaptabilidade e a previsibilidade de produção frente às variações ambientais.

\subsubsection{Método de Eberhart \& Russel}

Para vários genótipos o coeficiente de regressão $\left(b_{i}\right)$ foi significativamente diferente da unidade, indicando resposta ambiental diferenciada entre as variedades avaliadas. Os desvios de regressão foram significativos para quase todos os genótipos, mas o grau de imprevisibilidade não deve comprometer a indicação de algumas destas variedades, uma vez que várias delas apresentaram $\mathrm{R}^{2}$ superior a $80 \%$. Porém, observa-se que nem todas as 
variedades têm uma resposta linear diante da variação ambiental (Tabela 12).

No Ensaio de Caracterização/92 os genótipos números 10, 11 e 21 (SP80-0185, SP80-1816 e SP82-6034) foram os que mais responderam à melhoria ambiental, estando também entre os mais produtivos (ver tabela 9). Por outro lado, os genótipos 3 (SP70-1143) e 14 (SP81-1949) apresentaram baixos coeficientes de regressão, não produzindo satisfatoriamente nos ambientes de melhor potencial, indicando estes materiais apenas para condições desfavoráveis de ambiente. Os genótipos 9 e 10 (SP80-0147 e SP80-0185) foram os de maior previsibilidade, apresentando boa resposta ambiental e bom nivel de produtividade de açúcar.

No Ensaio de Caracterização/93 os genótipos números 19 (SP815259) e 9 (SP79-2312) responderam nitidamente à melhoria ambiental apresentando, na média dos ambientes, produtividade de açúcar apenas regular (Tabela 10). Por outro lado, os genótipos 3,2 e 18 seriam indicados apenas em condiçōes desfavoráveis de ambiente, com destaque para a boa produtividade dos dois últimos (RB785148 e SP81-5193). Os genótipos SP81-5193 e SP701143 , números 18 e 3 , respectivamente, foram os de maior previsibilidade para 0 tipo de resposta ambiental, já que obtiveram baixos valores para os desvios de regressão. 
Tabela 12 - Estimativas dos parâmetros de estabilidade calculados para a regressão linear da variável TPH5 em relação ao indice ambiental ( lj). Valores estimados para cada genótipo (GEN.) nos Ensaios de Caracterização 92, 93 e 94, segundo o método de Eberhart \& Russel.

\begin{tabular}{|c|c|c|c|c|c|c|c|c|c|c|c|c|}
\hline \multirow[b]{2}{*}{ GEN. } & \multicolumn{4}{|c|}{ Caracterização/92 } & \multicolumn{4}{|c|}{ Caracterização/93 } & \multicolumn{4}{|c|}{ Caracterização/94 } \\
\hline & $b_{i}+t^{2}$ & $\widehat{\sigma_{d}^{2}}$ & $F^{4}$ & $R^{2}(\%)^{5}$ & $b_{i} \quad t$ & $\widehat{\sigma_{d}^{2}}$ & $F R$ & $\mathrm{R}^{2}(\%)$ & $b_{i} t$ & $\hat{\sigma_{d}^{2}}$ & $F F$ & $R^{2}(\%)$ \\
\hline 1 & $1,31^{\star \star}$ & 1,49 & $\star \star$ & 74 & $1,27^{\star *}$ & 1,21 & $\star \star$ & 74 & $0,98 \mathrm{~ns}$ & 2,16 & $\star \star$ & 58 \\
\hline 2 & 1,36 ** & 1,60 & $\star \star *$ & 74 & $0,75^{\text {** }}$ & 0,64 & $\star \star$ & 63 & $0,85^{*}$ & 0,38 & $\star \star$ & 82 \\
\hline 3 & $0,57^{\star \star}$ & 0,34 & ** & 61 & 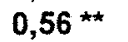 & 0,19 & * & 66 & $1,10 \mathrm{~ns}$ & 1,26 & ** & 74 \\
\hline 4 & $0,89 \mathrm{~ns}$ & 2,53 & $\star \star$ & 44 & $0,90 \mathrm{~ns}$ & 4,82 & ** & 29 & $0,97 \mathrm{~ns}$ & 0,54 & $\star \star \star$ & 82 \\
\hline 5 & $1,04 \mathrm{~ns}$ & 2,27 & $\star \star$ & 54 & $1,08 \mathrm{~ns}$ & 0,92 & ** & 73 & $0,95 \mathrm{~ns}$ & 0,44 & $\star \star$ & 83 \\
\hline 6 & $0,58^{* \star}$ & 0,75 & $\star \star \star$ & 49 & $0,89 \mathrm{~ns}$ & 0,87 & ** & 65 & $1,10 \mathrm{~ns}$ & 0,59 & ** & 84 \\
\hline 7 & $1,11 \mathrm{~ns}$ & 1,50 & $* *$ & 66 & $1,35^{\star *}$ & 4,16 & $\star \star$ & 52 & $0,91 \mathrm{~ns}$ & 1,12 & $\star \star$ & 69 \\
\hline 8 & $0,81^{*}$ & 0,54 & 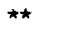 & 70 & $0,94 \mathrm{~ns}$ & 0,95 & ** & 66 & $0,51 * \star$ & 0,97 & $\star \star *$ & 44 \\
\hline 9 & $1,30^{\star \star}$ & 0,47 & $\star \star$ & 87 & $1,43^{\star \star}$ & 1,82 & $\star \star *$ & 72 & $1,19^{\star \star}$ & 1,11 & $\star \star$ & 79 \\
\hline 10 & $1,45^{\star \star}$ & 0,61 & $\star \star$ & 87 & $0,87 \mathrm{~ns}$ & 0,62 & $\star \star$ & 70 & $1.11 \mathrm{~ns}$ & 0,39 & $\star \star$ & 88 \\
\hline 11 & $1,54 * \star$ & 1,38 & $* *$ & 80 & $1,11 \mathrm{~ns}$ & 1,25 & $\star \star$ & 69 & 1,22 ** & 0,66 & $\star \star$ & 86 \\
\hline 12 & $0,69 * \star$ & 1,39 & $\star \star \star$ & 45 & $0,94 \mathrm{~ns}$ & 0,72 & $\star \star *$ & 71 & $1,02 \mathrm{~ns}$ & 0,62 & $\star \star$ & 82 \\
\hline 13 & $0,63^{\star \star}$ & 0,47 & $\star \star$ & 61 & $1,37^{\star \star}$ & 0,62 & $\star \star$ & 85 & $1,11 \mathrm{~ns}$ & 0,56 & $\star \star$ & 85 \\
\hline 14 & $0,43^{* *}$ & 0,93 & $* *$ & 31 & $0,88 \mathrm{~ns}$ & 0,40 & $\star *$ & 76 & $1,12 \mathrm{~ns}$ & 0,55 & $\star \star$ & 85 \\
\hline 15 & $1,21^{\star}$ & 1,00 & $\star \star \star$ & 77 & $0,94 \mathrm{~ns}$ & 1,11 & $\star \star$ & 63 & $1,07 \mathrm{~ns}$ & 0,33 & $\star \star$ & 89 \\
\hline 16 & $1,07 \mathrm{~ns}$ & 1,58 & $\star \star \star$ & 64 & $0,82^{*}$ & 0,43 & $\star \star$ & 73 & $0,86^{*}$ & 1,14 & $\star \star$ & 66 \\
\hline 17 & $1,16 \mathrm{~ns}$ & 0,96 & $* *$ & 77 & $0,80^{\star}$ & 0,94 & ** & 59 & $0,95 \mathrm{~ns}$ & 0,50 & $\star \star$ & 82 \\
\hline 18 & $0,64^{\star \star}$ & 2,69 & $\star \star$ & 28 & $0,79^{\star \star}$ & $-0,01$ & ns & 88 & $0,77^{\star \star}$ & 0,38 & $\star \star$ & 78 \\
\hline 19 & $0,62^{\star \star}$ & 2,84 & $\star \star \star$ & 26 & $1,45^{\star \star}$ & 0,99 & 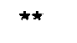 & 82 & $1,20^{\star \star}$ & 0,53 & $\star \star \star$ & 88 \\
\hline 20 & $0,88 \mathrm{~ns}$ & 0,58 & $\star \star$ & 73 & $0,87 \mathrm{~ns}$ & 1,00 & $\star \star$ & 62 & 1,01 ns & 0,92 & $\star \star$ & 76 \\
\hline 21 & $1,46^{\star \star}$ & 1,29 & $\star *$ & 80 & & & & & & & & \\
\hline 22 & $1,17^{\star}$ & 1,82 & ** & 65 & & & & & & & & \\
\hline 23 & $1,21^{*}$ & 1,12 & $\star \star$ & 75 & & & & & & & & \\
\hline 24 & $1,00 \mathrm{~ns}$ & 0,33 & $\star * *$ & 83 & & & & & & & & \\
\hline 25 & $0,87 \mathrm{~ns}$ & 0,45 & $\star \star$ & 75 & & & & & & & & \\
\hline
\end{tabular}

$1=$ coeficiente de regressåo linear

2 = significancia do coeficiente de regressão linear (Teste $t$ ), quando diferente de 1

$3=$ variância dos desvios da linearidade

4 = significåncia da variância dos desvios da linearidade (Teste $F$ ), quando diferente de 0

$5=$ coeficiente de determinaçăo

No Ensaio de Caracterização/94 os genótipos números 11,19 e 9 foram os que mais responderam à melhoria ambiental, sendo que o último (SP803280) apresentou a maior produtividade de açúcar neste ensaio (ver Tabela 11). Por outro lado, o genótipo 18 (SP82-4055) seria indicado apenas para locais desfavoráveis, sendo porém de baixa produtividade na média dos ambientes. Diversos genótipos apresentaram boa previsibilidade, destacando-se também pelo nivel de produtividade o clone SP80-3390. 


\subsubsection{Método de Silva \& Barreto}

Foram obtidos dois coeficientes de regressão ( $b_{1}$ e $\left.b_{1}+b_{2}\right)$, referentes aos ambientes desfavoráveis e favoráveis, respectivamente, além do coeficiente de determinação para a regressão bi-segmentada $\left(\mathrm{R}^{2} \%\right)$. Para este método cerca de dois terços dos coeficientes de regressão foram significativamente diferentes da unidade, indicando adaptação de vários genótipos a determinado tipo de ambiente. Os coeficientes de determinação variaram bastante entre os clones e variedades avaliados, sendo que em geral mantiveram-se ao redor de $75 \%$, valor que indica um bom ajuste deste tipo de regressão, com boa previsibilidade do comportamento dos genótipos. Observa-se que para vários genótipos o modelo se adequou melhor em relação ao método de Eberhart \& Russel, já que as menores estimativas de $\mathrm{R}^{2} \%$ foram aumentadas com o uso da regressão bi-segmentada (Tabela 12 e 13). 
Tabela 13 - Estimativas dos paråmetros de estabilidade calculados para a regressão linear da variável TPH5 em relação aos indices ambientais ( $\mathrm{lj}$ ) e $T(\mathrm{lj}$ ). Valores estimados para cada genótipo (GEN.) nos Ensaios de Caracterização 92, 93 e 94, segundo o método de Silva \& Barreto.

\begin{tabular}{|c|c|c|c|c|c|c|c|c|c|c|c|c|c|c|}
\hline & \multicolumn{5}{|c|}{ Caracterização/92 } & \multicolumn{5}{|c|}{ Caracterização/93 } & \multicolumn{4}{|c|}{ Caracterização/94 } \\
\hline GEN. & ${ }_{1}^{b} 1$ & $t^{2}$ & $b_{1}+$ & & 6) ${ }^{3}$ & $b_{1}$ & $t$ & $b_{1}+b_{2}$ & $\mathrm{t}$ & $\mathrm{R}^{2}(\%)$ & $b_{1} \quad t$ & $b_{1}+b_{2}$ & $t$ & $R^{2}(\%)$ \\
\hline 1 & 1,30 & & 1,32 & ns & 74 & 0,65 & & 1,98 & $\star \star$ & 79 & $1,91 \star \star$ & 0,27 & $\star \star$ & 73 \\
\hline 2 & 1,34 & & 1,36 & ns & 74 & 0,60 & & 0,93 & ns & 64 & $0,99 \mathrm{~ns}$ & 0,75 & ns & 82 \\
\hline 3 & $-0,17$ & & 0,92 & ns & 81 & 0,56 & ** & 0,55 & ns & 66 & $0,78 \mathrm{~ns}$ & 1,34 & t & 76 \\
\hline 4 & 0,81 & & 0,93 & ns & 44 & $-0,16$ & $; \star \star$ & 2,11 & ** & 41 & $0,74 \mathrm{~ns}$ & 1,15 & ns & 83 \\
\hline 5 & 1,03 & & 1,04 & ns & 54 & 1,42 & & 0,70 & ns & 75 & $0,53 * \star$ & 1,27 & ns & 88 \\
\hline 6 & 0,92 & & 0,38 & $\star \star$ & 52 & 1,09 & ns & 0,67 & ns & 66 & $0,92 \mathrm{~ns}$ & 1,24 & ns & 85 \\
\hline 7 & 1,68 & $\star \star \star$ & 0,83 & ns & 70 & 1,55 & $\star \star$ & 1,11 & ns & 52 & $0,71^{*}$ & 1,06 & ns & 69 \\
\hline 8 & 0,81 & & 0,81 & ns & 70 & 1,04 & ns & 0,82 & ns & 66 & $0,96 \mathrm{~ns}$ & 0,17 & $\star \star \star$ & 53 \\
\hline 9 & 1,27 & & 1,32 & ns & 87 & 1,81 & & 0,98 & ns & 74 & $1,18 \mathrm{~ns}$ & 1,20 & ns & 79 \\
\hline 10 & 0,80 & ns & 1,76 & $\star \star \star$ & 91 & 1,29 & ns & 0,39 & $\star$ & 75 & 1,54 ** & 0,79 & ns & 92 \\
\hline 11 & 1,97 & $\star \star \star$ & 1,34 & ns & 82 & 0,83 & ns & 1,43 & ns & 70 & $1,12 \mathrm{~ns}$ & 1,30 & ns & 86 \\
\hline 12 & 1,18 & ns & 0,46 & $\star * *$ & 49 & 0,84 & ns & 1.05 & ns & 71 & $1,26 \mathrm{~ns}$ & 0,83 & ns & 83 \\
\hline 13 & 0,45 & & 0,71 & ns & 62 & 1,49 & $* *$ & 1,23 & ns & 85 & $1,35 *$ & 0,93 & $\mathrm{~ns}$ & 86 \\
\hline 14 & $-0,02$ & & 0,64 & ns & 37 & 0,90 & ns & 0,85 & ns & 76 & $0,91 \mathrm{~ns}$ & 1,27 & ns & 86 \\
\hline 15 & 1,68 & & 0,98 & ns & 79 & 1,24 & ns & 0,59 & ns & 65 & $0,78 \mathrm{~ns}$ & 1,30 & ns & 90 \\
\hline 16 & 0,21 & $\star \star$ & 1,47 & $*$ & 72 & 0,98 & ns & 0,63 & ns & 74 & $0,74 \mathrm{~ns}$ & 0,94 & $\mathrm{~ns}$ & 66 \\
\hline 17 & 1,72 & & 0,89 & ns & 80 & 0,73 & ns & 0,88 & ns & 59 & $1,27 \mathrm{~ns}$ & 0,70 & $\mathrm{~ns}$ & 85 \\
\hline 18 & $-0,16$ & & 1,01 & ns & 36 & 0,95 & ns & 0,61 & ns & 89 & $0,63^{*}$ & 0,87 & ns & 79 \\
\hline 19 & 1,44 & & 0,23 & $\star \star$ & 35 & 1,36 & & 1,56 & * & 82 & $0,97 \mathrm{~ns}$ & 1,38 & $\star$ & 88 \\
\hline 20 & 0,37 & $* *$ & 1,13 & ns & 77 & 0,81 & ns & 0,94 & ns & 62 & 0,72 * & 1,23 & ns & 78 \\
\hline 21 & 0,38 & & 1,97 & $\star *$ & 88 & & & & & & & & & \\
\hline 22 & 2,47 & $\star \star$ & 0,56 & * & 80 & & & & & & & & & \\
\hline 23 & 1,96 & & 0,86 & ns & 81 & & & & & & & & & \\
\hline 24 & 0,89 & ns & 1,05 & ns & 83 & & & & & & & & & \\
\hline 25 & 0,65 & ns & 0,97 & ns & 76 & & & & & & & & & \\
\hline
\end{tabular}

$1=$ coeficientes de regressão linear

2 = significância dos coeficientes de regressão linear (Teste t), quando diferente de 1

$3=$ coeficiente de determinação

No Ensaio de Caracterização/92 os genótipos números 21 e 10 (SP82-6034 e SP80-0185) podem ser considerados de comportamento ideal, já que foram bastante produtivos, tolerantes nos piores ambientes $\left(b_{1}<1\right)$ e muito responsivos à melhoria ambiental $\left(b_{1}+b_{2}>1\right)$, com elevado nivel de previsibilidade do comportamento produtivo, devido aos altos valores de $R^{2} \%$. Os genótipos 3 , 13, 14 e 20 apresentaram baixos coeficientes de regressão nos ambientes desfavoráveis, indicando adaptação destes materiais nestes locais, com destaque para a alta produtividade de açúcar obtida pelo clone número 20 (SP82-4210). 
Cabe lembrar que este genótipo também apresentou elevado nivel de estabilidade do tipo biológica (ver Tabela 9).

No Ensaio de Caracterização/93 o genótipo número 1 (variedadepadrão RB72454) foi o único que apresentou comportamento mais próximo do considerado ideal. Os genótipos 3 (SP70-1143) e 19 (SP81-5259) foram os mais adaptados aos ambientes desfavoráveis e favoráveis, respectivamente, mas ambos com baixa produtividade de açúcar.

Para o grupo de ensaios de 1994 nenhum clone ou variedade mostrou comportamento próximo do ideal, sendo que os genótipos 5 e 7 demonstraram especificidade de adaptação para os piores ambientes, com produtividade apenas regular. Observa-se que apenas para alguns genótipos os coeficientes de regressão foram significativos.

\subsubsection{Método de Cruz, Torres \& Vencovsky}

Nesta metodologia maior número de genótipos apresentou coeficientes de regressão $b_{i}$ significativos, em relação ao método de Silva \& Barreto (Tabela 14$)$. Isto ocorreu principalmente para o coeficiente $\left(b_{1}+b_{2}\right)$, nos ensaios de Caracterização 92 e 94 , que foram os ensaios que apresentaram maior amplitude nas médias dos ambientes. Desta forma, a melhor diferenciação conseguida no padrão de resposta dos genótipos avaliados, deve relacionar-se com as próprias características do modelo, que pressupõe ausência de correlações residuais entre as estimativas dos coeficientes $b_{1}$ e $b_{2}$ (Cruz e Regazzi, 1994). Nas duas metodologias bi-segmentadas os coeficientes de determinação foram semelhantes entre a maioria dos genótipos, nos três grupos de ensaios avaliados.

Ao contrário do método discutido anteriormente, nenhum genótipo apresentou padrão ideal de comportamento. Poucos foram os materiais com adaptação mais próxima do desejável $\left(b_{1}<1\right.$ e $\left.b_{1}+b_{2}>1\right)$ e, quando ocorreram, apresentaram baixas produtividade e nível de previsibilidade ruim.

O método de Cruz, Torres \& Vencovsky também distinguiu diversos 
genótipos com adaptação ambiental específica, destacados na Tabela 14.

Tabela 14 - Estimativas dos parâmetros de estabilidade calculados para a regressão linear da variável TPH5 em relação aos índices ambientais ( lj ) e T( lj ). Valores estimados para cada genótipo (GEN.) nos Ensaios de Caracterização 92,93 e 94, segundo o método de Cruz, Torres \& Vencovsky.

\begin{tabular}{|c|c|c|c|c|c|c|c|c|c|c|c|c|c|c|c|}
\hline & \multicolumn{5}{|c|}{ Caracterização/92 } & \multicolumn{5}{|c|}{ Caracterização/93 } & \multicolumn{5}{|c|}{ Caracterização/94 } \\
\hline GEN. & $b_{1} 1$ & $t^{2}$ & $b_{1}+b_{2}$ & $t^{2}$ & $(\%)^{3}$ & $b_{1}$ & $t$ & $b_{1}+b_{2}$ & $t$ & $R^{2}(\%)$ & $b_{1}$ & $t$ & $b_{1}+b_{2}$ & $\mathrm{t}$ & $\mathrm{R}^{2}(\%)$ \\
\hline 1 & 1,13 & $\mathrm{~ns}$ & 1,70 & $\star \star$ & 77 & 1,17 & $\star \star$ & 2,31 & $\star \star$ & 79 & 1,08 & ns & $-0,71$ & $\star \star$ & 69 \\
\hline 2 & 1,29 & $\star \star$ & 1,49 & $\star \star$ & 74 & 0,77 & $\star \star$ & 0,62 & ns & 63 & 0,91 & ns & $-0,17$ & $\star \star$ & 89 \\
\hline 3 & 0,47 & $\star *$ & 0,77 & $\mathrm{~ns}$ & 64 & 0,53 & $\star \star$ & 0,81 & ns & 67 & 1,11 & ns & 0,91 & ns & 74 \\
\hline 4 & 1,00 & ns & 0,67 & * & 46 & 0,77 & $\star \star$ & 2,23 & $\star \star$ & 36 & 0,99 & ns & 0,61 & ns & 82 \\
\hline $\begin{array}{l}5 \\
6\end{array}$ & $\begin{array}{l}1,12 \\
0.68\end{array}$ & ns & $\begin{array}{l}0,85 \\
0,37\end{array}$ & ns & $\begin{array}{l}55 \\
52\end{array}$ & $\begin{array}{l}1,08 \\
086\end{array}$ & ns & $\begin{array}{l}1,18 \\
125\end{array}$ & ns & $\begin{array}{l}73 \\
66\end{array}$ & 0,94 & ns & $\begin{array}{l}1,16 \\
2,58\end{array}$ & $n_{\star \star}$ & $\begin{array}{l}84 \\
93\end{array}$ \\
\hline 7 & $\begin{array}{l}0,00 \\
1,13\end{array}$ & ns & 1,05 & ns & $\begin{array}{l}52 \\
66\end{array}$ & $\begin{array}{l}0,00 \\
1,38\end{array}$ & $\begin{array}{l}n S \\
\star \star\end{array}$ & $\begin{array}{l}1,20 \\
1,03\end{array}$ & ns & $\begin{array}{l}00 \\
52\end{array}$ & 0,87 & ns & $\begin{array}{l}2,58 \\
1,54\end{array}$ & ns & $\begin{array}{l}93 \\
71\end{array}$ \\
\hline 8 & 0,89 & $\mathrm{~ns}$ & 0,64 & $\star$ & 72 & 0,93 & ns & 1,03 & ns & 66 & 0,56 & $\star \star$ & $-0,27$ & $\star \star$ & 50 \\
\hline 9 & 1,31 & $\star \star$ & 1,29 & * & 87 & 1,48 & $\star \star$ & 0,88 & ns & 73 & 1,14 & * & 2,07 & $\star \star$ & 82 \\
\hline 10 & 1,35 & $\star *$ & 1,68 & $\star \star$ & 88 & 0,99 & ns & $-0,35$ & $\star \star$ & 84 & 1,11 & ns & 1,21 & ns & 88 \\
\hline 11 & 1,58 & $\star *$ & 1,46 & $\star \star$ & 80 & 1,14 & ns & 0,80 & ns & 69 & 1,22 & $\star \star$ & 1,34 & ns & 86 \\
\hline 12 & 0,77 & * & 0,53 & $\star *$ & 46 & 0,94 & ns & 0,94 & ns & 71 & 1,04 & ns & 0,67 & ns & 82 \\
\hline 13 & 0,56 & 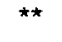 & 0,77 & ns & 62 & 1,36 & $\star \star \star$ & 1,48 & ns & 85 & 1,14 & * & 0,60 & ns & 86 \\
\hline 14 & 0,18 & $\star \star$ & 0,98 & ns & 54 & 0,91 & ns & 0,56 & ns & 77 & 1,12 & ns & 1,06 & ns & 85 \\
\hline 15 & 1,21 & * & 1,22 & ns & 77 & 0,88 & ns & 1,51 & ns & 65 & 1,08 & ns & 0,97 & ns & 89 \\
\hline 16 & 0,88 & ns & 1,47 & $\star \star$ & 68 & 0,83 & $\star$ & 0,76 & ns & 73 & 0,86 & * & 0,86 & ns & 66 \\
\hline 17 & 1,25 & * & 0,96 & ns & 78 & 0,84 & $\star$ & 0,44 & * & 60 & 0,96 & ns & 0,84 & ns & 82 \\
\hline 18 & 0,36 & $\star \star$ & 1,24 & ns & 39 & 0,84 & * & 0,34 & * & 91 & 0,77 & $\star \star$ & 0,75 & ns & 78 \\
\hline 19 & 0,89 & ns & 0,04 & $\star \star$ & 36 & 1,41 & $\star \star$ & 1,88 & $\star \star$ & 83 & 1,17 & $\star$ & 1,86 & $\star \star \star$ & 89 \\
\hline 20 & 0,79 & * & 1,08 & ns & 74 & 0,92 & ns & 0,31 & $\star \star$ & 64 & 0,94 & ns & 2,13 & $\star \star *$ & 82 \\
\hline 21 & 1,38 & $\star \star$ & 1,63 & $\star \star$ & 80 & & & & & & & & & & \\
\hline 22 & 1,47 & $\star \star$ & 0,53 & $\star \star$ & 74 & & & & & & & & & & \\
\hline 23 & 1,40 & $\star \star$ & 0,82 & ns & 79 & & & & & & & & & & \\
\hline 24 & 0,97 & ns & 1,06 & ns & 83 & & & & & & & & & & \\
\hline 25 & 0,94 & ns & 0,70 & $\star$ & 77 & & & & & & & & & & \\
\hline
\end{tabular}

$1=$ coeficientes de regressão linear

2 = significancia dos coeficientes de regressão linear (Teste t), quando diferente de 1

$3=$ coeficiente de determinaçäo

\subsection{Estimativas de correlação ordinal ( $r_{u u^{\prime}}$ de Spearman) entre os} parâmetros de estabilidade fenotípica

\subsubsection{Parâmetros de estabilidade dos Grupos A e B}

Dentro destes dois grupos, visto que os métodos Tradicional e o de Plaisted \& Peterson equivalem aos de Roemer e Wricke, respectivamente, os 
dois primeiros foram suprimidos nas análises de correlação ordinal. Desta forma, foram correlacionadas a produtividade de açúcar estimada para a média de 5 cortes (TPH5), as duas estimativas obtidas pelo método de Langer $\left(L 1_{i}\right.$ e $\left.L 2_{i}\right)$, as estimativas de Roemer e a de Wricke, estando os resultados obtidos expressos na Tabela 15.

Utilizando-se a variância de ambientes dentro de cada genótipo, sabe-se que os genótipos com as menores estimativas desta variância são os mais estáveis. Tais genótipos são não sensiveis à variação ambiental e são, segundo alguns autores, na maior parte dos casos variedades que apresentam baixo rendimento, sendo de uso mais restrito. Também é desejável, para uma análise de estabilidade mais eficiente, uma boa amplitude de variação ambiental para avaliação do grupo de experimentos, e com isto, dificilmente haverá variedades estáveis por este conceito.

Contrariamente a esta colocação de alguns autores, observa-se, em todos os três grupos de ensaios (92, 93 e 94), que a produtividade dos genótipos foi independente dos parâmetros de estabilidade biológica (grupos A e B). Este comportamento é muito interessante para o melhoramento da cultura, indicando a possibilidade de seleção de clones produtivos e com nivel adequado de estabilidade do tipo biológica, conforme foi observado para algumas variedades nas Tabelas 9 a 11. Portanto, além das estimativas de produtividade média de açúcar, as estimativas destes parâmetros podem auxililar na obtenção de variedades produtivas e de boa estabilidade, devendo ser utilizadas em conjunto. 
Tabela 15 - Estimativas da correlação ordinal entre a produtividade de açúcar (TPH5) e os parâmetros de estabilidade dos grupos A e B, nos Ensaios de Caracterização 92, 93 e 94.

\begin{tabular}{|c|c|c|c|c|c|c|c|c|c|c|c|c|}
\hline & \multicolumn{4}{|c|}{ Caracterização/92 } & \multicolumn{4}{|c|}{ Caracterizaçāo/93 } & \multicolumn{4}{|c|}{ Caracterização/94 } \\
\hline & & aráme & $\operatorname{ros}^{1}$ & & & Parân & etros & & & Parâr & etros & \\
\hline & $\mathrm{Ll}_{2}$ & $\mathrm{~L}_{2} \mathrm{i}_{2}$ & $\mathrm{Ro}_{\sigma_{1}^{2}}^{2}$ & $\omega_{i}$ & $\mathrm{Ll}_{\mathrm{i}}$ & $\mathrm{L} 2 \mathrm{i}_{\mathrm{i}}$ & $\operatorname{Ro\sigma } \sigma_{1}^{2}$ & $\omega_{i}$ & $\mathrm{Ll}_{\mathrm{i}}$ & $\mathrm{L} 2 \mathrm{i}_{\mathrm{i}}$ & $\operatorname{Ro} \sigma_{1}^{2}$ & $\omega_{i}$ \\
\hline TPH5 & 0,25 ns $^{5}$ & $0,30 \mathrm{~ns}$ & $0,39 \mathrm{~ns}$ & $-0,15 \mathrm{~ns}$ & $-0,03 \mathrm{~ns}$ & $-0,29$ ns & $-0,03 \mathrm{~ns}$ & $0,14 \mathrm{~ns}$ & $0,38 \mathrm{~ns}$ & $0,31 \mathrm{~ns}$ & $0,30 \mathrm{~ns}$ & $0,10 \mathrm{~ns}$ \\
\hline $\mathrm{Lli}_{\mathrm{i}}$ & & $0,82=$ & $0,91 \%$ & $0,42^{*}$ & & $0,79 \approx$ & $0,98=$ & $0,88^{--}$ & & 0,82 & $0,88 *$ & $0,30 \mathrm{~ns}$ \\
\hline$L 2{ }_{i}$ & & & $0,90^{* *}$ & $0,27 \mathrm{~ns}$ & & & $0,80^{* *}$ & $0,67^{* *}$ & & & $0,81 *$ & $0,16 \mathrm{~ns}$ \\
\hline$R \circ \sigma_{1}^{2}$ & & & & $0,43^{*}$ & & & & $0,88^{-}$ & & & & $0,35 \mathrm{~ns}$ \\
\hline
\end{tabular}

1 = paràmetros dos grupos $A$ e B, segundo Lin et al (1986)

2 = método de Langer

3 = método de Roemer

4 = método de Wricke

$5=$ significância do Teste $t$, sendo ns : não significativo

* = significativamente diferente de zero, ao nivel de $5 \%$ de probabilidade

** = significativamente diferente de zero, ao nivel de $1 \%$ de probabilidade

As duas estimativas, $L 1_{i}$ e $L 2{ }_{i}$, obtidas pelo método de Langer são equivalentes. Quando comparadas com as estimativas obtidas pelo método de Roemer, em todos os casos, estiveram significativamente correlacionadas, indicando que estes três parâmetros avaliam de forma semelhante 0 comportamento dos genótipos entre os ambientes $e$, portanto, não se justifica o uso conjunto destas estimativas. Como consequência desta associação, genótipos que apresentaram maior amplitude para produtividade de açúcar também foram os mais variáveis no conjunto de ambientes. De qualquer forma, pela facilidade de aplicação, tanto o método de Langer quanto o método de Roemer podem ser utilizados devido a facilidade de aplicação.

A metodologia de Wricke, em alguns casos, foi independente em relação aos outros parâmetros e, pela facilidade de utilização, também deve ser preferida para avaliação da estabilidade dos genótipos, quantificando o nível de interação destes com os ambientes. Conforme relatado pelo próprio autor, 
também nos dados aqui analisados observou-se independência entre este parâmetro e a produtividade de açúcar das variedades.

\subsubsection{Parâmetros de estabilidade dos Grupos A, B, C e D}

Foram obtidas as estimativas de correlação ordinal entre os principais parâmetros de produtividade e de estabilidade fenotípica. Os parâmetros $b$ e $R^{2} \%$, obtidos pelos três diferentes métodos de regressão linear (Grupos C e D), também foram correlacionados com a produtividade de açúcar (TPH5) e com os dois principais parâmetros dos grupos $A$ e $B$, quais sejam as estimativas de Roemer e Wricke. As considerações a seguir, pertinentes a estas correlações, encontram-se na Tabela 16.

A produtividade de açúcar (TPH5), na maioria dos casos, não se relacionou de forma significativa com os coeficientes de regressão e de determinação. Não havendo relacionamento evidente entre estes parâmetros, existe a possibilidade de alguns clones aliarem boa produtividade com parâmetros de estabilidade favoráveis.

Para os parâmetros dos grupos $A$ e $B$, apenas a estimativa de Roemer se mostrou mais consistentemente relacionada com os coeficientes de regressão e de determinação ( $b$ e $R^{2} \%$ ), para os três métodos baseados em regressão linear. Desta forma, genótipos que apresentaram maior variabilidade na produtividade entre os diversos ambientes, ou melhores classificações para o parâmetro de Roemer, também obtiveram maior padrão de resposta ambiental, com estimativas mais elevadas para os coeficientes $b$ e $R^{2} \%$. Para a ecovalência, método de Wricke, os resultados de correlação com outros parâmetros foram bastante diferenciados entre os grupos de ensaios.

Os coeficientes de regressão $\left(b_{i}\right.$ e $\left.b_{1}\right)$ e de determinação $\left(R^{2} \%\right)$ foram equivalentes nas três metodologias de regressão linear, com altíssimas correlações. Portanto, avaliam da mesma forma o nível de resposta e o grau de ajuste das regressões lineares. 
Tabela 16 - Estimativas da correlação ordinal entre a produtividade de açúcar (TPH5) e os principais parâmetros de estabilidade dos grupos $A, B, C$ e D, obtidos para os genótipos, nos Ensaios de Caracterização 92, 93 e 94.

\section{Ensaio de Caracterização/92}

Parâmetros

\begin{tabular}{|c|c|c|c|c|c|c|c|c|c|c|c|}
\hline & \multicolumn{2}{|c|}{ E. R. } & \multicolumn{4}{|c|}{ S. B. } & \multicolumn{4}{|c|}{ Cruz et al. } \\
\hline & & $b_{i}$ & $\mathrm{R}_{2} \%$ & $b_{1}$ & $\mathrm{~b}_{2}$ & $\mathrm{~b}_{1}+\mathrm{b}_{2}$ & $\mathrm{R}_{2} \%$ & $b_{1}$ & $b_{2}$ & $b_{1}+b_{2}$ & $R_{2} \%$ \\
\hline & TPH5 & $0,47^{*}$ & $0,53^{\star *}$ & $0,26 \mathrm{~ns}$ & & $0.27 \mathrm{~ns}$ & $0,52^{* *}$ & $0,45^{*}$ & & $0,34 \mathrm{~ns}$ & $0,56^{*}$ \\
\hline & $\operatorname{Ro\sigma }_{i}^{2} \quad 1$ & $0,93 *$ & $0,51^{* *}$ & $0,52^{* *}$ & & $0,60^{\star \star}$ & $0,46^{*}$ & $0,88^{* x}$ & & $0.57^{* *}$ & $0,53^{* *}$ \\
\hline & $\omega_{1} \quad 2$ & $0,04 \mathrm{~ns}$ & $-0,53^{* *}$ & $0,15 \mathrm{~ns}$ & & $-0,09$ is & $-0,46^{*}$ & $0,10 \mathrm{~ns}$ & & $-0,07 \mathrm{~ns}$ & $-0,49^{*}$ \\
\hline E. R. & $b_{i}$ & & $0,79^{* *}$ & 0,43 & & $0,68 * *$ & 0,84 ** & $0,92^{* *}$ & & $0,62 *$ & $0,80^{*}$ \\
\hline 3 & $R_{2} \%$ & & & $0,27 \mathrm{~ns}$ & & 0,62 ** & 0,96 & $0,70^{* *}$ & & $0,58 *$ & $0,98^{* *}$ \\
\hline & & & & & $-0,89 *$ & $-0,29 \mathrm{~ns}$ & $0,26 \mathrm{~ns}$ & $0,67^{* *}$ & & $-0,30 \mathrm{~ns}$ & $0,22 \pi \mathrm{s}$ \\
\hline S. B. & $b_{1}+b_{2}$ & & & & & & $0,69 \cdots$ & $0,39 \mathrm{~ns}$ & & $0,91^{*}$ & $0,69 *$ \\
\hline 4 & $R_{2} \%$ & & & & & & & $0,82 \star$ & & $0,58 *$ & $0,98^{\star *}$ \\
\hline Cruz et al. & $b_{1}$ & & & & & & & & $-0,47^{*}$ & $0,41^{*}$ & $0,76^{\star *}$ \\
\hline 5 & $b_{1}+b_{2}$ & & & & & & & & & & $0,56 * *$ \\
\hline
\end{tabular}

Ensaio de Caracterização/93

\begin{tabular}{|c|c|c|c|c|c|c|c|c|c|c|c|}
\hline & TPH5 & $-0,09 \mathrm{~ns}$ & $0,26 \mathrm{~ns}$ & $-0,37 \mathrm{~ns}$ & & $-0,10 \mathrm{~ns}$ & $-0,05 \mathrm{~ns}$ & $-0,33 \mathrm{~ns}$ & & $0,06 \mathrm{~ns}$ & $-0,15 \mathrm{~ns}$ \\
\hline & 1 & $0,90 * *$ & $0,83 *$ & $-0,11 \mathrm{~ns}$ & & $0,52^{* *}$ & $0,72^{\star *}$ & $-0,09 \mathrm{~ns}$ & & $0,74 *$ & 0,65 * \\
\hline & 2 & \multirow[t]{8}{*}{$0,64 * *$} & $0,94 *$ & \multirow{3}{*}{\multicolumn{2}{|c|}{$\begin{array}{l}-0,49 * \\
0,60 * \\
0,39 \text { ns }\end{array}$}} & \multirow{2}{*}{$\begin{array}{l}0,17^{\mathrm{ns}} \\
0,60^{*}\end{array}$} & \multirow{2}{*}{$\begin{array}{l}0,71^{\star *} \\
0,17 \mathrm{~ns}\end{array}$} & $-0,48^{*}$ & & $0,46^{*}$ & $0,54 *$ \\
\hline & $b_{i}$ & & $0,17 \mathrm{~ns}$ & & & & & $0,86^{*}$ & & $0,64 *$ & $0.12 \mathrm{~ns}$ \\
\hline 3 & $R_{2} \%$ & & & & & $-0,15 \mathrm{~ns}$ & $0,99^{* *}$ & $0,27 \mathrm{~ns}$ & & $-0,07 \mathrm{~ns}$ & $0,94^{*}$ \\
\hline & $b_{1}$ & & & & $-0,82 * *$ & $0,07 \mathrm{~ns}$ & $0,28 \mathrm{~ns}$ & \multirow{4}{*}{$\begin{array}{l}0,65^{* *} \\
0,71 * \\
0,27 \text { ns }\end{array}$} & & \multirow{2}{*}{$\begin{array}{l}0,56^{* *} \\
0,35 \text { ns }\end{array}$} & $0,28 \mathrm{~ns}$ \\
\hline & $b_{1}+b_{2}$ & & & & & & $0,01 \mathrm{~ns}$ & & & & $-0,07$ ns \\
\hline 4 & $R_{2} \%$ & & & & & & & & & $0,27 \mathrm{~ns}$ & $0,97^{* *}$ \\
\hline & $b_{1}$ & & & & & & & & $-0,12 \mathrm{~ns}$ & $0,65 *$ & $0,34 \mathrm{~ns}$ \\
\hline 5 & $b_{1}+b_{2}$ & & & & & & & & & & $0,10 \mathrm{~ns}$ \\
\hline
\end{tabular}

\section{Ensaio de Caracterização/94}

\begin{tabular}{|c|c|c|c|c|c|c|c|c|c|c|c|}
\hline & TPH5 & $0,33 \mathrm{~ns}$ & $0,08 \mathrm{~ns}$ & \multicolumn{2}{|l|}{0,67 ** } & $-0,38 \mathrm{~ns}$ & $0.18 \mathrm{~ns}$ & $0,34 \mathrm{~ns}$ & & $-0,02 \mathrm{~ns}$ & $0,08 \mathrm{~ns}$ \\
\hline & 1 & $0,95 *$ & 0,44 * & \multicolumn{2}{|l|}{$0,37 \mathrm{~ns}$} & $0,67^{*}$ & $0,37^{n s}$ & $0,91^{* *}$ & & $0,60^{n x}$ & $0,37^{n s}$ \\
\hline & 2 & $-0,05 n s$ & $-0,70^{* *}$ & \multirow{3}{*}{\multicolumn{2}{|c|}{$\begin{array}{c}-0,03 \mathrm{~ns} \\
0,56 \approx \\
0,38 \mathrm{~ns}\end{array}$}} & \multirow{3}{*}{$\begin{array}{l}0,04 \mathrm{~ns} \\
0,58 * \\
0,53^{\star *}\end{array}$} & \multirow{2}{*}{$\begin{array}{r}-0,76 \\
0,66\end{array}$} & $-0,06 \mathrm{~ns}$ & & \multirow{2}{*}{$\begin{array}{l}0,10^{\text {ns }} \\
0,50^{*}\end{array}$} & $-0,58^{* *}$ \\
\hline \multirow[b]{2}{*}{3} & $b_{i}$ & & $0,73^{\star *}$ & & & & & $0,97^{\star *}$ & & & $0,73^{* *}$ \\
\hline & $R_{2} \%$ & & & & & & $0,97^{*}$ & \multirow{5}{*}{ 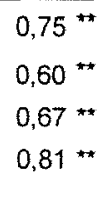 } & & $0,25 \mathrm{~ns}$ & 0,93 * \\
\hline & $b_{1}$ & & & & $-0,88^{* *}$ & $-0,24 \mathrm{~ns}$ & $0,52^{* *}$ & & & $-0,18 \mathrm{~ns}$ & $0,39 \mathrm{~ns}$ \\
\hline & $b_{1}+b_{2}$ & & & & & & $0,52^{* *}$ & & & $0,72 *$ & $0,56 *$ \\
\hline 4 & $\mathrm{R}_{2} \%$ & & & & & & & & & 0,48 * & $0,98^{* *}$ \\
\hline & $\mathrm{b}_{\mathrm{t}}$ & & & & & & & & $0,14 \mathrm{~ns}$ & $0,56 *$ & 0,75 * \\
\hline 5 & $b_{1}+b_{2}$ & & & & & & & & & & $0,25 \mathrm{~ns}$ \\
\hline
\end{tabular}


Comparando-se o método de Eberhart \& Russel com as outras duas metodologias de regressão linear, verificou-se associação direta do coeficiente de regressão $b_{i}$ com as estimativas $b_{1}$ e $b_{1}+b_{2}$. Isto indica que $\circ$ tipo de resposta dos genótipos, avaliada pela reta de regressão simples, foi similar à encontrada com o uso das linhas de regressão bi-segmentadas, ou seja, o tipo de adaptação geral, para efeito de classificação dos genótipos, relacionou-se diretamente com o tipo de adaptação tanto para ambientes desfavoráveis quanto para os favoráveis. Contudo, estas indicações năo podem ser generalizadas, uma vez que diversas variedades apresentaram comportamentos diferenciados nos ambientes piores e melhores, independentemente das estimativas obtidas para $b_{i}$. No caso do coeficiente de regressão para os ambientes desfavoráveis, $b_{1}$, embora estimados pelos métodos de Silva \& Barreto e o de Cruz, Torres \& Vencovsky de forma diferente, percebe-se que há alta correlação entre os mesmos.

As relações entre os coeficientes $b_{1}$ e $b_{2}$, dentro da metodologia de Silva \& Barreto foram sempre significativamente negativas. Tal fato confirma o inconveniente estatístico deste método, pois há dependência dos parâmetros que estimam a resposta dos genótipos nos ambientes desfavoráveis $\left(b_{1}\right)$ e favoráveis $\left(b_{1}+b_{2}\right)$. Isto acaba distorcendo o real comportamento das variedades, ocasionando a ocorrência de genótipos do tipo ideal, $b_{1}<1$ e $\left(b_{1}+b_{2}\right)>1$, que na realidade podem não existir. Já para o método de Cruz, Torres \& Vencovsky os coeficientes $b_{1}$ e $b_{2}$ não se relacionam, demonstrando que o comportamento dos genótipos nos melhores e piores ambientes é independente, como se espera do modelo matemático. 


\section{CONCLUSÕES}

Através da análise conjunta para os diferentes caracteres, nos diversos ambientes dos três grupos de experimentação, conclui-se que:

- Proporcionalmente, a grande variabilidade existente entre os locais avaliados foi a causa predominante da variação observada nos caracteres produtividade de colmos, teor de açúcar e produtividade de açúcar dos genótipos. A diversidade genética das variedades estudadas e a interação destas com os locais de experimentação também contribuíram significativamente com a variabilidade total para os referidos caracteres. A importância da interação GA justifica estudos de estratificação de ambientes e de estabilidade fenotípica;

- Devido à menor proporção da interação GA encontrada para a variável teor de sacarose foi possivel estabelecer agrupamentos para esta característica. Em diversos dos grupos formados houve indícios de padrões comuns de teor de sacarose entre os genótipos, para ambientes localizados em regiões próximas ou com tipos de solo semelhantes. Por outro lado, a elevada magnitude da interação GA para a produtividade de colmos e de açúcar não permitiu o estabelecimento de grupos, pelo menos ao nivel de $5 \%$ de probabilidade;

- Os parâmetros de estabilidade fenotípica, do tipo biológica, foram estimados com maior facilidade e independência pelas metodologias de Roemer, Langer e Wricke, que devem ser utilizadas em conjunto com a produtividade de açúcar na seleção de clones; 
- Os parâmetros de estabilidade agronômica dos genótipos foram determinados de forma eficiente pelas três metodologias de regressão linear avaliadas. Os métodos bi-segmentados são melhores, já que fornecem informações mais detalhadas de adaptação e previsibilidade da resposta ambiental. Deve-se dar preferência à utilização da metodologia de Cruz, Torres \& Vencovsky que, além de descriminar melhor o comportamento adaptativo dos genótipos, não apresentou o inconveniente estatístico de correlação entre os coeficientes de regressão $b_{1}$ e $b_{2}$;

- De forma geral a produtividade de açúcar dos genótipos apresentou linearidade em relação a qualidade ambiental para diversas variedades, e foi independente dos parâmetros de estabilidade e adaptabilidade. Portanto, com o emprego das metodologias mais adequadas, há potencial para ganhos em produtividade com a melhoria ambiental e possibilidade de seleção simultânea de clones produtivos e com caracteristicas desejáveis de estabilidade e adaptação;

- Entre as variedades cultivadas comercialmente, destacaram-se em produtividade de açúcar e nível de estabilidade fenotípica a SP83-5073, SP800185 e RB785148. Outros clones, também de boa produtividade, apresentaram caracteristicas de estabilidade interessantes, sendo especificos para determinado tipo de ambiente, devendo ser melhor avaliados para cultivo em condições específicas, ou também empregados como padrões em futuros ensaios. Entre estes podemos citar a SP82-4010, SP82-6034, SP80-3390, SP80-4445, SP800147, SP81-1949 e SP81-5193. 


\section{REFERÊNCIAS BIBLIOGRÁFICAS}

ALLARD, R.W.; BRADSHAW, A.D. Implications of genotype-environmental interactions in applied plant breeding. Crop Science, v.4, p.503-508, 1964.

BARBOSA, G.V.S. A interação genótipo vs ambiente. In: II Simpósio nacional da agroindústria da cana-de-açúcar. Resumos. Belo Horizonte-MG, 1992.

BARBOSA, G.V.S. Análise da interação de novas variedades RB de cana-deaçúcar (Saccharum spp.) com ambientes de cultivo em Alagoas. In: $5^{\circ}$ CONGRESSO NACIONAL DA SOCIEDADE DOS TÉCNICOS AÇUCAREIROS E ALCOOLEIROS DO BRASIL (STAB). Anais. Águas de São Pedro-SP, 1993. p. $115-120$.

BASSINELLO, A.I. Interações de genótipos $x$ ambientes em cana-de-açúcar. Piracicaba, 1984. 110p. Dissertação (Mestrado) - Escola Superior de Agricultura "Luiz de Queiroz", Universidade de São Paulo.

BASSINELLO, A.I. Comportamento de progênies de cana-de-açúcar (Saccharum spp.) em ambientes contrastantes. Piracicaba, 1991. 126p. Tese (Doutorado) - Escola Superior de Agricultura "Luiz de Queiroz", Universidade de São Paulo.

BECKER, H.C. Correlations among some statistical measures of phenotypic stability. Euphytica, v.30, p.835-840, 1981.

BECKER, H.C.; LEON, J. Stability analysis in plant breeding. Plant Breeding, v.101, p.1-23, 1988. 
BHULLAR, G.S.; GILL, K.S.; KHEHRA, A.S. Stability analysis over various filial generations in bread wheat. Theoretical Applied Genetics, v.51, p.41-44, 1977.

BILBRO, J.D.; RAY, L.L. Environmental stability and adaptation of several cotton cultivars. Crop Science, v.16, p.821-824, 1976.

BRAGA JÚNIOR, R.L.C.(a) Interação genótipo-ambiente em novos clones de cana-de-açúcar. In: VI SEMINÁRIO DE TECNOLOGIA AGRONÔMICA, Piracicaba-SP, 1994. Anais. Piracicaba-SP: COPERSUCAR, 1994. p.119129.

BRAGA JÚNIOR, R.L.C.(b) Equação para estimativa da produtividade média de cinco cortes a partir dos dois primeiros corte. In: VI SEMINÁRIO DE TECNOLOGIA AGRONÓMICA, Piracicaba-SP, 1994. Anais. Piracicaba-SP: COPERSUCAR, 1994. p.131-136.

BUCIO ALANIS, L. Environmental and genotype-environmental components of variability. I. Inbred lines. Heredity, v.21, p.387-397, 1966.

BUCIO ALANIS, L.; HILL, J. Environmental and genotype-environmetal components of variability. II. Heterozygotes. Heredity, v.21, p.399-405, 1966.

CALHEIROS, G.G. Estabilidade de variedades da cana-de-açúcar (Saccharum spp.) no Estado de Alagoas. Piracicaba, 1977. 53 p. Dissertação (Mestrado) Escola Superior de Agricultura "Luiz de Queiroz", Universidade de São Paulo.

CALHEIROS, G.G.; BARBOSA, G.V.S. Análise da interação de genótipos RB de cana-de-açúcar (Saccharum spp.) com ambientes de cultivo em Alagoas. In: $6^{\circ}$ Congresso Nacional da Sociedade dos Técnicos Açucareiros e Alcooleiros do Brasil (STAB). Anais. Maceió-AL, 1996. p.253-262. 
COMSTOCK, R.E.; MOLL, R.H. Genotype-environment interactions. In: HANSON, W.D. \& ROBINSON, H.F. (Ed.). Statistical Genetics and Plant Breeding. Washington: Nat. Acad. Sci. Nat. Res. Council, publ. 982, 1963. p.164-196.

COPERSUCAR. Censo varietal quantitativo 1996. São Paulo, jun. 1997. Cadernos Copersucar, $12 p$.

CROSSA, J. A comparison of results obtained with two methods for assessing yield stability. Theoretical Applied Genetics, v.75, p.460-467, 1988.

CROSSA, J. Statistical analysis of multilocations trails. Advances in Agronomy, v.44, p.55-85, 1990.

CRUZ, C.D.; TORRES, R.A.; VENCOVSKY, R. An alternative approach to the stability analisys proposed by Silva and Barreto. Revista Brasileira de Genética, Ribeirão Preto-SP, v.12, n.2, p.567-580, 1989.

CRUZ, C.D. Aplicação de algumas técnicas multivariadas no melhoramento de plantas. Piracicaba, 1990. 188 p. Tese (Doutorado) - Escola Superior de Agricultura "Luiz de Queiroz", Universidade de São Paulo.

CRUZ, C.D.; REGAZZI, A.J. Modelos Biométricos aplicados ao Melhoramento Genético. Universidade Federal de Viçosa, 1994. 390p.

CRUZ, C.D. Programa GENES - Aplicativo Computacional em Genética e Estatística. Universidade Federal de Viçosa, 1997. 442p.

DUARTE, J.B.; ZIMMERMANN, M.J.O. Correlation among yield stability parameters in common bean. Crop Science, v.35, p.905-912, 1995.

EBERHART, S.A.; RUSSEL, W.A. Stability parameters for comparing varieties. Crop Science, v.6, p.36-40, 1966. 
FERREIRA, D.F.; RAMALHO, M.A.P.; ABREU, A.F.B. Utilização da testemunha na avaliação da estabilidade em ensaios de competição de cultivares. Ciência e Prática, Lavras-MG, v.16, n.3, p.394-399, 1992.

FINLAY, K.W.; WILKINSON, G.N. The analysis of adaptation in a plant breeding programme. Australian Journal Agricultural Research, v.14, p.742-754, 1963.

FOX, P.N.; CROSSA, J.; ROMAGOSA, I. Multi-environment testing and genotype $x$ environment interaction. In: KEMPTON, R.A.; FOX, P.N. (Ed.) Statistical Methods for Plant Variety Evaluation. New York: Chapman and Hall, 1997. cap.8, p.117-138.

FRANCIS, T.R.; KANNENBERG, L.W. Yield stability studies in short season maize. I - A descriptive method for grouping genotypes. Canadian Journal Plant Science, v.58, p.1029-1034, 1978.

FUNDAÇÃO INSTITUTO BRASILEIRO DE GEOGRAFIA E ESTATISTICA. Anuário Estatístico do Brasil. Rio de Janeiro, IBGE. v.56, p.3-52, 1996.

GALVEZ, G. The genotype-environment interactions in experiments of sugarcane variety trials (Saccharum spp.): comparison of three stability methods. In: XVII INTERNATIONAL SOCIETY OF SUGARCANE TECHNOLOGISTS CONGRESS. Manila, Filipinas, 1980. Proceedings. v.02, p.1152-1160.

JOWETT, D. Yield stability parameters for sorghum in East Africa. Crop Science, v. 12, p.314-317, 1972.

KANG, M.S.; MILLER, J.D. Genotype-environment interactions for cane and sugar yield and their implications in sugarcane breeding. Crop Science, v.24, p.435$440,1984$. 
LANDELL, M.G.A.; CAMPANA, M.P.; FIGUEIREDO, P.; ZIMBACK, L.; SILVA, M.A.; PRADO, $H$. Novas variedades de cana-de-açúcar. Boletim Técnico IAC. Instituto Agronômico de Campinas, n.169, 1997, 27 p.

LIMA, L.F.N.; BARBOSA, G.V.S. Interação de genótipos de cana-de-açúcar (Saccharum spp.) com ambientes de cultivo na usina Caeté. In: $6^{\circ}$ CONGRESSO NACIONAL DA SOCIEDADE DOS TÉCNICOS AÇUCAREIROS E ALCOOLEIROS DO BRASIL (STAB). Anais. Maceió-AL, 1996. p. 213-223.

LIN, C.S.; BINNS, M.R.; LEFKOVITCH, L.P. Stability analysis: where do we stand? Crop Science, v.26, p.894-900, 1986.

LO, C.C. Sugarcane breeding for different environments. In: COPERSUCAR INTERNATIONAL SUGARCANE BREEDING WORKSHOP, Piracicaba-SP, 1987. Anais. p.189:202.

MARIOTTI, J.A. The effect of environments of the effectiveness of clonal selection in sugarcane. In: XV INTERNATIONAL SOCIETY OF SUGARCANE TECHNOLOGISTS CONGRESS. Durban, África do Sul, 1974. Proceedings. v.01, p.89-95.

MARIOTTI, J.A.; OYARZABAL, E.S.; OSA, J.M.; BULACIO, A.N.R.; ALMADA, G.H. Analisis de estabilidade y adaptabilidad de genotipos de caña de azúcar. I. Interacciones dentro de un localidad experimental. Rev. Agron. N. O. Argent., v.13, p.105-127, 1976.

MARIOTTI, J.A. Clonal selection across environments on sugarcane. In: XVII INTERNATIONAL SOCIETY OF SUGARCANE TECHNOLOGISTS CONGRESS. Manila, Filipinas, 1980. Proceedings. v.02, p.1142-1150.

OLIVEIRA, A.C. Comparação de alguns métodos de determinação da estabilidade em plantas cultivadas. Brasilia, 1976 . 64p. Dissertação (Mestrado) - Universidade Federal de Brasilia. 
PEIXOTO, T.C.; SILVA, J.G.C.; BARRETO, M.N. Técnicas de análises de interação genótipo por ambiente e estabilidade de clones de cana-de-açúcar. In: III SEMINÁRIO DE TECNOLOGIA AGRONÔMICA, Piracicaba-SP, 1986. Anais. Piracicaba-SP: COPERSUCAR, 1986. p.11-21.

PIMENTEL GOMES, F. Curso de Estatística Experimental. 13a Edição. São Paulo: Nobel, 1990. 468p.

PIRES, C.E.L.S.; COSTA, E.F.S. Association between some characters of sugarcane (Saccharum spp.) growing in four localities in the Northeast of Brazil. In: XVII INTERNATIONAL SOCIETY OF SUGARCANE TECHNOLOGISTS CONGRESS. Manila, Filipinas, 1980. Proceedings. v.02, p.1365-1372.

PIRES, C.E.L.S. Estabilidade fenotípica de variedades de cana-de-açúcar (Saccharum spp.) nos Estados de Pernambuco e Rio Grande do Norte. Piracicaba, 1981. 72p. Dissertação (Mestrado) - Escola Superior de Agricultura "Luiz de Queiroz", Universidade de São Paulo.

PLAISTED, R.L.; PETERSON, L.C. A technique for evaluating the ability of selections to yield consistently in different locations or seasons. American Potato Journal, v.36, p.381-385, 1959.

PLAISTED, R.L. A shorter method for evaluating the ability of selections to yield consistently over locations. American Potato Journal, v.37, p.166-172, 1960.

POLLOCK, J.S. Selection consequences of differential performance of standard clones across environments. Sugarcane Breeder's Newsletter, v.35, p.36-41, 1975.

RUSHEL, R. Phenotypic stability of some sugarcane varieties (Saccharum spp.) in Brazil. In: XVI INTERNATIONAL SOCIETY OF SUGARCANE TECHNOLOGISTS CONGRESS. São Paulo, Brasil, 1977. Proceedings. v.01, p.275-281. 
SILVA, J.G.C.; BARRETO, J.N. Aplicação da regressão linear segmentada em estudos de interação genótipo $x$ ambiente. In: $1^{\circ}$ SIMPÓSIO DE ESTATÍSTICA APLICADA À EXPERIMENTAÇÃO AGRONOMMICA, Piracicaba-SP, Fundação Cargill, 1985. Resumos. p.49-50.

SINGH, S.P.; KHAN, A.Q. Selection of sugar cane genotypes for different environments. Sugar Cane, v.5, p.10-12, 1997.

SKINNER, J.C. Selection in sugarcane: A review. In: XIV INTERNATIONAL SOCIETY OF SUGARCANE TECHNOLOGISTS CONGRESS. New Orleans, USA, 1971. Proceedings. v.01, p.149-161.

SKINNER, J.C.; HOGARTH, D.M.; WU, K.K. Selection methods, criteria, and indices. In: HEINZ, D.J. (Ed.) Sugarcane Improvement Through Breeding. New York: Elsevier, 1987. cap 11, p. 409-453.

STORCK, L. Modelo de regressão bi-segmentado descontínuo com erros de medida aplicado na análise de estabilidade de cultivares. Piracicaba, 1989. 217 p. Tese (Doutorado) - Escola Superior de Agricultura "Luiz de Queiroz", Universidade de São Paulo.

TAI, G.C.C. Genotypic stability analysis and its application to potato regional trials. Crop Science, v.11, p.184-190, 1971.

TANIMOTO, T. The press method of cane analysis. Hawaiian Plants Recorder, n. 5, v. 2, p. $133-150,1969$.

VENCOVSKY, R.; BARRIGA, P. Genética Biométrica no Fitomelhoramento. Rib. Preto, Revista Brasileira de Genética, 1992. 486p.

VERMA, M.M.; CHAHAL, G.S.; MURTY, B.R. Limitations of conventional regression analisys: a proposed modifications. Theoretical Applied Genetics, v.53, p.89-91, 1978. 
WESTCOTT, B. A method of assessing the yield stability of crop genotypes. Journal Agriculture Science, v.108, p.267-274, 1987.

YATES, F.; COCHRAN, M.G. The analysis of group of experiments. Journal Agriculture Science, v.28, p.556-580, 1938. 
7. ANEXOS 
Anexo 1 - Resultados das análises de variância individuais e parâmetros genéticos em cada ambiente.

Estimativas para a variável produtividade de colmos (TCH) no Ensaio de Caracterização/92.

Média para 25 genótipos analisados, nos referidos cortes.

\begin{tabular}{|c|c|c|c|c|c|c|c|c|c|c|c|c|c|c|c|c|c|c|}
\hline $\mathrm{BB}^{1}$ & $F(G E N)^{2}$ & $\begin{array}{c}\text { Média }^{3} \\
\text { TCH1 }\end{array}$ & $\begin{array}{l}\mathrm{CV}_{\mathrm{e}} \\
(\%)\end{array}$ & $\begin{array}{r}C V_{\mathrm{g}} \\
(\%)\end{array}$ & $h_{m}^{2}$ & $\begin{array}{l}\text { Gs } \\
(\%)\end{array}$ & $F(G E N)$ & $\begin{array}{l}\text { Média } \\
\text { TCH2 }\end{array}$ & $\begin{array}{r}\mathrm{CV}_{\mathrm{e}} \\
(\%)\end{array}$ & $\begin{array}{r}\mathrm{CV}_{\mathrm{g}} \\
(\%)\end{array}$ & $h_{m}^{2}$ & $\begin{array}{l}\text { Gs } \\
(\%)\end{array}$ & & $\begin{array}{l}\text { Média } \\
\text { TCH5 }\end{array}$ & $\begin{array}{l}\mathrm{CV}_{\mathrm{e}} \\
(\%)\end{array}$ & $\begin{array}{r}\mathrm{CV}_{\mathrm{g}} \\
(\%)\end{array}$ & $h_{m}^{2}$ & $\begin{array}{l}\text { Gs } \\
(\%)\end{array}$ \\
\hline 1 & $94^{\star \star}$ & 25,29 & .25 & 11,67 & 0,93 & 15,7 & 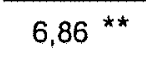 & 88,40 & 12,54 & 15,18 & 0,85 & 19 & & 5,97 & 9,86 & 13,47 & 88 & . \\
\hline 2 & $9,67^{\star \star}$ & 151,57 & 6,64 & 9,77 & 0,90 & 12,96 & $14,31^{* \star}$ & 107,03 & 6,56 & 11,96 & 0,93 & 16,15 & $16,09^{* \star}$ & 105,28 & 5,55 & 10,78 & 1,94 & 14,61 \\
\hline 3 & $11,48^{\star \star}$ & 149,60 & 6,19 & 10,03 & 0,91 & 13,41 & $13,49^{\star *}$ & 115,91 & 7,41 & 13,10 & 0,93 & 17 & $15,33^{\text {** }}$ & 111,15 & 6,22 & 11,76 & 93 & 15,92 \\
\hline 4 & $8,91^{* *}$ & 177,13 & 6,44 & 9,06 & 0,89 & 11,94 & $14,26^{* *}$ & 121,11 & 7.21 & 13,12 & 0,93 & 17,71 & $15,55^{* *}$ & 120,22 & 5,99 & 11,42 &, 94 & 15,46 \\
\hline 5 & $21,87^{\star \star}$ & 137,83 & 4,32 & 9,86 & 0,95 & 13,49 & $14,47^{\star \star}$ & 87,92 & 6,88 & 12,63 & 0,93 & 17,06 & $18,30^{\star \star}$ & 89,14 & 5,21 & 10,83 & ,95 & 14,74 \\
\hline 6 & $36,19 * *$ & 104,17 & 5,22 & 15,49 & 0,97 & 21,39 & $23,99^{\star \star}$ & 85,85 & 7,57 & 18,14 & 0,96 & 24,86 & 33,20 ** & 0,94 & 5,95 & 16,87 & 0,97 & 23 \\
\hline 7 & $27,77^{\star \star}$ & 155,06 & 5,80 & 15,01 & 0,96 & 20,63 & $28,81^{\star \star}$ & 101,40 & 6,73 & 17,74 & 0,97 & 24,40 & $32,00^{* *}$ & 102,05 & 5,82 & 16,20 & 0,97 & 22,32 \\
\hline 8 & $8,65^{\star \star}$ & 131,07 & 6,42 & 8,88 & 0,88 & $\$ 1,69$ & $7,55^{* *}$ & 105,04 & 8,96 & 11,47 & 0,87 & 14 & $8,07^{\star \star}$ & 99,77 & 7,58 & 10,08 & 0,88 & 13 \\
\hline 9 & $13,95^{* *}$ & 135,81 & 5,98 & 10,76 & 0,93 & 14,52 & $14,28^{\star \star}$ & 94,94 & 7.26 & 13,23 & 0,93 & 17,87 & $17,39^{* *}$ & 93,65 & 6,01 & 12,16 & 0,94 & 16,53 \\
\hline 10 & $22,19^{* \star}$ & 139,74 & 5,13 & 11,81 & 0,95 & 16,16 & $14,31^{\star \star}$ & 99,39 & 6,32 & 11,54 & 0,93 & 15,58 & $17,88^{* \star}$ & 97,53 & 5,14 & 10,55 & 0,94 & 14 \\
\hline 11 & 16,46 ** & 147,39 & 7,69 & 15,12 & 0,94 & 20,51 & $35,67^{* *}$ & 105,03 & 6,13 & 18,06 & 0,97 & 24,92 & $33,49^{* *}$ & 103,06 & 5,80 & 16,52 & 0,97 & 22,78 \\
\hline 12 & 15,24 ** & 120,25 & 5,38 & 10,15 & 0,93 & 13,74 & 9,29 ** & 96,53 & 5,07 & 7,30 & 0,89 & 9,66 & $11,96^{\star \star}$ & 91,68 & 4,38 & 7,25 & 0,92 & 9,72 \\
\hline 13 & $21,49^{* \star}$ & 149,99 & 3,84 & 8,68 & 0,95 & 11,87 & $13,43^{\star \star}$ & 95,36 & 6,25 & 11,01 & 0,93 & 14,82 & 16,21 ** & 96,80 & 5,08 & 9,91 & 0,94 & 13,44 \\
\hline 14 & $7,32^{\star \star}$ & 177,25 & 7,16 & 9,00 & 0,86 & 11,71 & $20,84^{\star \star}$ & 121,52 & 5,28 & 11,76 & 0,95 & 16,06 & $19,03^{* *}$ & 120,55 & 4,93 & 10,47 & 0,95 & 14,27 \\
\hline
\end{tabular}

$1=$ número referente ao ambiente, ver tabela 2

2 = valor do Teste $\mathrm{F}$ calculado para a fonte de variação de Genótipos (variedades), com nivel de significância

3 = valores médios (t cana/ha) para o respectivo corte 
Anexo 2 - Resultados das análises de variância individuais e parâmetros genéticos em cada ambiente. Estimativas para a variável teor de sacarose (PCC) no Ensaio de Caracterização/92.

Média para 25 genótipos analisados, nos referidos cortes.

\begin{tabular}{|c|c|c|c|c|c|c|c|c|c|c|c|c|c|c|c|c|c|c|}
\hline 1 & $F(G E N)^{2}$ & $\begin{array}{l}\text { Média }^{3} \\
\text { PCC1 }\end{array}$ & $\begin{array}{c}\mathrm{CV}_{\mathrm{e}} \\
(\%)\end{array}$ & $\begin{array}{l}\mathrm{CV}_{\mathrm{g}} \\
(\%)\end{array}$ & $h_{m}^{2}$ & $\begin{array}{l}\text { Gs } \\
(\%)\end{array}$ & 1) & $\begin{array}{l}\text { Média } \\
\text { PCC2 }\end{array}$ & $\begin{array}{c}\mathrm{CV}_{\mathrm{c}} \\
(\%)\end{array}$ & $\begin{array}{l}\mathrm{CV}_{\mathrm{g}} \\
(\%)\end{array}$ & $h_{m}^{2}$ & $\begin{array}{l}\text { Gs } \\
(\%)\end{array}$ & $F$ & $\begin{array}{l}\text { Média } \\
\text { PCCM }\end{array}$ & $\begin{array}{l}C V_{i} \\
(\%)\end{array}$ & $\begin{array}{l}\mathrm{CV}_{\mathrm{g}} \\
(\%)\end{array}$ & $h_{\mathrm{rn}}^{2}$ & $\begin{array}{l}\text { Gs } \\
(\%)\end{array}$ \\
\hline 1 & $9,85^{\star *}$ & 4,97 & 3,63 & 5,41 & 0,90 & 7,17 & 10,00 & .42 & 3,16 & 6,08 & 0,94 & 8,24 & 10,00 & 20 & 53 & 5,46 & 95 & 7,4 \\
\hline 2 & $9,19^{* *}$ & 14,47 & 3,79 & 5,42 & 0,89 & 7,16 & $8,21^{* *}$ & 14,90 & 6,08 & 8,17 & 0,88 & 10,71 & $14,02^{* *}$ & 14,69 & 3,41 & 6,15 & 0,93 & 8,29 \\
\hline 3 & 4,09 ** & 14,11 & 4,72 & 4,15 & 0,76 & 5,05 & $10,91^{* *}$ & 14,07 & 3,73 & 5,88 & 0,91 & 7,84 & $9,66^{\text {** }}$ & 14,10 & 3,26 & 4,79 & 0,90 & 6,35 \\
\hline 4 & $3,22^{* *}$ & 13,81 & 6,97 & 5,20 & 0,69 & 6,04 & $6,11^{\star *}$ & 14,06 & 7,58 & 8,56 & 0,84 & 10,96 & $6,78^{\star \star}$ & 13,94 & 5,21 & 6,27 & 0,85 & 8,10 \\
\hline 5 & $6,14^{\star *}$ & 15,21 & 3,12 & 3,54 & 0,84 & 4,53 & $9,11^{\star \star}$ & 16,73 & 3,45 & 4,91 & 0,89 & 6,48 & 11,68 ** & 15,97 & 2,38 & 3,89 & 0,91 & 5,21 \\
\hline 6 & $13,26^{* *}$ & 15,28 & 2,71 & 4,75 & 0,92 & 6,39 & $19,39^{\star \star *}$ & 16,83 & 2,55 & 5,46 & 0,95 & 7,44 & 23,80 ** & 16,06 & 1,92 & 4,59 & 0,96 & 6,29 \\
\hline 7 & $7,55^{\star \star}$ & 13,35 & 4,57 & 5,85 & 0,87 & 7,63 & $12,57^{\star \star}$ & 13,51 & 4,10 & 6,97 & 0,92 & 9,36 & $14,16^{\star \star *}$ & 3,43 & 3,19 & 5,79 & 93 & 7,82 \\
\hline 8 & $8,63^{\star \star}$ & 15,10 & 3,29 & 4,54 & 0,88 & 5,97 & $44,47^{* \star}$ & 14,34 & 2,42 & 7,99 & 0,98 & 11,06 & 38,69 ** & 14,72 & 1,99 & 6,10 & 0,97 & 8,42 \\
\hline 9 & $7,05^{\star \star}$ & 15,29 & 4,02 & 4,95 & 0,86 & 6,42 & $17,37^{\star \star}$ & 16,19 & 2,75 & 5,56 & 0,94 & 7,55 & $15,09^{\star \star}$ & 15,74 & 2,66 & 5,00 & 0.93 & 6,77 \\
\hline 10 & 11,26 ** & 15,56 & 2,99 & 4,79 & 0,91 & 6,40 & 22,52 ** & 14,29 & 3,13 & 7,25 & 0,96 & 9,93 & $23,55^{\star \star}$ & 14,93 & 2,43 & 5,77 & 0,96 & 7,90 \\
\hline 11 & $6,83^{\star *}$ & 15,28 & 3,52 & 4,25 & 0,85 & 5,50 & $14,22^{\star \star}$ & 13,71 & 3,41 & 6,19 & 0,93 & 8,36 & $15,78^{* *}$ & 14,49 & 2,62 & 5,04 & 0,94 & 6,83 \\
\hline 12 & $12,52^{\star *}$ & 15,16 & 3,74 & 6,35 & 0,92 & 8,52 & $15,03^{\star \star}$ & 14,53 & 3,88 & 7,27 & 0,93 & 9,83 & 20,93 ** & 14,85 & 2,82 & 6,30 & 0,95 & 8,61 \\
\hline 13 & 13,36 ** & 15,55 & 3,05 & 5,36 & 0,93 & 7,22 & 22,23 ** & 16,12 & 2,84 & 6,54 & 0,96 & 8,95 & $25,40^{\star \star}$ & 15,84 & 2,16 & 5,32 & 0,96 & 7,31 \\
\hline 14 & $7,68^{\star \star}$ & 15,45 & 3,84 & 4,96 & 0,87 & 6,47 & $14,69^{* *}$ & 16,40 & 3,00 & 5,55 & 0,93 & 7,49 & $16,69^{\star \star}$ & 15,93 & 2,43 & 4,81 & 0,94 & 6,53 \\
\hline
\end{tabular}

1 = número referente ao ambiente, ver tabela 2

2 = valor do Teste $F$ calculado para a fonte de variação de Genótipos (variedades), com nível de significância

$3=$ valores médios $(\%)$ para o respectivo corte 
Anexo 3 - Resultados das análises de variância individuais e parâmetros genéticos em cada ambiente.

Estimativas para a variável produtividade de açúcar (TPH) no Ensaio de Caracterização/92.

Média para 25 genótipos analisados, nos referidos cortes.

\begin{tabular}{|c|c|c|c|c|c|c|c|c|c|c|c|c|c|c|c|c|c|c|}
\hline $\mathrm{AB}^{1}$ & N) ${ }^{2}$ & $\begin{array}{c}\text { Média }^{3} \\
\text { TPH1 }\end{array}$ & $\begin{array}{l}\mathrm{CV}_{\mathrm{e}} \\
(\%)\end{array}$ & $\begin{array}{r}\mathrm{CV}_{\mathrm{g}} \\
(\%)\end{array}$ & $\mathbf{h}_{\mathrm{m}}^{2}$ & $\begin{array}{l}\text { Gs } \\
(\%)\end{array}$ & $F(G E N)$ & $\begin{array}{l}\text { Média } \\
\text { TPH2 }\end{array}$ & $\begin{array}{l}\mathrm{CV}_{\mathrm{e}} \\
(\%)\end{array}$ & $\begin{array}{r}C V_{g} \\
(\%)\end{array}$ & $h_{m}^{2}$ & $\begin{array}{l}\text { Gs } \\
(\%)\end{array}$ & F(GEN) & $\begin{array}{l}\text { Média } \\
\text { TPH5 }\end{array}$ & $\begin{array}{l}\mathrm{CV}_{\mathrm{e}} \\
(\%)\end{array}$ & $\begin{array}{r}\mathrm{CV}_{\mathrm{g}} \\
(\%)\end{array}$ & $h_{m}^{2}$ & $\begin{array}{l}\text { Gs } \\
(\%)\end{array}$ \\
\hline 1 & $7,59^{\star \star}$ & 18,66 & 6,76 & 8,67 & 0,87 & 11,3 & 0,44 & 54 & 11,94 & 12,58 & 0,82 & 15,91 & 100 & 13 & 9,29 & 10,16 & 0,83 & 12, \\
\hline 2 & $4,57^{\star \star}$ & 21,87 & 7,98 & 7,54 & 0,78 & 9,33 & $7,17^{\star \star *}$ & 15,88 & 9,10 & 11,30 & 0,86 & 14,68 & $8,52^{\star \star}$ & 15,41 & 6,31 & 8,65 & 0,88 & 11,38 \\
\hline 3 & $7,59 * *$ & 21,10 & 7,79 & 10,01 & 0,87 & 13,05 & $10,84^{* *}$ & 16,27 & 7,92 & 12,42 & 0,91 & 16,57 & 12,88 ** & 15,64 & 6,57 & 11,33 & 0,92 & 15,23 \\
\hline 4 & 5,39 ** & 24,42 & 8,93 & 9,36 & 0,81 & 11,83 & 14,66 ** & 17,05 & 9,45 & 17,46 & 0,93 & 23,60 & $16,37^{* \star}$ & 16,74 & 6,69 & 13,12 & 0,94 & 17,80 \\
\hline 5 & $11,44^{* \star}$ & 20,95 & 5.73 & 9,25 & 0,91 & 12,38 & 12,11 ** & 14,69 & 7,52 & 12,54 & 0,92 & 16,82 & $13,65^{\star \star}$ & 14,22 & 5,62 & 10,00 & 0,93 & 13,48 \\
\hline 6 & 24,02 ** & 15,88 & 6,13 & 14,71 & 0,96 & 20,16 & $24,58^{* \star}$ & 14,50 & 8,24 & 19,99 & 0,96 & 27,42 & 33,95 ** & 13,00 & 6,07 & 17,42 & 0,97 & 24,03 \\
\hline 7 & $27,99 * \star$ & 20,73 & 6,67 & 17,31 & 0,96 & 23,80 & 23,00 ** & 13,69 & 7,90 & 18,52 & 0,96 & 25,36 & 32,40 ** & 13,71 & 6,14 & 17,21 & 0,97 & 23,72 \\
\hline 8 & $4,38^{\star \star}$ & 19,75 & 7,83 & 7,20 & 0,77 & 8,86 & $5,26^{\star \star}$ & 14,97 & 8,83 & 9,11 & 0,81 & 11,48 & $5,07^{\star \star}$ & 14,63 & 7,92 & 8,00 & 0,80 & 10,03 \\
\hline 9 & 7,36 ** & 20,70 & 7,21 & 9,10 & 0,86 & 11,84 & $8,27^{\star *}$ & 15,32 & 8,38 & 11,30 & 0,88 & 14,83 & $34^{\star *}$ & 14,69 & 7,21 & 9,76 & 0,88 & 12,82 \\
\hline 10 & $13,01 * \star$ & 21,71 & 6,21 & 10,75 & 0,92 & 14,46 & $12,68^{* *}$ & 14,18 & 7,27 & 12,42 & 0,92 & 16,69 & 15,72 ** & 14,53 & 5,45 & 10,45 & 0,94 & 14,16 \\
\hline 11 & $13,97^{\text {** }}$ & 22,45 & 7,74 & 13,94 & 0,93 & 18,81 & $25,18^{\star *}$ & 14,37 & 7,20 & 17.71 & 0,96 & 24,30 & $28,20^{* *}$ & 14,90 & 6,02 & 15,71 & 0,96 & 21,60 \\
\hline 12 & $7,46^{\star \star}$ & 18,17 & 6,84 & 8,69 & 0,87 & 11,32 & $9,78^{\star \star}$ & 13,99 & 6,06 & 8,97 & 0,90 & 11,90 & $8,52^{\star \star}$ & 13,58 & 5,10 & 6,99 & 0,88 & 9,19 \\
\hline 13 & $15,82^{* \star}$ & 23,30 & 4,61 & 8,87 & 0,94 & 12,02 & $8,62^{* *}$ & 15,32 & 7,10 & 9,80 & 0,88 & 12,90 & $10,82^{\star \star}$ & 15,29 & 5,57 & 8,72 & 0,91 & 11,63 \\
\hline 14 & $4,24^{\star *}$ & 7,35 & 8,80 & 7,92 & 0,76 & 9,69 & $18,80^{* \star}$ & 19.91 & 5,98 & 12,61 & 0,95 & 17,17 & $13,45^{\star \star}$ & 19,18 & 5,87 & 10,36 & 0,93 & 13,96 \\
\hline
\end{tabular}

$1=$ número referente ao ambiente, ver tabela 2

2 = valor do Teste $\mathrm{F}$ calculado para a fonte de variação de Genótipos (variedades), com nivel de significância

$3=$ valores médios ( $t$ açúcar/ha) para o respectivo corte 
Anexo 4 - Resultados das análises de variấhcia individuais e parâmetros genéticos em cada ambiente. Estimativas para a variável produtividade de colmos (TCH) no Ensaio de Caracterização/93.

Média para 20 genótipos analisados, nos referidos cortes.

\begin{tabular}{|c|c|c|c|c|c|c|c|c|c|c|c|c|c|c|c|c|c|c|}
\hline $\mathrm{AMB}^{1}$ & $F(G E N)^{2}$ & $\begin{array}{c}\text { Média }^{3} \\
\text { TCH1 }\end{array}$ & $\begin{array}{l}\mathrm{CV}_{e} \\
(\%)\end{array}$ & $\begin{array}{l}C V_{g} \\
(\%)\end{array}$ & $h_{m}^{2}$ & $\begin{array}{l}\text { Gs } \\
(\%)\end{array}$ & $F(G E N)$ & $\begin{array}{l}\text { Média } \\
\text { TCH2 }\end{array}$ & $\begin{array}{r}\mathrm{CV}_{\mathrm{e}} \\
(\%)\end{array}$ & $\begin{array}{c}C V_{B} \\
(\%)\end{array}$ & $h_{m}^{2}$ & $\begin{array}{l}\text { Gs } \\
(\%)\end{array}$ & $F(G E N)$ & $\begin{array}{l}\text { Média } \\
\text { TCH5 }\end{array}$ & $\begin{array}{r}C V_{\mathrm{e}} \\
(\%)\end{array}$ & $\begin{array}{l}\mathrm{CV}_{\mathrm{g}} \\
(\%)\end{array}$ & $\mathrm{h}_{\mathrm{m}}^{2}$ & $\begin{array}{l}\text { Gs } \\
(\%)\end{array}$ \\
\hline 1 & $20,23^{* *}$ & 113,41 & 4,43 & 9,71 & 0,95 & 13,26 & $14,88^{* *}$ & 91,43 & 8,59 & 16,00 & 0,93 & 21,64 & 16,60 & 86,75 & 6,80 & 13,42 & 0.94 & 18,22 \\
\hline 2 & $10,81^{* *}$ & 109,78 & 6,71 & 10,51 & 0,91 & 14,02 & $8,00^{* *}$ & 58,33 & 15,01 & 19,85 & 0,87 & 26,00 & $8,29^{\star \star}$ & 62,81 & 10,57 & 14,27 & 0,88 & 18,73 \\
\hline 3 & $15,45^{\star \star}$ & 139,55 & 5,41 & 10,29 & 0,94 & 13,93 & $23,09 \star \star$ & 103,50 & 6,63 & 15,57 & 0,96 & 21,32 & $22,45^{\star \star}$ & 100,39 & 5,87 & 13,60 & 0,96 & 18,61 \\
\hline 4 & $18,29 *$ & 113,91 & 5,72 & 11,89 & 0,95 & 16,19 & $28,21 * *$ & 59,51 & 8,96 & 23,37 & 0,96 & 32,13 & $26,89^{\star \star}$ & 64,50 & 7,17 & 18,23 & 0,96 & 25,05 \\
\hline 5 & 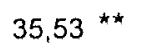 & 113,04 & 4,03 & 11,84 & 0,97 & 16,34 & $29,67 * \star$ & 74,90 & 6,99 & 18,72 & 0,97 & 25,77 & $28,21^{\star *}$ & 5 & 65 & 14,74 &, 96 & 20,27 \\
\hline 6 & $19,20^{* *}$ & 122,63 & 4,86 & 10,37 & 0,95 & 14,14 & $11,85^{\star \star}$ & 85,09 & 9,97 & 16,42 & 0,92 & 22,00 & $13,88^{\star \star}$ & 14 & 48 & 13,42 & 0,93 & 18,09 \\
\hline 7 & $11,58 * \star$ & 130,26 & 7,96 & 12,95 & 0,91 & 17,33 & $16,42^{\star \star}$ & 109,06 & 8,79 & 17,26 & 0,94 & 23,42 & $15,91 * \star$ & 102,44 & 8,07 & 15,58 & 0,94 & 21.11 \\
\hline 8 & $23,59 \star \star *$ & 128,85 & 4,99 & 11,86 & 0,96 & 16,24 & $16,20^{* *}$ & 70,70 & 12,03 & 23,45 & 0,94 & 31,80 & $18,39^{\star \star}$ & 75,31 & 8,75 & 18,24 & 0,95 & 24,83 \\
\hline 9 & $14,86^{\star \star}$ & 125,88 & 3,83 & 7,13 & 0,93 & 9,64 & $11,99 \star \star$ & 87,25 & 7,35 & 12,19 & 0,92 & 16,33 & $12,66^{\star \star}$ & 86,29 & 5,66 & 9,66 & 0,92 & 12,98 \\
\hline 10 & $21,44^{\star *}$ & 134,56 & 6,30 & 14,24 & 0,95 & 19,47 & $25.29^{\star \star}$ & 92,65 & 8,04 & 19,81 & 0,96 & 27,18 & $28,97^{\star \star}$ & 91,79 & 6.45 & 17,06 & 0,97 & 23,46 \\
\hline 11 & $31,71^{\star \star}$ & 108,94 & 5,27 & 14,60 & 0,97 & 20,11 & $31,97^{\star *}$ & 73,25 & 8,57 & 23,84 & 0,97 & 32,85 & $34,31^{\star \star}$ & 73,11 & 6,96 & 20,09 & 0,97 & 27.71 \\
\hline 12 & $18,76^{\star \star}$ & 101,25 & 5,50 & 11,59 & 0,95 & 15,78 & $29,23 \star \star *$ & 85,96 & 7.97 & 21,17 & 0,97 & 29,13 & $30,70^{\star \star}$ & 80,45 & 6,51 & 17,73 & 0.97 & 24,41 \\
\hline 13 & $10,18^{\star \star \star}$ & 114,43 & 5,81 & 8,81 & 0,90 & 11,71 & $21,70^{\star \star}$ & 75,45 & 7,57 & 17,23 & 0,95 & 23,55 & $18,95^{\star \star}$ & 75,74 & 6,50 & 13,76 & 0,95 & 18,75 \\
\hline 14 & $7,59^{\star \star}$ & 151,91 & 6,68 & 8,58 & 0,87 & 11,19 & $8,73 * *$ & 107,79 & 8,01 & 11,14 & 0,89 & 14,68 & $8,83^{\star *}$ & 105,89 & 6,71 & 9,38 & 0,89 & 12,37 \\
\hline 15 & $8,20^{* *}$ & 143,94 & 5,76 & 7,72 & 0,88 & 10,13 & $17,86^{\star *}$ & 71,73 & 8,31 & 17,07 & 0,94 & 23,22 & $13,95^{\star *}$ & 79,03 & 6,62 & 11,91 & 0,93 & 16,07 \\
\hline 16 & $10,44^{* *}$ & 132,45 & 6,46 & 9,93 & 0,90 & 13,22 & $17,47^{\star \star}$ & 95,79 & 6,87 & 13,94 & 0,94 & 18.95 & $16,16^{\star \star}$ & 93,59 & 5,73 & 11,15 & 0,94 & 15,12 \\
\hline
\end{tabular}

1 = número referente ao ambiente, ver tabela 2

2 = valor do Teste $F$ calculado para a fonte de variação de Genótipos (variedades), com nível de significância

3 = valores médios (t cana/ha) para o respectivo corte 
Anexo 5 - Resultados das análises de variância individuais e parâmetros genéticos em cada ambiente. Estimativas para a variável teor de sacarose (PCC) no Ensaio de Caracterização/93.

Média para 20 genótipos analisados, nos referidos cortes.

\begin{tabular}{|c|c|c|c|c|c|c|c|c|c|c|c|c|c|c|c|c|c|c|}
\hline $\mathrm{AMB}^{1}$ & p & $\begin{array}{l}\text { Média }^{3} \\
\text { PCC1 }\end{array}$ & $\begin{array}{l}\mathrm{CV}_{\mathrm{e}} \\
(\%)\end{array}$ & $\begin{array}{c}\mathrm{CV}_{\mathrm{g}} \\
(\%)\end{array}$ & $h_{i n}^{2}$ & $\begin{array}{l}\text { Gs } \\
(\%)\end{array}$ & GENI & $\begin{array}{l}\text { Média } \\
\text { PCC2 }\end{array}$ & $\begin{array}{l}\mathrm{CV}_{\mathrm{c}} \\
(\%)\end{array}$ & $\begin{array}{l}C V_{\mathrm{g}} \\
(\%)\end{array}$ & $h_{m}^{2}$ & $\begin{array}{l}\text { Gs } \\
(\%)\end{array}$ & v) & $\begin{array}{l}\text { Média } \\
\text { PCCM }\end{array}$ & $\begin{array}{l}\mathrm{CV}_{\mathrm{c}} \\
(\%)\end{array}$ & $\begin{array}{l}\mathrm{CV}_{\mathrm{g}} \\
(\%)\end{array}$ & $h_{m}^{2}$ & $\begin{array}{l}\text { Gs } \\
(\%)\end{array}$ \\
\hline 1 & $r, 01$ & 14,27 & 4,43 & 5,46 & 0,86 & 7,08 & 0,30 & 6,70 & 3,69 & 5,05 & 0,88 & 6,64 & 11,30 & 15,49 & 2,85 & 4,58 & 0,91 & 6,12 \\
\hline 2 & $7,83^{* *}$ & 16,17 & 3,84 & 5,01 & 0,87 & 6,56 & $8,53^{\star \star}$ & 17,61 & 2,60 & 3,57 & 0,88 & 4,70 & $11,26^{\text {** }}$ & 16,89 & 2,40 & 3,84 & 0,91 & 5,13 \\
\hline 3 & $3,95^{* *}$ & 13,80 & 5,28 & 4,54 & 0,75 & 5,49 & $4,77^{\star \star}$ & 15,72 & 4,96 & 4,81 & 0,79 & 5,99 & $5,55^{\star \star}$ & 4,76 & 3,43 & 3,66 & 0,82 & 4,63 \\
\hline 4 & 23,26 ** & 14,40 & 2,68 & 6,33 & 0,96 & 8,67 & $14,21^{* *}$ & 18,11 & 2,13 & 3,87 & 0,93 & 5,22 & 27,72 ** & 16,26 & 1,81 & 4,68 & 0,96 & 6,44 \\
\hline 5 & $5,42^{\star \star}$ & 15,75 & 3,90 & 4,10 & 0,82 & 5,18 & $6,99 * *$ & 16,98 & 3,22 & 3,93 & 0,86 & 5,10 & $10,88^{\star *}$ & 16,37 & 2,39 & 3,76 & 0.91 & 5,01 \\
\hline 6 & $5,04^{\star \star}$ & 15,86 & 4,76 & 4,78 & 0,80 & 5,99 & $6,71^{* *}$ & 17,23 & 3,46 & 4,14 & 0,85 & 5,34 & $9,02^{\star \star}$ & 16,55 & 2,91 & 4,12 & 0,89 & 5,43 \\
\hline 7 & 11,01 ** & 13,49 & 5,59 & 8,84 & 0,91 & 11,80 & $3,84^{* \star}$ & 41 & 4,69 & 3,95 & 0,74 & 4,76 & $10,78^{\star \star}$ & 95 &, 76 & 5,89 & 91 & 7,85 \\
\hline 8 & $4,01^{\star *}$ & 15,79 & 4,81 & 4,17 & 0,75 & 5,06 & 12,34 ** & 16,64 & 3,29 & 5,53 & 0,92 & 7,42 & $7,27^{\star \star}$ & 16,21 & 2,89 & 3,62 & 0,86 & 4,70 \\
\hline 9 & $6,62^{* *}$ & 16,03 & 4,28 & 5,08 & 0,85 & 6,55 & $6,08^{\star \star}$ & 17,04 & 3,10 & 3,50 & 0,84 & 4,48 & $8,35^{* *}$ & 6,54 & 2,82 & 3,82 & 0,88 & 5,01 \\
\hline 10 & $6,84^{* *}$ & 15,54 & 3,98 & 4,81 & 0,85 & 6,22 & $9,86^{\star \star}$ & 16,92 & 2,86 & 4,25 & 0,90 & 5,64 & $15,10^{\star \star}$ & 16,23 & 2,24 & 4,20 & 0,93 & 5,69 \\
\hline 11 & $9,22^{* *}$ & 15,44 & 3,98 & 5,71 & 0,89 & 7,55 & 12,08 ** & 16,43 & 3,58 & 5,96 & 0,92 & 7,99 & $16,37^{\star \star}$ & 5,94 & 2,69 & 5,27 & 0,94 & 7,16 \\
\hline 12 & 9,89 ** & 14,41 & 4,40 & 6,55 & 0,90 & 8,70 & $8,43^{* *}$ & 16,36 & 3,60 & 4,91 & 0,88 & 6,45 & $17,50^{\star \star}$ & 15,39 & 2,48 & 5,04 & 0,94 & 6,85 \\
\hline 13 & $19,51^{* \star}$ & & 2,75 & 5,92 & 0,95 & 8,07 & $7,80^{* \star}$ & 17,69 & 2,99 & 3,90 & 0,87 & 5,10 & 22,86 ** & 16,55 & 2,03 & 4,74 & 0,96 & 6,49 \\
\hline 14 & $4,42^{* *}$ & 13,98 & 5,95 & 5,50 & 0,77 & 6,78 & 8,08 ** & 15,33 & 4,87 & 6,48 & 0,88 & 8,50 & $8,50^{* *}$ & 14,66 & 4,09 & 5,60 & 0,88 & 7,37 \\
\hline 15 & $5,36^{\star *}$ & 16,26 & 3,75 & 3,92 & 0,81 & 4.95 & $14,45^{\star \star}$ & 16,67 & 2.46 & 4,51 & 0,93 & 6,09 & $16,50^{\star \star}$ & 16,47 & 1,92 & 3,78 & 0,94 & 5,13 \\
\hline 16 & $6,14^{\text {k* }}$ & 15,44 & 4,28 & 4,85 & 0,84 & 6,22 & $5,21 * \star$ & 16,86 & 4,55 & 4,67 & 0,81 & 5,88 & $6,69^{\star \star}$ & 16,15 & 3,27 & 3,90 & 0,85 & 5,04 \\
\hline
\end{tabular}

1 = número referente ao ambiente, ver tabela 2

2 = valor do Teste $\mathrm{F}$ calculado para a fonte de variação de Genótipos (variedades), com nível de significância

$3=$ valores médios (\%) para o respectivo corte 
Anexo 6 - Resultados das análises de variância individuais e parâmetros genéticos em cada ambiente.

Estimativas para a variável produtividade de açúcar (TPH) no Ensaio de Caracterização/93.

Média para 20 genótipos analisados, nos referidos cortes.

\begin{tabular}{|c|c|c|c|c|c|c|c|c|c|c|c|c|c|c|c|c|c|c|}
\hline $\mathrm{AMB}^{1}$ & $F(G E N)^{2}$ & $\begin{array}{c}\text { Média }^{3} \\
\text { TPH1 }\end{array}$ & $\begin{array}{c}C V_{c} \\
(\%)\end{array}$ & $\begin{array}{c}C V_{g} \\
(\%)\end{array}$ & $h_{m}^{2}$ & $\begin{array}{l}\text { Gs } \\
(\%)\end{array}$ & $F(G E N)$ & $\begin{array}{l}\text { Média } \\
\text { TPH2 }\end{array}$ & $\begin{array}{r}C V_{e} \\
(\%)\end{array}$ & $\begin{array}{r}\mathrm{CV}_{\mathrm{g}} \\
(\%)\end{array}$ & $\mathrm{h}_{\mathrm{m}}^{2}$ & $\begin{array}{l}\text { Gs } \\
(\%)\end{array}$ & $F(G E N)$ & $\begin{array}{l}\text { Média } \\
\text { TPH5 }\end{array}$ & $\begin{array}{l}\mathrm{CV}_{\mathrm{e}} \\
(\%)\end{array}$ & $\begin{array}{r}C V_{B} \\
(\%)\end{array}$ & $\mathrm{h}_{\mathrm{m}}^{2}$ & $\begin{array}{l}\text { Gs } \\
(\%)\end{array}$ \\
\hline 1 & $11,65^{\star *}$ & 10,14 & 5,52 & 9,00 & 0,91 & 12,05 & $\overline{13,07^{\star *}}$ & 15,24 & 8,86 & 15,39 & 0,92 & 20,71 & 14,00 & 13,39 & 6,55 & 12,19 & .93 & 16,49 \\
\hline 2 & $9,06^{* *}$ & 17,75 & 7,92 & 11,25 & 0,89 & 14,85 & 7,25 ** & 10,23 & 14,55 & 18,19 & 0,86 & 23,65 & $7,42^{\star \star}$ & 10,58 & 10,19 & 12,91 & 87 & 16,81 \\
\hline 3 & $5,69^{\star *}$ & 3,23 & 8,37 & 9,07 & 0,82 & 11,52 & $24,65^{\star *}$ & 16,28 & 6,90 & 16,79 & 0,96 & 23,02 & $19,31^{\star \star}$ & 3 & 36 & 13,61 & 95 & 18,56 \\
\hline 4 & $12,73^{\star \star}$ & 16,35 & 6,57 & 11,24 & 0,92 & 15,11 & 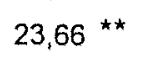 & 10,75 & 9,34 & 22,23 & 0,96 & 30,46 & $20,63^{\star \star}$ & 10,45 & 62 & 16,88 & 0,95 & 23,06 \\
\hline 5 & 18,20 ** & 70 & 5,59 & 11,60 & 0,95 & 15,79 & $26,59^{* *}$ & 1071 & 7,13 & 18,03 & 0,96 & 24,76 & $22,79^{\star \star}$ & 7 & 86 & 13,67 & 96 & 18,72 \\
\hline 6 & $10,60 \star \star$ & 19,41 & 6,46 & 10,02 & 0,91 & 13,34 & $11,36^{\star *}$ & 14,69 & 10,53 & 16,95 & 0,91 & 22,67 & $12,82^{\star \star}$ & 92 & .84 & 13,48 & 0,92 & 18,12 \\
\hline 7 & $10,58 * \star$ & $17 \wedge 6$ & 7,90 & 12,23 & 0,91 & 16,29 & 15,21 ** & 15,64 & 8,27 & 15,60 &, 93 & 21,11 & $17,10^{\star \star}$ & 14,20 & 6,61 & 13,26 & 0,94 & 18,01 \\
\hline 8 & $11,74^{\star *}$ & 20,33 & 7,21 & 11,81 & 91 & 15,81 & $14,57^{\star *}$ & 11,76 & 12,71 & 23,40 & 0.93 & 31,62 & $13,27^{\star *}$ & & 9,96 & 17,44 & 0,92 & 23,48 \\
\hline 9 & $7,39^{* \star}$ & 20,17 & 6,34 & 8,01 & 0,86 & 10,43 & $8,07^{\star \star}$ & 14,83 & 8,04 & 10,69 & 0,88 & 14,00 & $7,79^{\star \star}$ & 14,24 & 6,43 & 8,38 & 0,87 & 10,95 \\
\hline 10 & $14,01^{* *}$ & 20,84 & 7,16 & 12,91 & 0,93 & 17,42 & 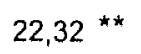 & 15,69 & 8,57 & 19,80 & 0,96 & 27,09 & $24,60^{\star \star}$ & 14,88 & 76 & 16,41 & 0,96 & 22,50 \\
\hline 11 & $27,34^{\star \star}$ & 10,01 & 5,92 & 15,18 & 0,96 & 20,86 & $29,38^{\star \star}$ & 12,06 & 9,18 & 24,45 & 0,97 & 33,65 & $36,09^{\star \star}$ & 11,65 & 6,77 & 5 & 0,97 & 27 \\
\hline 12 & $9,87^{\star *}$ & 14,53 & 6,74 & 10,04 & 0,90 & 13,33 & $20,74^{\star \star}$ & 14,01 & 8,83 & 19,61 & 0,95 & 26,79 & $20,22^{\star \star}$ & 12,32 & 7,01 & 15,36 & 0,95 & 20,96 \\
\hline 13 & 10,91 ** & 17,58 & 5,56 & 8,75 & 0,91 & 11,68 & $16,86^{* *}$ & 13,34 & 8,49 & 16,91 & 0,94 & 22,96 & 16,52 ** & 12,51 & 6,64 & 13,08 & 0,94 & 17,75 \\
\hline 14 & $3,52^{\star *}$ & 21,21 & 9,98 & 7,92 & 0,72 & 9,39 & $3,91 * *$ & 16,44 & 9,72 & 8,30 & 0,74 & 10,02 & $3,03 * \star$ & 15,46 & 8,43 & 6,00 & 0,67 & 6,87 \\
\hline 15 & 5,99 *ᄎ & 23,35 & 6,52 & 7,29 & 0,83 & 9,31 & $14,26^{\star *}$ & 11,94 & 9,10 & 16,57 & 0,93 & 22,37 & $10,86^{* \star}$ & 12,99 & 7,22 & 11,33 & 0,91 & 15,12 \\
\hline 16 & $7,09^{\star *}$ & 20,43 & 8,13 & 10,03 & 0,86 & 13,01 & $12,50^{\star \star}$ & 16,13 & 8,04 & 13,63 & 0,92 & 18,30 & $11,03^{\star *}$ & 15,09 & 6,50 & 10,30 & 0.91 & 13,7 \\
\hline
\end{tabular}

1 = número referente ao ambiente, ver tabela 2

2 = valor do Teste $F$ calculado para a fonte de variação de Genótipos (variedades), com nivel de significância

3 = valores médios ( $\mathrm{t}$ açúcar/ha) para o respectivo corte 
Anexo 7 - Resultados das análises de variância individuais e parâmetros genéticos em cada ambiente.

Estimativas para a variável produtividade de colmos (TCH) no Ensaio de Caracterização/94.

Média para 20 genótipos analisados, nos referidos cortes.

\begin{tabular}{|c|c|c|c|c|c|c|c|c|c|c|c|c|c|c|c|c|c|c|}
\hline 1 & $F(C$ & $\begin{array}{c}\text { Média }^{3} \\
\text { TCH1 }\end{array}$ & $\begin{array}{l}C V_{\mathrm{e}} \\
(\%)\end{array}$ & $\begin{array}{c}C V_{\mathrm{g}} \\
(\%)\end{array}$ & $h_{\mathrm{s}}^{2}$ & $\begin{array}{l}\text { Gs } \\
(\%)\end{array}$ & v) & $\begin{array}{l}\text { Média } \\
\text { TCH2 }\end{array}$ & $\begin{array}{l}\mathrm{CV}_{\mathrm{e}} \\
(\%)\end{array}$ & $\begin{array}{c}\mathrm{CV}_{\mathrm{g}} \\
(\%)\end{array}$ & $h_{m}^{2}$ & $\begin{array}{l}\text { Gs } \\
(\%)\end{array}$ & ) & $\begin{array}{l}\text { Média } \\
\text { TCH5 }\end{array}$ & $\begin{array}{l}\mathrm{CV}_{\mathrm{e}} \\
(\%)\end{array}$ & $\begin{array}{r}\mathrm{CV}_{\mathrm{g}} \\
(\%)\end{array}$ & $h_{m}^{2}$ & $\begin{array}{l}\text { Gs } \\
(\%)\end{array}$ \\
\hline 1 & $13,70^{\star *}$ & 99,29 & 6,54 & 11,66 & 0,93 & 15,71 & 10,00 & 72,08 & 10,00 & 15,28 & 0,90 & 20,33 & 1,00 & 70,31 & 8,38 & 13,24 & 0,91 & 11,00 \\
\hline 2 & $8,01^{\star *}$ & 118,43 & 7,43 & 9,84 & 0,88 & 12,88 & 12,26 ** & 93,84 & 6,51 & 10,93 & 0,92 & 14,66 & 12,66 ** & 89,41 & 5,94 & 10,13 & 0,92 & 13,62 \\
\hline 3 & $12,56^{* *}$ & 94,08 & 5,69 & 9,68 & 0,92 & 13,00 & $42,23^{\star \star}$ & 92,24 & 4,47 & 14,36 & 0,98 & 19,86 & $39,85^{\star \star}$ & 83,39 & 4,14 & 12,92 & 0,97 & 17,85 \\
\hline 4 & 12,72 ** & 114,73 & 7,04 & 12,05 & 0,92 & 16,20 & 9,94 ** & 104,84 & 6,77 & 10,13 & 0,90 & 13,44 & 10,68 ** & 96,36 & 5,92 & 9,21 & 0,91 & 12,28 \\
\hline 5 & $28,49^{\star \star}$ & 93,79 & 4,30 & 11,28 & 0,96 & 15,52 & $16,45^{\star \star *}$ & 84,75 & 7,09 & 13,93 & 0,94 & 18,90 & 19,38 ** & 78,15 & 6,00 & 12,86 & 0,95 & 17,53 \\
\hline 6 & 28,59 ** & 97,65 & 5,56 & 14,61 & 0,97 & 20,09 & 23,59 ** & 75,71 & 6,05 & 14,37 & 0,96 & 19,69 & $26,87^{* *}$ & 72,59 & 5,51 & 14,02 & 0,96 & 19,26 \\
\hline 7 & $17,47^{\star *}$ & 135,99 & 4,77 & 9,68 & 0,94 & 13,16 & $8,96^{\star \star \star}$ & 69,75 & 11,21 & 15,81 & 0,89 & 20,86 & $10,23^{* *}$ & 76,00 & 8,22 & 12,49 & 0,90 & 16,61 \\
\hline 8 & 9,51 ** & 110,73 & 7,43 & 10,84 & 0,89 & 14,36 & $43,76^{\star \star}$ & 83,00 & 6,89 & 22,54 & 0,98 & 31,19 & $35,49^{\star \star}$ & 80,28 & 6,31 & 18,52 & 0,97 & 25,56 \\
\hline 9 & $18,30^{\star *}$ & 99,10 & 4,90 & 10,18 & 0,95 & 13,86 & $14,48^{* *}$ & 66,68 & 7,64 & 14,03 & 0,93 & 18,95 & $13,13^{\text {** }}$ & 66,54 & 6.10 & 10,62 & 0,92 & 14,29 \\
\hline 10 & $17,70^{* *}$ & 115,30 & 5,53 & 11,29 & 0,94 & 15,35 & $15,32^{\text {** }}$ & 85,88 & 5,52 & 10,44 & 0,93 & 14,13 & $18,72^{\text {** }}$ & 83,23 & 4,69 & 9,87 & 0,95 & 13,44 \\
\hline 11 & $4,47^{\star *}$ & 143,43 & 6,40 & 5,96 & 0,78 & 7,35 & $8,75^{* \star}$ & 109,83 & 6,49 & 9,04 & 0,89 & 11,91 & $8,79^{\star \star}$ & 105,60 & 5,65 & 7,88 & 0,89 & 10,38 \\
\hline 12 & $19,47^{\star \star}$ & 99,20 & 4,72 & 10,14 & 0,95 & 13,83 & $14,01 * *$ & 75,44 & 7,22 & 13,03 & 0,93 & 17,57 & 16,71 ** & 72,73 & 5,79 & 11,48 & 0,94 & 15,59 \\
\hline 13 & $13,04^{* *}$ & $\$ 15,11$ & 5,96 & 10,34 & 0,92 & 13,90 & $11,67^{* *}$ & 94,31 & 8,92 & 14,58 & 0,91 & 19,51 & $11,23^{\text {** }}$ & 89,10 & 7,65 & 12,23 & 0,91 & 16,34 \\
\hline
\end{tabular}

1 = número referente ao ambiente, ver tabela 2

2 = valor do Teste $\mathrm{F}$ calculado para a fonte de variação de Genótipos (variedades), com nível de significância

$3=$ valores médios ( $\mathrm{t}$ cana/ha) para o respectivo corte 
Anexo 8 - Resultados das análises de variância individuais e parâmetros genéticos em cada ambiente. Estimativas para a variável teor de sacarose (PCC) no Ensaio de Caracterização/94.

Média para 20 genótipos analisados, nos referidos cortes.

\begin{tabular}{|c|c|c|c|c|c|c|c|c|c|c|c|c|c|c|c|c|c|c|}
\hline 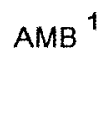 & 1 & $\begin{array}{c}\text { Média }^{3} \\
\text { PCC1 }\end{array}$ & $\begin{array}{l}\mathrm{CV}_{e} \\
(\%)\end{array}$ & $\begin{array}{l}\mathrm{CV}_{\mathrm{g}} \\
(\%)\end{array}$ & $h_{m}^{2}$ & $\begin{array}{l}\text { Gs } \\
\text { (\%) }\end{array}$ & d) & $\begin{array}{l}\text { Média } \\
\text { PCC2 }\end{array}$ & $\begin{array}{l}\mathrm{CV}_{\mathrm{c}} \\
(\%)\end{array}$ & $\begin{array}{c}\mathrm{CV}_{\mathrm{g}} \\
(\%)\end{array}$ & 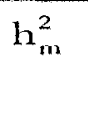 & $\begin{array}{l}\text { Gs } \\
(\%)\end{array}$ & & $\begin{array}{l}\text { Média } \\
\text { PCCM }\end{array}$ & $\begin{array}{l}C V_{\mathrm{e}} \\
(\%)\end{array}$ & $\begin{array}{c}\mathrm{CV}_{\mathrm{g}} \\
(\%)\end{array}$ & $h_{m}^{2}$ & $\begin{array}{l}\text { Gs } \\
(\%)\end{array}$ \\
\hline 1 & & & 3 & 4 & $c$ & & & & $\because 60$ & 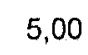 & 0,96 & & & & 75 & 88 & & \\
\hline 2 & $16,25^{\star \star}$ & 33 & 3,14 & 6,13 & 0.94 & 8,32 & $62^{\star \star}$ & 36 & 2,55 & 5,05 & 0,94 & 6,85 & & 84 & 09 & 53 & 97 & 7,60 \\
\hline 3 & $1.1,31^{* \star}$ & 4,76 & 3,64 & 5,84 & 0,91 & 7,8 & & 12 & 2,93 & 5,70 & 0.94 & 7,73 & & 94 & 2,36 & 31 & 0.95 & 7,26 \\
\hline 4 & $0^{*}$ & 89 & 4,14 & 4,45 & 0 & 5,6 & $\mathrm{ut}^{+}$ & 8 & 2,85 & 5,39 & 93 & 7. & $* *$ & 34 & 49 & 46 & 93 & 6,01 \\
\hline 5 & $88^{* *}$ &, 07 & 3,38 & 4,33 & 0,87 & 5,65 & & 94 &, 77 & 4,85 & 92 & 6,53 & $3 * \star$ & 51 & 37 & 19 & 93 & 5,64 \\
\hline 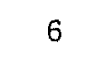 & 1,89 * & 94 & 1,91 & 4,16 & & 5,6 & 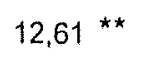 & 33 & 2.42 & 4,13 & 92 & 5,5 & & & 1,62 & 99 & & 5,47 \\
\hline 7 & $11^{* *}$ & 2 & 3,68 & 5,24 & 0 & 69 & $11,31^{\star \star}$ & 30 & 3,00 & 4,82 & 91 & 6,45 & $\star \star \star$ & 76 & 2,30 & 89 & 09 & 6,67 \\
\hline 8 & 2 & 15,44 & 3,02 & 4,85 & & 6.4 & & & 1,80 & 5,00 & & 6,8 & & 80 & 84 & 24 & & 5,81 \\
\hline 9 & & 15,23 & 2,92 & 5,09 & 0 & 6,8 & $67^{\star \star}$ & & 2,88 & 8,24 & 0,97 & 11,3 & & & 30 & 2 & & 7,57 \\
\hline 10 & $42,13^{\star \star}$ & & 2,09 & 6 & 0,98 & & 0,122 & & 2,50 & 6,86 & 0,97 & & & & 81 & 38 & 0,98 & 8,84 \\
\hline 11 & $12,23^{\star \star}$ & 13,52 & 5,01 & 8,40 & 0,92 & 11,27 & $18,46^{* *}$ & 16,15 & 2,58 & 5,40 & 0,95 & 7,3 & $22,12^{\star \star}$ & 14,84 & 2,64 & 6,06 & 0.95 & 8,29 \\
\hline 12 & $24,76^{* \star}$ & 20 & 2,36 & 5,1 & 0,9 & 7.8 & & & 2,4 & & & & & & & 67 & & 6,40 \\
\hline 13 & $6,61^{* *}$ &, 31 & 5,03 & 96 & 0,85 & 7,68 & $10,98^{\star \star}$ & 15,65 & 3,34 &, 28 & 0,91 & 7,0 & $9,06^{\star *}$ & 15,48 & 3,55 & 5,04 & 0,89 & 6,66 \\
\hline
\end{tabular}

$1=$ número referente ao ambiente, ver tabela 2

2 = valor do Teste $\mathrm{F}$ calculado para a fonte de variação de Genótipos (variedades), com nível de significância

$3=$ valores médios $(\%)$ para o respectivo corte 
Anexo 9 - Resultados das análises de variância individuais e parâmetros genéticos em cada ambiente. Estimativas para a variável produtividade de açücar (TPH) no Ensaio de Caracterização/94.

Média para 20 genótipos analisados, nos referidos cortes.

\begin{tabular}{|c|c|c|c|c|c|c|c|c|c|c|c|c|c|c|c|c|c|c|}
\hline $\mathrm{AMB}^{1}$ & $F(G E N)^{2}$ & $\begin{array}{c}\text { Média }^{3} \\
\text { TPHI }\end{array}$ & $\begin{array}{c}C V_{e} \\
(\%)\end{array}$ & $\begin{array}{c}\mathrm{CV}_{\mathrm{g}} \\
(\%)\end{array}$ & $h_{m}^{2}$ & $\begin{array}{l}\text { Gs } \\
(\%)\end{array}$ & $F(G E N)$ & $\begin{array}{l}\text { Média } \\
\text { TPH2 }\end{array}$ & $\begin{array}{r}C V_{c} \\
(\%)\end{array}$ & $\begin{array}{l}\mathrm{CV}_{\mathrm{g}} \\
(\%)\end{array}$ & $\mathrm{h}_{\mathrm{m}}^{2}$ & $\begin{array}{l}\text { Gs } \\
(\%)\end{array}$ & $F(G E N)$ & $\begin{array}{l}\text { Média } \\
\text { TPH5 }\end{array}$ & $\begin{array}{l}\mathrm{CV}_{\mathrm{c}} \\
(\%)\end{array}$ & $\begin{array}{l}\mathrm{CV}_{\mathrm{g}} \\
(\%)\end{array}$ & $h_{t n}^{2}$ & $\begin{array}{l}\text { Gs } \\
(\%)\end{array}$ \\
\hline 1 & $12,86^{\star \star}$ & 15,88 & 6,16 & 10,61 & 0,92 & 14,27 & $9,09 * \star$ & 11,85 & 10,19 & 14,50 & 0,89 & 19,15 & $9,38^{* *}$ & 11,40 & 8,06 & 11,66 & 0,89 & 15,43 \\
\hline 2 & $6,79^{* *}$ & 19,32 & 8,79 & 10,58 & 0,85 & 13,67 & $10,42^{* *}$ & 16,26 & 6,98 & 10,72 & 0,90 & 14,26 & $11,87^{\star \star}$ & 15,03 & 6,16 & 10,16 & 0,92 & 13,61 \\
\hline 3 & $6,42^{* *}$ & 13,84 & 6,53 & 7,61 & 0,84 & 9,79 & $30,13^{\star *}$ & 13,92 & 5,23 & 14,12 & 0,97 & 19,44 & $22,86^{\star \star}$ & 12,42 & 4,92 & 11,50 & 0,96 & 15,75 \\
\hline 4 & $6,73^{\star \star}$ & 18,16 & 8,21 & 9,83 & 0,85 & 12,69 & $10,21^{* *}$ & 16,54 & 7,25 & 11,00 & 0,90 & 14,63 & $8,51^{\star *}$ & 15,24 & 6,48 & 8,88 & 0,88 & 11,68 \\
\hline 5 & $15,38 * *$ & 15,03 & 5,19 & 9,84 & 0,94 & 13,32 & $15,04^{\star *}$ & 12,63 & 6,99 & 13,10 & 0,93 & 17,72 & $15,35^{* \star}$ & 12,09 & 5,99 & 11,34 & 0,93 & 15,35 \\
\hline 6 & $26,30^{* \star}$ & 16,50 & 5,51 & 13,86 & 0,96 & 19,03 & $12,56^{\star *}$ & 12,69 & 6,89 & 11,70 & 0,92 & 15,72 & $18,11^{* *}$ & 12,22 & 5,86 & 12,12 & 0,94 & 16,49 \\
\hline 7 & $11,33^{* \star}$ & 18,60 & 5,14 & 8,26 & 0,91 & 11,05 & $5,51^{\star *}$ & 10,96 & 11,74 & 12,47 & 0,82 & 15,79 & $6,12^{\star \star}$ & $\uparrow 1,17$ & 8,21 & 9,29 & 0,84 & 11,89 \\
\hline 8 & $9,46 * *$ & 17,07 & 7,53 & 10,94 & 0,89 & 14,49 & $43,28^{* \star}$ & 13,41 & 7,08 & 23,02 & 0,98 & 31,85 & $30,74^{* *}$ & 12,66 & 6,47 & 17,64 & 0,97 & 24,29 \\
\hline 9 & $13,31 * *$ & 15,07 & 5,85 & 10,27 & 0,92 & 13,83 & $18,10^{* *}$ & 8,97 & 7,77 & 16,07 & 0,94 & 21,87 & $10,17^{\star *}$ & 9,52 & 6,32 & 9,57 & 0,90 & 12,72 \\
\hline 10 & $17,36^{\star \star}$ & 17,24 & 6,39 & 12,91 & 0,94 & 17,55 & $17,71^{\star \star}$ & 13,18 & 6,22 & 12,71 & 0,94 & 17,28 & $19,36^{\star \star}$ & 12,60 & 5,22 & 11,18 & 0,95 & 15,24 \\
\hline 11 & $6,20^{* *}$ & 19,39 & 8,62 & 9,82 & 0,84 & 12,59 & $13,17^{\star *}$ & 17,73 & 6,12 & 10,67 & 0,92 & 14,36 & $10,27^{\star *}$ & 15,66 & 6,07 & 9,24 & 0,90 & 12,29 \\
\hline 12 & $21,10^{* \star}$ & 16,05 & 4,83 & 10,83 & 0,95 & 14,80 & $14,15^{* *}$ & 12,11 & 7,32 & 13,27 & 0,93 & 17,91 & $15,86^{\star \star}$ & 11,71 & 5,82 & 11,23 & 0,94 & 15,21 \\
\hline 13 & $5,82^{\star \star}$ & 17,55 & 7,89 & 8,67 & 0,83 & 11,05 & $7,55^{\star \star}$ & 14,70 & 9,62 & 12,31 & 0,87 & 16,05 & $5,21^{\star \star}$ & 13,73 & 8,38 & 8,60 & 0,81 & 10,82 \\
\hline
\end{tabular}

1 = número referente ao ambiente, ver tabela 2

2 = valor do Teste $F$ calculado para a fonte de variação de Genótipos (variedades), com nível de significância

3 = valores médios ( $t$ açúcar/ha) para o respectivo corte 
Anexo 10 - Resultados das análises conjuntas de variância e parämetros genéticos obtidos.

Estimativas para as variáveis TCH, PCC e TPH no Ensaio de Caracterizaçäo/92, para os respectivos cortes.

Estimativas para 25 genótipos analisados em 14 ambientes.

ANALISE DE VARLÃNCLA - TCH1

ANÁLISE DE VARIÃNCLA - PCC1

ANALISE DE VARLĀNCIA - TPHA

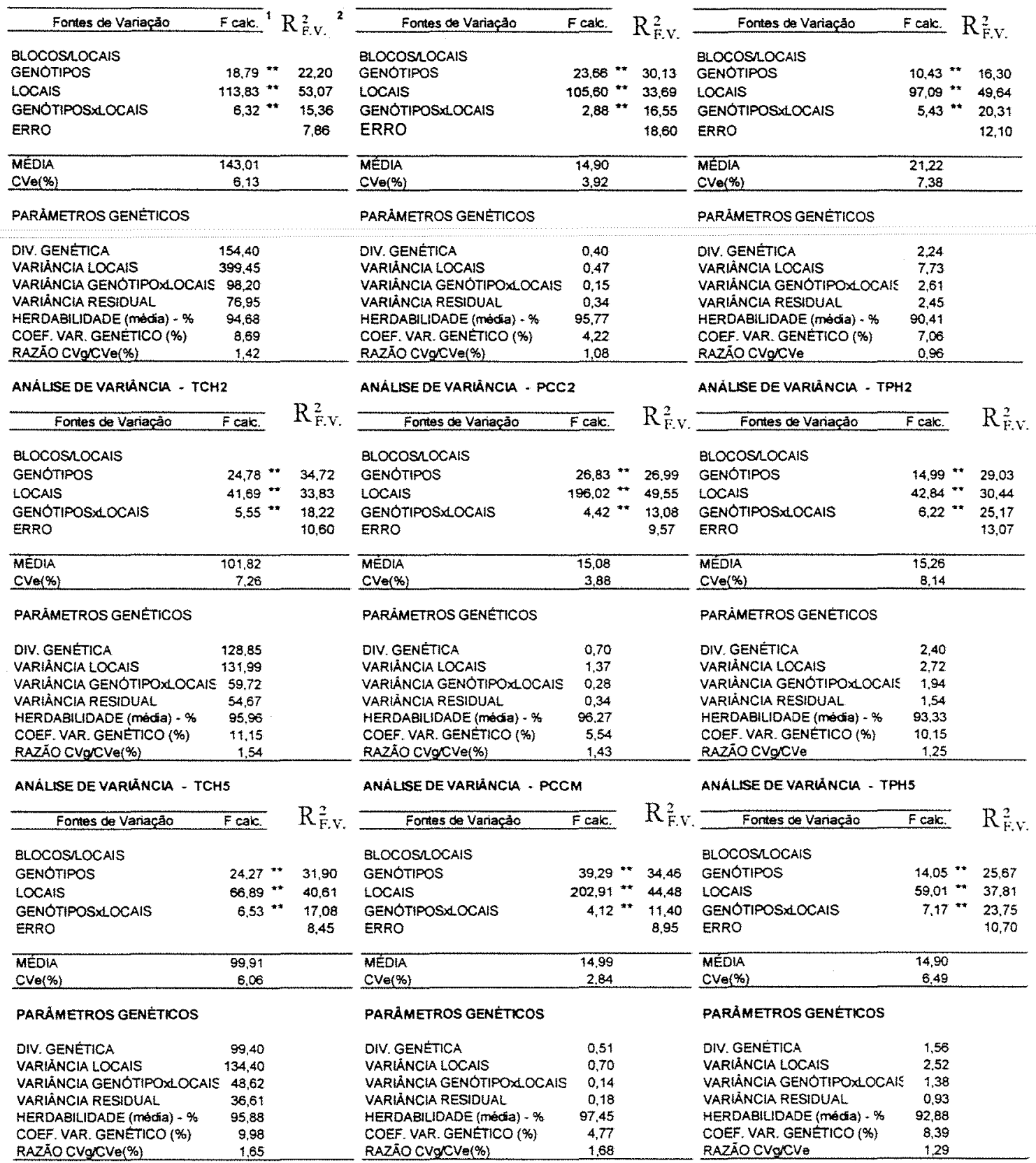

$i=$ valores de $F$ calculado e nivel de significância

2 = participação percentual das fontes de variação na soma de quadrados total 
Anexo 11 - Resultados das análises conjuntas de variancia e parámetros genéticos obtidos.

Estimativas para as variáveis TCH, PCC e TPH no Ensaio de Caracterizaçăo/93, para os respectivos cortes.

Estimativas para 20 genótipos analisados em 16 ambientes.

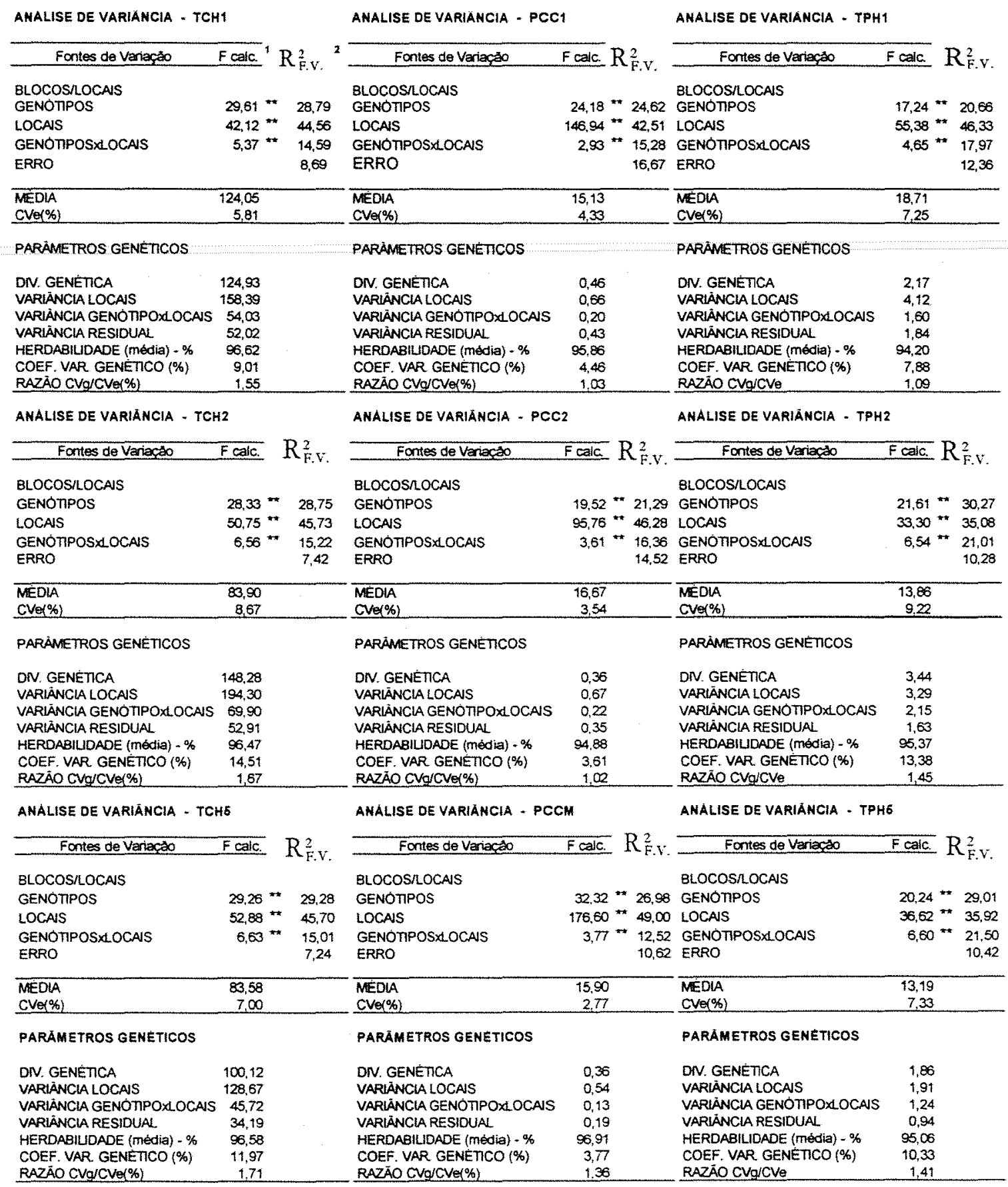

$1=$ valores de F calculado e nivel de significancia

2 = participaçăo percentual das fontes de variaçāo na soma de quadrados total 
Anexo 12 - Resultados das análises conjuntas de variância e parâmetros genéticos obtidos.

Estimativas para as variáveis $\mathrm{TCH}_{\mathrm{r}} \mathrm{PCC}$ e TPH no Ensaio de Caracterizaçăo/94, para os respectivos cortes.

Estimativas para 20 genótipos analisados em 13 ambientes.

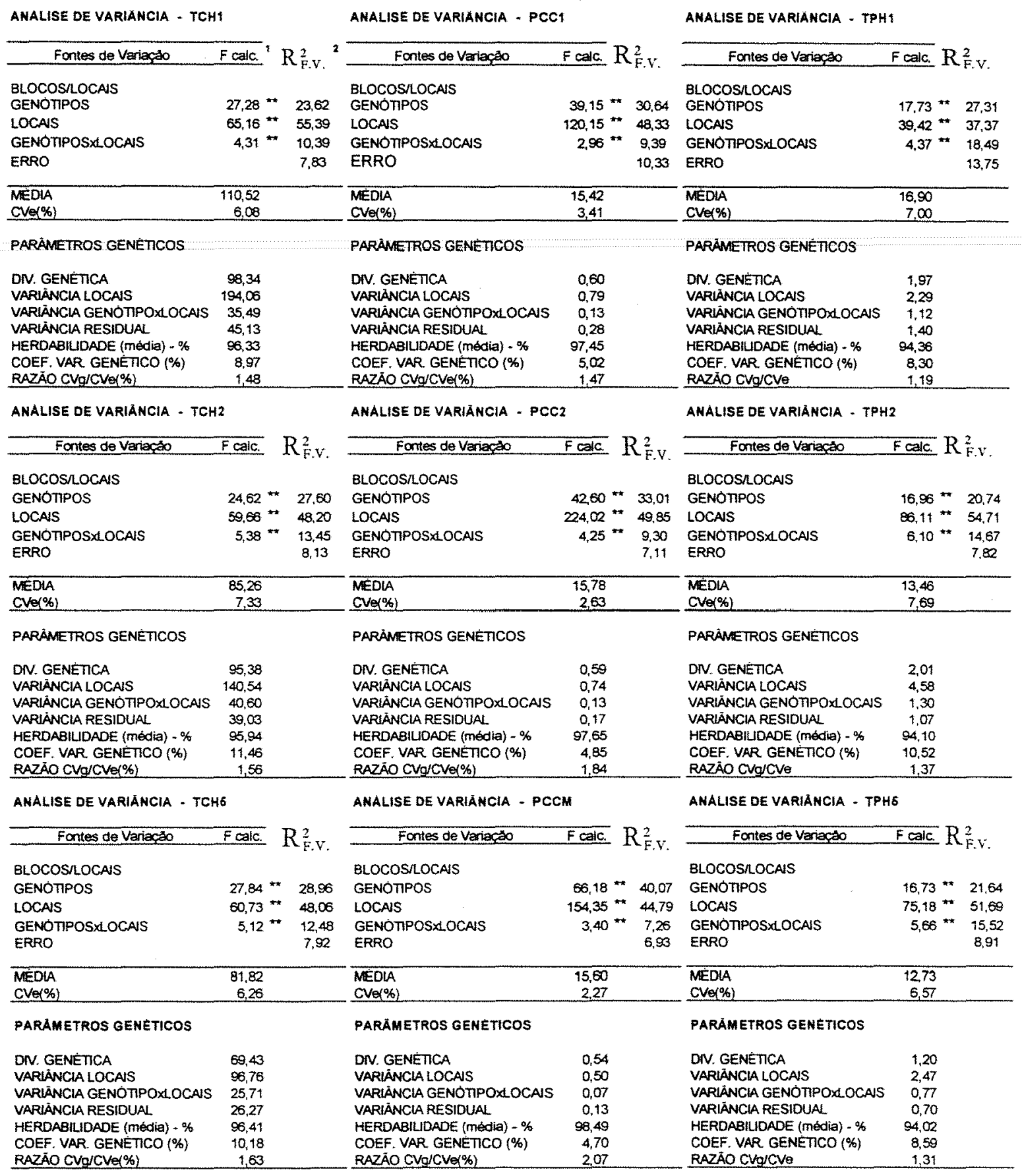

1 = valores de $F$ calculado e nivel de significância

2 = participaçăo percentual das fontes de variação na soma de quadrados total 
Anexo 13 - Resultados médios de quatro repetições para os genótipos (GEN.) em cada local (amb.) para a variável produtividade de açúcar estimada para cinco cortes (TPH5), nos três grupos de ensaios avaliados.

GRUPO 1 - CARACTERIZAÇĀO/92

\begin{tabular}{|c|c|c|}
\hline GEN. & LOCAL & TPH5 \\
\hline 1 & 1 & 13,72 \\
\hline 1 & 2 & 15,70 \\
\hline 1 & 3 & 17,21 \\
\hline 1 & 4 & 19,84 \\
\hline 1 & 5 & 16,85 \\
\hline 1 & 6 & 15,89 \\
\hline 1 & 7 & 15,51 \\
\hline 1 & 8 & 15,55 \\
\hline 1 & 9 & 17,62 \\
\hline 1 & 10 & 16,25 \\
\hline 1 & 11 & 19,11 \\
\hline 1 & 12 & 13,00 \\
\hline 1 & 13 & 16,21 \\
\hline 1 & 14 & 22,54 \\
\hline 2 & 1 & 11,46 \\
\hline 2 & 2 & 13,79 \\
\hline 2 & 3 & 13,97 \\
\hline 2 & 4 & 16,93 \\
\hline 2 & 5 & 11,25 \\
\hline 2 & 6 & 8,59 \\
\hline 2 & 7 & 12,28 \\
\hline 2 & 8 & 13,59 \\
\hline 2 & 9 & 15,05 \\
\hline 2 & 10 & 13,12 \\
\hline 2 & 11 & 11,97 \\
\hline 2 & 12 & 14,26 \\
\hline 2 & 13 & 13,16 \\
\hline 2 & 14 & 19,06 \\
\hline 3 & 1 & 14,05 \\
\hline 3 & 2 & 13,60 \\
\hline 3 & 3 & 14,26 \\
\hline 3 & 4 & 15,15 \\
\hline 3 & 5 & 12,94 \\
\hline 3 & 6 & 13,72 \\
\hline 3 & 7 & 12,86 \\
\hline 3 & 8 & 13,26 \\
\hline 3 & 9 & 13,81 \\
\hline 3 & 10 & 12,12 \\
\hline 3 & 11 & 12,73 \\
\hline 3 & 12 & 12,78 \\
\hline 3 & 13 & 13,84 \\
\hline 3 & 14 & 16,74 \\
\hline 4 & 1 & 11,95 \\
\hline 4 & 2 & 14,37 \\
\hline 4 & 3 & 10,92 \\
\hline 4 & 4 & 14,03 \\
\hline 4 & 5 & 12,07 \\
\hline 4 & 6 & 9,34 \\
\hline 4 & 7 & 7,48 \\
\hline 4 & 8 & 13,13 \\
\hline 4 & 9 & 11,15 \\
\hline 4 & 10 & 10,74 \\
\hline
\end{tabular}

GRUPO 2 - CARACTERIZAÇÃO/93

\begin{tabular}{rrr}
\hline GEN. & LOCAL & TPH5 \\
\hline 1 & 1 & 14,74
\end{tabular}

11,30

15,98

10,54

11,52

13,08

15,06

13,50

13,48

17,47

14,00

12,56

13,55

17,72

12,72

18,13

14,24

11,53

16,21

12,18

12,53

15,01

14,72

12,05

14,51

14,57

15,07

13,81

11,84

15,34

13,73

15,72

12,94

11,95

12,95

10,15

11,98

13,30

12,64

13,22

13,18

12,99

12,38

12,43

12,34

14,64

12,60

14,85

8,21

9,00

7,70
GRUPO 3 - CARACTERIZAÇĀO/94

\begin{tabular}{|c|c|c|}
\hline GEN. & LOCAL & TPH5 \\
\hline 1 & 1 & 13,25 \\
\hline 1 & 2 & 18,14 \\
\hline 1 & 3 & 12,71 \\
\hline 1 & 4 & 14,31 \\
\hline 1 & 5 & 14,04 \\
\hline 1 & 6 & 15,74 \\
\hline 1 & 7 & 12,42 \\
\hline 1 & 8 & 14,64 \\
\hline 1 & 9 & 8,71 \\
\hline 1 & 10 & 14,34 \\
\hline 1 & 11 & 15,06 \\
\hline 1 & 12 & 12,82 \\
\hline 1 & 13 & 16.41 \\
\hline 2 & 1 & 11,05 \\
\hline 2 & 2 & 14,28 \\
\hline 2 & 3 & 11,79 \\
\hline 2 & 4 & 13,67 \\
\hline 2 & 5 & 11,15 \\
\hline 2 & 6 & 11,23 \\
\hline 2 & 7 & 10,57 \\
\hline 2 & 8 & 12,20 \\
\hline 2 & 9 & 8,52 \\
\hline 2 & 10 & 10,10 \\
\hline 2 & 11 & 13,15 \\
\hline 2 & 12 & 10,52 \\
\hline 2 & 13 & 13,71 \\
\hline 3 & 1 & 9,75 \\
\hline 3 & 2 & 13,69 \\
\hline 3 & 3 & 10,23 \\
\hline 3 & 4 & 14,07 \\
\hline 3 & 5 & 10,73 \\
\hline 3 & 6 & 11,23 \\
\hline 3 & 7 & 10,59 \\
\hline 3 & 8 & 7,79 \\
\hline 3 & 9 & 7,85 \\
\hline 3 & 10 & 12,45 \\
\hline 3 & 11 & 14,86 \\
\hline 3 & 12 & 9,73 \\
\hline 3 & 13 & 12,93 \\
\hline 4 & 1 & 10,16 \\
\hline 4 & 2 & 15,79 \\
\hline 4 & 3 & 12,58 \\
\hline 4 & 4 & 15,33 \\
\hline 4 & 5 & 13,70 \\
\hline 4 & 6 & 11,43 \\
\hline 4 & 7 & 11,67 \\
\hline 4 & 8 & 12,67 \\
\hline 4 & 9 & 10,44 \\
\hline 4 & 10 & 11,56 \\
\hline 4 & 11 & 15,45 \\
\hline 4 & 12 & 12,16 \\
\hline 4 & 13 & 14,38 \\
\hline
\end{tabular}


Anexo 13 (cont.) - Resultados médios de quatro repetiçōes para os genótipos (GEN.) em cada local ( amb.) para a variável produtividade de açúcar estimada para cinco cortes (TPH5), nos três grupos de ensaios avaliados.

GRUPO 1 - CARACTERIZAÇÃO/92

\begin{tabular}{|c|c|c|}
\hline GEN. & LOCAL & TPH5 \\
\hline 4 & 11 & 9,55 \\
\hline 4 & 12 & 12,07 \\
\hline 4 & 13 & 12,95 \\
\hline 4 & 14 & 15,37 \\
\hline 5 & 1 & 11,06 \\
\hline 5 & 2 & 13,29 \\
\hline 5 & 3 & 12,85 \\
\hline 5 & 4 & 14,49 \\
\hline 5 & 5 & 10,68 \\
\hline 5 & 6 & 7,56 \\
\hline 5 & 7 & 9,43 \\
\hline 5 & 8 & 12,83 \\
\hline 5 & 9 & 11,23 \\
\hline 5 & 10 & 12,68 \\
\hline 5 & 11 & 8,48 \\
\hline 5 & 12 & 12,84 \\
\hline 5 & 13 & 11,88 \\
\hline 5 & 14 & 15,75 \\
\hline 6 & 1 & 12,64 \\
\hline 6 & 2 & 16,04 \\
\hline 6 & 3 & 14,77 \\
\hline 6 & 4 & 13,40 \\
\hline 6 & 5 & 13,96 \\
\hline 6 & 6 & 13,49 \\
\hline 6 & 7 & 11,86 \\
\hline 6 & 8 & 14,78 \\
\hline 6 & 9 & 13,65 \\
\hline 6 & 10 & 13,23 \\
\hline 6 & 11 & 15,22 \\
\hline 6 & 12 & 13,88 \\
\hline 6 & 13 & 14,82 \\
\hline 6 & 14 & 16,86 \\
\hline 7 & 1 & 11,32 \\
\hline 7 & 2 & 14,65 \\
\hline 7 & 3 & 14,56 \\
\hline 7 & 4 & 15,98 \\
\hline 7 & 5 & 12,39 \\
\hline 7 & 6 & 10,20 \\
\hline 7 & 7 & 13,47 \\
\hline 7 & 8 & 12,83 \\
\hline 7 & 9 & 15,21 \\
\hline 7 & 10 & 16,03 \\
\hline 7 & 11 & 15,37 \\
\hline 7 & 12 & 15,11 \\
\hline 7 & 13 & 15,16 \\
\hline 7 & 14 & 18,78 \\
\hline 8 & 1 & 12,40 \\
\hline 8 & 2 & 14,74 \\
\hline 8 & 3 & 16,26 \\
\hline 8 & 4 & 15,94 \\
\hline 8 & 5 & 14,11 \\
\hline 8 & 6 & 14,36 \\
\hline
\end{tabular}

GRUPO 2 - CARACTERIZAÇÃO/93

\begin{tabular}{rrr}
\hline GEN. & LOCAL & TPH5 \\
\hline 4 & 5 & 7,24 \\
4 & 6 & 7,36
\end{tabular}

$4 \quad 6 \quad 7,36$

$4 \quad 8 \quad 5,13$

$\begin{array}{rrr}4 & 9 & 11,59 \\ 4 & 10 & 6,89\end{array}$

$4 \quad 11 \quad 8,89$

$4 \quad 12 \quad 5,29$

$4 \quad 13 \quad 6,86$

$4 \quad 14 \quad 15,21$

$4 \quad 15 \quad 8,95$

$4 \quad 16 \quad 11,19$

$\begin{array}{rrr}5 & 1 & 11,61 \\ 5 & 2 & 9,79\end{array}$

$\begin{array}{rrr}5 & 2 & 9,79 \\ 5 & 3 & 14,63\end{array}$

$\begin{array}{lll}5 & 4 & 8,57\end{array}$

$\begin{array}{lll}5 & 5 & 12,61\end{array}$

$\begin{array}{lll}5 & 6 & 13,83\end{array}$

$\begin{array}{lll}5 & 7 & 14,71\end{array}$

$\begin{array}{lll}5 & 8 & 13,79\end{array}$

$\begin{array}{lrr}5 & 9 & 15,35\end{array}$

$5 \quad 10 \quad 14,55$

$511 \quad 12,96$

$\begin{array}{lll}5 & 12 & 11,43\end{array}$

$\begin{array}{lll}5 & 13 & 11,72\end{array}$

$5 \quad 14 \quad 14,40$

$\begin{array}{lll}5 & 15 & 13,76\end{array}$

$5 \quad 16 \quad 15,43$

13,42

11,03

15,19

10,00

12,58

11,23

13,37

12,15

14,88

14,47

11,55

12,01

11,85

14,83

15,44

14,82

16,13

12,91

17,17

11,45

16,56

15,31

17,50

15,43
GRUPO 3 - CARACTERIZAÇĀO/94

\begin{tabular}{|c|c|c|}
\hline GEN. & LOCAL & TPH5 \\
\hline 5 & 1 & 12,52 \\
\hline 5 & 2 & 15,55 \\
\hline 5 & 3 & 12,03 \\
\hline 5 & 4 & 14,57 \\
\hline 5 & 5 & 11,59 \\
\hline 5 & 6 & 11,76 \\
\hline 5 & 7 & 10,53 \\
\hline 5 & 8 & 12,31 \\
\hline 5 & 9 & 10,14 \\
\hline 5 & 10 & 10,98 \\
\hline 5 & 11 & 16,05 \\
\hline 5 & 12 & 12,51 \\
\hline 5 & 13 & 13,56 \\
\hline 6 & 1 & 11.49 \\
\hline 6 & 2 & 15,88 \\
\hline 6 & 3 & 13,23 \\
\hline 6 & 4 & 15,31 \\
\hline 6 & 5 & 13,20 \\
\hline 6 & 6 & 11,87 \\
\hline 6 & 7 & 10,79 \\
\hline 6 & 8 & 13,50 \\
\hline 6 & 9 & 9,86 \\
\hline 6 & 10 & 12,25 \\
\hline 6 & 11 & 17,48 \\
\hline 6 & 12 & 12,43 \\
\hline 6 & 13 & 12,19 \\
\hline 7 & 1 & 11,77 \\
\hline 7 & 2 & 12,67 \\
\hline 7 & 3 & 11,55 \\
\hline 7 & 4 & 14,33 \\
\hline 7 & 5 & 9,71 \\
\hline 7 & 6 & 10,77 \\
\hline 7 & 7 & 11,10 \\
\hline 7 & 8 & 13,08 \\
\hline 7 & 9 & 9,72 \\
\hline 7 & 10 & 13,01 \\
\hline 7 & 11 & 16,33 \\
\hline 7 & 12 & 9,80 \\
\hline 7 & 13 & 12,70 \\
\hline 8 & 1 & 12,75 \\
\hline 8 & 2 & 12,84 \\
\hline 8 & 3 & 13,52 \\
\hline 8 & 4 & 14,18 \\
\hline 8 & 5 & 13,42 \\
\hline 8 & 6 & 13,49 \\
\hline 8 & 7 & 12,89 \\
\hline 8 & 8 & 15,11 \\
\hline 8 & 9 & 10,62 \\
\hline 8 & 10 & 11,73 \\
\hline 8 & 11 & 15,05 \\
\hline 8 & 12 & 12,01 \\
\hline 8 & 13 & 15,07 \\
\hline
\end{tabular}


Anexo 13 (cont.) - Resultados médios de quatro repetições para os genótipos (GEN.) em cada local ( amb.) para a variável produtividade de açúcar estimada para cinco cortes (TPH5), nos três grupos de ensaios avaliados.

GRUPO 1 - CARACTERIZAÇĂO/92

\begin{tabular}{|c|c|c|}
\hline GEN. & LOCAL & TPH5 \\
\hline 8 & 7 & 12,40 \\
\hline 8 & 8 & 14,96 \\
\hline 8 & 9 & 13,17 \\
\hline 8 & 10 & 13,47 \\
\hline 8 & 11 & 13,97 \\
\hline 8 & 12 & 12,03 \\
\hline 8 & 13 & 14,36 \\
\hline 8 & 14 & 17,41 \\
\hline 9 & 1 & 13,92 \\
\hline 9 & 2 & 15,82 \\
\hline 9 & 3 & 16,02 \\
\hline 9 & 4 & 20,11 \\
\hline 9 & 5 & 14,84 \\
\hline 9 & 6 & 12,79 \\
\hline 9 & 7 & 13,97 \\
\hline 9 & 8 & 14,94 \\
\hline 9 & 9 & 15,74 \\
\hline 9 & 10 & 13,77 \\
\hline 9 & 11 & 16,07 \\
\hline 9 & 12 & 13,81 \\
\hline 9 & 13 & 15,81 \\
\hline 9 & 14 & 20,43 \\
\hline 10 & 1 & 13,82 \\
\hline 10 & 2 & 16,76 \\
\hline 10 & 3 & 17,05 \\
\hline 10 & 4 & 19,16 \\
\hline 10 & 5 & 15,51 \\
\hline 10 & 6 & 13,60 \\
\hline 10 & 7 & 15,83 \\
\hline 10 & 8 & 13,69 \\
\hline 10 & 9 & 14,18 \\
\hline 10 & 10 & 15,51 \\
\hline 10 & 11 & 16,06 \\
\hline 10 & 12 & 13,88 \\
\hline 10 & 13 & 15,71 \\
\hline 10 & 14 & 22,67 \\
\hline 11 & 1 & 11,75 \\
\hline 11 & 2 & 16,42 \\
\hline 11 & 3 & 18,32 \\
\hline 11 & 4 & 20,94 \\
\hline 11 & 5 & 14,00 \\
\hline 11 & 6 & 14,16 \\
\hline 11 & 7 & 16,17 \\
\hline 11 & 8 & 15,90 \\
\hline 11 & 9 & 16,19 \\
\hline 11 & 10 & 16,44 \\
\hline 11 & 11 & 18,14 \\
\hline 11 & 12 & 13,59 \\
\hline 11 & 13 & 15,78 \\
\hline 11 & 14 & 21,90 \\
\hline 12 & 1 & 13,13 \\
\hline 12 & 2 & 15,34 \\
\hline
\end{tabular}

GRUPO 2 - CARACTERIZAÇÃO/93

\begin{tabular}{rrr}
\hline GEN. & LOCAL & TPH5 \\
\hline 7 & 9 & 15,57
\end{tabular}

18,04

6,40

14,90

14,19

17,90

14,10

16,73

13,25

11,50

16,81

10,71

12,66

15,22

12,29

12,93

16,69

14,73

13,25

12,50

12,99

15,40

14,85

15,50

13,00

8,18

12,61

6,49

12,14

14,64

11,35

8,69

13,54

11,89

8,63

12,31

10,57

16,34

10,75

14,26

15,34

10,35

15,41

11,19

12,18

13,84

15,59

12,11

14,32

15,62

12,68

11,81
GRUPO 3 - CARACTERIZAÇĀO/94

\begin{tabular}{|c|c|c|}
\hline GEN. & LOCAL & TPH5 \\
\hline 9 & 1 & 13,55 \\
\hline 9 & 2 & 15,87 \\
\hline 9 & 3 & 15,54 \\
\hline 9 & 4 & 19,00 \\
\hline 9 & 5 & 11,70 \\
\hline 9 & 6 & 13,90 \\
\hline 9 & 7 & 13,56 \\
\hline 9 & 8 & 15,23 \\
\hline 9 & 9 & 10,86 \\
\hline 9 & 10 & 15,40 \\
\hline 9 & 11 & 18,68 \\
\hline 9 & 12 & 12,91 \\
\hline 9 & 13 & 14,85 \\
\hline 10 & 1 & 12,08 \\
\hline 10 & 2 & 16,66 \\
\hline 10 & 3 & 15,14 \\
\hline 10 & 4 & 16,60 \\
\hline 10 & 5 & 13,47 \\
\hline 10 & 6 & 13,54 \\
\hline 10 & 7 & 12,23 \\
\hline 10 & 8 & 15,89 \\
\hline 10 & 9 & 10,18 \\
\hline 10 & 10 & 13,99 \\
\hline 10 & 11 & 17,52 \\
\hline 10 & 12 & 13,92 \\
\hline 10 & 13 & 15,06 \\
\hline 11 & 1 & 10,87 \\
\hline 11 & 2 & 15,49 \\
\hline 11 & 3 & 9,83 \\
\hline 11 & 4 & 16,05 \\
\hline 11 & 5 & 11,28 \\
\hline 11 & 6 & 11,42 \\
\hline 11 & 7 & 9,47 \\
\hline 11 & 8 & 11,80 \\
\hline 11 & 9 & 8,29 \\
\hline 11 & 10 & 12,86 \\
\hline 11 & 11 & 14,89 \\
\hline 11 & 12 & 12,30 \\
\hline 11 & 13 & 12,91 \\
\hline 12 & 1 & 12,17 \\
\hline 12 & 2 & 17,24 \\
\hline 12 & 3 & 13,04 \\
\hline 12 & 4 & 16,79 \\
\hline 12 & 5 & 14,46 \\
\hline 12 & 6 & 14,17 \\
\hline 12 & 7 & 10,77 \\
\hline 12 & 8 & 13,77 \\
\hline 12 & 9 & 10,75 \\
\hline 12 & 10 & 14,47 \\
\hline 12 & 11 & 15,39 \\
\hline 12 & 12 & 12,92 \\
\hline 12 & 13 & 14,79 \\
\hline
\end{tabular}


Anexo 13 (cont.) - Resultados médios de quatro repetiçōes para os genótipos (GEN.) em cada local ( amb.) para a variável produtividade de açúcar estimada para cinco cortes (TPH5), nos três grupos de ensaios avaliados.

GRUPO 1 - CARACTERIZAÇÃOI92

\begin{tabular}{|c|c|c|}
\hline GEN. & LOCAL & TPH5 \\
\hline 12 & 3 & 17,35 \\
\hline 12 & 4 & 14,26 \\
\hline 12 & 5 & 14,77 \\
\hline 12 & 6 & 15,21 \\
\hline 12 & 7 & 12,94 \\
\hline 12 & 8 & 17,35 \\
\hline 12 & 9 & 15,36 \\
\hline 12 & 10 & 14,85 \\
\hline 12 & 11 & 16,08 \\
\hline 12 & 12 & 13,81 \\
\hline 12 & 13 & 16,51 \\
\hline 12 & 14 & 18,62 \\
\hline 13 & 1 & 14,90 \\
\hline 13 & 2 & 13,97 \\
\hline 13 & 3 & 15,74 \\
\hline 13 & 4 & 15,65 \\
\hline 13 & 5 & 13,86 \\
\hline 13 & 6 & 13,20 \\
\hline 13 & 7 & 14,79 \\
\hline 13 & 8 & 14,01 \\
\hline 13 & 9 & 14,80 \\
\hline 13 & 10 & 15,73 \\
\hline 13 & 11 & 15,79 \\
\hline 13 & 12 & 14,90 \\
\hline 13 & 13 & 16,37 \\
\hline 13 & 14 & 18,34 \\
\hline 14 & 1 & 15,20 \\
\hline 14 & 2 & 13,72 \\
\hline 14 & 3 & 15,24 \\
\hline 14 & 4 & 14,05 \\
\hline 14 & 5 & 14,59 \\
\hline 14 & 6 & 15,28 \\
\hline 14 & 7 & 13,42 \\
\hline 14 & 8 & 15,88 \\
\hline 14 & 9 & 16,03 \\
\hline 14 & 10 & 14,46 \\
\hline 14 & 11 & 15,61 \\
\hline 14 & 12 & 14,00 \\
\hline 14 & 13 & 14,69 \\
\hline 14 & 14 & 18,35 \\
\hline 15 & 1 & 12,55 \\
\hline 15 & 2 & 14,24 \\
\hline 15 & 3 & 16,67 \\
\hline 15 & 4 & 19,66 \\
\hline 15 & 5 & 14,41 \\
\hline 15 & 6 & 13,33 \\
\hline 15 & 7 & 14,43 \\
\hline 15 & 8 & 17,35 \\
\hline 15 & 9 & 16,10 \\
\hline 15 & 10 & 15,09 \\
\hline 15 & 11 & 16,78 \\
\hline 15 & 12 & 14,08 \\
\hline
\end{tabular}

GRUPO 2 - CARACTERIZAÇĀO/93

\begin{tabular}{rrr}
\hline GEN. & LOCAL & \multicolumn{1}{c}{ TPH5 } \\
\hline 10 & 13 & 13,23 \\
10 & 14 & 13,57
\end{tabular}

GRUPO 3 - CARACTERIZAÇĀO/94

\begin{tabular}{ccc}
\hline GEN. & LOCAL & TPH5 \\
\hline 13 & 1 & 13,18 \\
13 & 2 & 16,71 \\
13 & 3 & 13,50 \\
13 & 4 & 17,38 \\
13 & 5 & 13,77 \\
13 & 6 & 13,35 \\
13 & 7 & 12,09 \\
13 & 8 & 16,51 \\
13 & 9 & 10,45
\end{tabular}

11,77

14,57

16,81

12,06

14,33

16,33

14,93

12,22

12,18

15,12

11,83

16,14

12,51

9,79

14,86

11,99

11,95

15,51

14,95

11,87

13,29

14,18

11,14

12,38

12,61

16,59

12,91

13,21

13,10

8,53

15,22

9,85

11,93

12,95

13,63

11,72

14,47

15,33

8,08

12,73

12,28

16,21

12,70

14,27
13,15

16,92

13,59

15,98

10,92

14,60

10,96

13,74

11,33

11,58

10,66

10,65

8,88

13,18

16,62

10,29

13,76

10,30

15,64

11,33

14,23

12,15

11,32

9,87

10,40

9,22

11,74

15,06

11,12

13,18

7,73

12,18

12,49

13,84

9,95

8,87

10,18

10,23

9.11

11,95

13,43

9,69

11,90 
Anexo 13 (cont.) - Resultados médios de quatro repetições para os genótipos (GEN.) em cada local ( amb.) para a variável produtividade de açúcar estimada para cinco cortes (TPH5), nos três grupos de ensaios avaliados.

GRUPO 1 - CARACTERIZAÇÃO/92

\begin{tabular}{|c|c|c|}
\hline GEN. & LOCAL & TPH5 \\
\hline 15 & 13 & 16,31 \\
\hline 15 & 14 & 20,01 \\
\hline 16 & 1 & 12,59 \\
\hline 16 & 2 & 14,55 \\
\hline 16 & 3 & 15,11 \\
\hline 16 & 4 & 16,70 \\
\hline 16 & 5 & 16,19 \\
\hline 16 & 6 & 15,59 \\
\hline 16 & 7 & 12,29 \\
\hline 16 & 8 & 13,83 \\
\hline 16 & 9 & 14,71 \\
\hline 16 & 10 & 12,73 \\
\hline 16 & 11 & 13,63 \\
\hline 16 & 12 & 12,21 \\
\hline 16 & 13 & 14,54 \\
\hline 16 & 14 & 20,21 \\
\hline 17 & 1 & 9,41 \\
\hline 17 & 2 & 15,39 \\
\hline 17 & 3 & 14,49 \\
\hline 17 & 4 & 15,30 \\
\hline 17 & 5 & 14,16 \\
\hline 17 & 6 & 12,28 \\
\hline 17 & 7 & 13,97 \\
\hline 17 & 8 & 13,92 \\
\hline 17 & 9 & 14,66 \\
\hline 17 & 10 & 14,47 \\
\hline 17 & 11 & 13,82 \\
\hline 17 & 12 & 12,20 \\
\hline 17 & 13 & 15,58 \\
\hline 17 & 14 & 18,94 \\
\hline 18 & 1 & 15,52 \\
\hline 18 & 2 & 13,63 \\
\hline 18 & 3 & 12,68 \\
\hline 18 & 4 & 14,14 \\
\hline 18 & 5 & 14,59 \\
\hline 18 & 6 & 14,50 \\
\hline 18 & 7 & 9,93 \\
\hline 18 & 8 & 12,88 \\
\hline 18 & 9 & 13,40 \\
\hline 18 & 10 & 13,28 \\
\hline 18 & 11 & 15,99 \\
\hline 18 & 12 & 12,33 \\
\hline 18 & 13 & 14,06 \\
\hline 18 & 14 & 18,29 \\
\hline 19 & 1 & 13,22 \\
\hline 19 & 2 & 18,39 \\
\hline 19 & 3 & 14,65 \\
\hline 19 & 4 & 16,48 \\
\hline 19 & 5 & 16,21 \\
\hline 19 & 6 & 11,81 \\
\hline 19 & 7 & 17,64 \\
\hline 19 & 8 & 15,03 \\
\hline
\end{tabular}

GRUPO 2 - CARACTERIZAÇĀO/93

\begin{tabular}{rrr}
\hline GEN. & \multicolumn{1}{c}{ LOCAL } & \multicolumn{1}{c}{ TPH5 } \\
\hline 14 & 1 & 13,35 \\
14 & 2 & 9,96 \\
14 & 3 & 14,58
\end{tabular}

$\begin{array}{rrr}14 & 2 & 9,96 \\ 14 & 3 & 14,58 \\ 14 & 4 & 11,38\end{array}$

$\begin{array}{rrr}14 & 4 & 11,38 \\ 14 & 5 & 11,62\end{array}$

$14 \quad 6 \quad 13,54$

$14 \quad 7 \quad 12,95$

$14 \quad 8 \quad 10,51$

$1499 \quad 14,44$

$14 \quad 10 \quad 14,77$

$14 \quad 11 \quad 10,68$

$14 \quad 12 \quad 11,70$

$14 \quad 13 \quad 13,62$

$14 \quad 14 \quad 14,49$

$14 \quad 15 \quad 12,25$

$14 \quad 16 \quad 13,45$

$15 \quad 1 \quad 12,53$

$15 \quad 2 \quad 10,88$

$15 \quad 3 \quad 16,41$

$15 \quad 4 \quad 11,81$

$15 \quad 5 \quad 14,40$

$15 \quad 6 \quad 16,43$

$\begin{array}{lll}15 & 7 & 15,12\end{array}$

$15 \quad 8 \quad 14,30$

$\begin{array}{lll}15 & 9 & 14,23\end{array}$

$15 \quad 10 \quad 17,86$

$\begin{array}{lll}15 & 11 & 12,98\end{array}$

$15 \quad 12 \quad 15,20$

$15 \quad 13 \quad 14,21$

$\begin{array}{lll}15 & 14 & 15,89\end{array}$

$15 \quad 15 \quad 15,72$

$15 \quad 16 \quad 15,71$

$\begin{array}{lll}16 & 1 & 12,69\end{array}$

$\begin{array}{lll}16 & 2 & 9,87\end{array}$

$\begin{array}{lll}16 & 3 & 13,29\end{array}$

$\begin{array}{lll}16 & 4 & 10,47\end{array}$

$16 \quad 5 \quad 10,30$

$\begin{array}{lll}16 & 6 & 13,59\end{array}$

$\begin{array}{lll}16 & 7 & 14,26\end{array}$

$\begin{array}{lll}16 & 8 & 11,93\end{array}$

$\begin{array}{lll}16 & 9 & 13,20\end{array}$

$16 \quad 10 \quad 14,51$

$16 \quad 11 \quad 12,46$

$\begin{array}{lll}16 & 12 & 12,37\end{array}$

$16 \quad 13 \quad 13,99$

$16 \quad 14 \quad 14,53$

$16 \quad 15 \quad 12,53$

$\begin{array}{lll}16 & 16 & 14,25\end{array}$

$17 \quad 1 \quad 14,25$

$\begin{array}{lll}17 & 2 & 11,47\end{array}$

$17 \quad 3 \quad 16,03$

$\begin{array}{lll}17 & 4 & 11,32\end{array}$
GRUPO 3 - CARACTERIZAÇĀO/94

\begin{tabular}{|c|c|c|}
\hline GEN. & LOCAL & TPH5 \\
\hline 17 & 1 & 11,40 \\
\hline 17 & 2 & 14,58 \\
\hline 17 & 3 & 12,61 \\
\hline 17 & 4 & 16,36 \\
\hline 17 & 5 & 12,27 \\
\hline 17 & 6 & 13,13 \\
\hline 17 & 7 & 12,16 \\
\hline 17 & 8 & 12,17 \\
\hline 17 & 9 & 8,97 \\
\hline 17 & 10 & 14,33 \\
\hline 17 & 11 & 15,04 \\
\hline 17 & 12 & 13,06 \\
\hline 17 & 13 & 13,89 \\
\hline 18 & 1 & 10,71 \\
\hline 18 & 2 & 13,06 \\
\hline 18 & 3 & 10,74 \\
\hline 18 & 4 & 13,88 \\
\hline 18 & 5 & 10,98 \\
\hline 18 & 6 & 12,16 \\
\hline 18 & 7 & 9,54 \\
\hline 18 & 8 & 10,08 \\
\hline 18 & 9 & 8,69 \\
\hline 18 & 10 & 9,93 \\
\hline 18 & 11 & 12,77 \\
\hline 18 & 12 & 9,94 \\
\hline 18 & 13 & 11,78 \\
\hline 19 & 1 & 10,18 \\
\hline 19 & 2 & 15,37 \\
\hline 19 & 3 & 12,30 \\
\hline 19 & 4 & 15,40 \\
\hline 19 & 5 & 10,52 \\
\hline 19 & 6 & 12,39 \\
\hline 19 & 7 & 11,88 \\
\hline 19 & 8 & 10,66 \\
\hline 19 & 9 & 8,47 \\
\hline 19 & 10 & 12,74 \\
\hline 19 & 11 & 16,35 \\
\hline 19 & 12 & 11,23 \\
\hline 19 & 13 & 12,73 \\
\hline 20 & 1 & 12,10 \\
\hline 20 & 2 & 14,48 \\
\hline 20 & 3 & 13,39 \\
\hline 20 & 4 & 15,86 \\
\hline 20 & 5 & 12,32 \\
\hline 20 & 6 & 11,01 \\
\hline 20 & 7 & 10,41 \\
\hline 20 & 8 & 14,44 \\
\hline 20 & 9 & 10,76 \\
\hline 20 & 10 & 11,93 \\
\hline 20 & 11 & 17,12 \\
\hline 20 & 12 & 11,36 \\
\hline 20 & 13 & 12,77 \\
\hline
\end{tabular}


Anexo 13 (cont.) - Resultados médios de quatro repetições para os genótipos (GEN.) em cada local ( amb.) para a variável produtividade de açúcar estimada para cinco cortes (TPH5), nos três grupos de ensaios avaliados.

GRUPO 1 - CARACTERIZAÇĂO/92

\begin{tabular}{|c|c|c|}
\hline GEN. & LOCAL & TPH5 \\
\hline 19 & 9 & 14,74 \\
\hline 19 & 10 & 16,75 \\
\hline 19 & 11 & 13,62 \\
\hline 19 & 12 & 13,12 \\
\hline 19 & 13 & 16,92 \\
\hline 19 & 14 & 17,01 \\
\hline 20 & 1 & 14,91 \\
\hline 20 & 2 & 16,75 \\
\hline 20 & 3 & 16,99 \\
\hline 20 & 4 & 18,28 \\
\hline 20 & 5 & 14,00 \\
\hline 20 & 6 & 15,73 \\
\hline 20 & 7 & 14,56 \\
\hline 20 & 8 & 16,53 \\
\hline 20 & 9 & 14,69 \\
\hline 20 & 10 & 15,16 \\
\hline 20 & 11 & 16,30 \\
\hline 20 & 12 & 14,92 \\
\hline 20 & 13 & 14,73 \\
\hline 20 & 14 & 20,02 \\
\hline 21 & 1 & 14,90 \\
\hline 21 & 2 & 16,51 \\
\hline 21 & 3 & 17,31 \\
\hline 21 & 4 & 19,83 \\
\hline 21 & 5 & 14,43 \\
\hline 21 & 6 & 14,15 \\
\hline 21 & 7 & 16,62 \\
\hline 21 & 8 & 14,08 \\
\hline 21 & 9 & 14,63 \\
\hline 21 & 10 & 15,66 \\
\hline 21 & 11 & 14,62 \\
\hline 21 & 12 & 15,03 \\
\hline 21 & 13 & 18,00 \\
\hline 21 & 14 & 23,37 \\
\hline 22 & 1 & 13,12 \\
\hline 22 & 2 & 17,69 \\
\hline 22 & 3 & 18,06 \\
\hline 22 & 4 & 19,18 \\
\hline 22 & 5 & 15,52 \\
\hline 22 & 6 & 10,73 \\
\hline 22 & 7 & 16,51 \\
\hline 22 & 8 & 14,99 \\
\hline 22 & 9 & 17,60 \\
\hline 22 & 10 & 16,37 \\
\hline 22 & 11 & 16,86 \\
\hline 22 & 12 & 14,83 \\
\hline 22 & 13 & 16,82 \\
\hline 22 & 14 & 19,35 \\
\hline 23 & 1 & 13,79 \\
\hline 23 & 2 & 16,16 \\
\hline 23 & 3 & 18,10 \\
\hline 23 & 4 & 15,92 \\
\hline
\end{tabular}

GRUPO 2 - CARACTERIZAÇĀOI93

\begin{tabular}{crr}
\hline GEN. & LOCAL & TPH5 \\
\hline 17 & 5 & 12,81 \\
17 & 6 & 14,68 \\
17 & 7 & 16,30 \\
17 & 8 & 11,99 \\
17 & 9 & 12,09 \\
17 & 10 & 15,83 \\
17 & 11 & 13,71 \\
17 & 12 & 12,82 \\
17 & 13 & 13,01 \\
17 & 14 & 14,56 \\
17 & 15 & 12,27 \\
17 & 16 & 14,77 \\
18 & 1 & 13,61 \\
18 & 2 & 11,78 \\
18 & 3 & 14,29 \\
18 & 4 & 10,81 \\
18 & 5 & 13,09 \\
18 & 6 & 14,62 \\
18 & 7 & 14,49 \\
18 & 8 & 12,64 \\
18 & 9 & 15,39 \\
18 & 10 & 14,30 \\
18 & 11 & 11,84 \\
18 & 12 & 12,54 \\
18 & 13 & 12,54 \\
18 & 14 & 15,09 \\
18 & 15 & 13,31 \\
18 & 16 & 14,49 \\
19 & 1 & 12,98 \\
19 & 2 & 7,61 \\
19 & 3 & 15,62 \\
19 & 4 & 10,73 \\
20 & 5 & 12,27 \\
19 & 7 & 15,18 \\
20 & 8 & 13,92 \\
19 & 5 & 13,18 \\
19 & 6 & 13,79 \\
19 & 7 & 14,03 \\
19 & 8 & 14,12 \\
19 & 9 & 14,07 \\
19 & 10 & 15,12 \\
19 & 11 & 8,96 \\
19 & 12 & 11,57 \\
19 & 13 & 11,87 \\
19 & 14 & 16,65 \\
19 & 15 & 12,29 \\
19 & 16 & 16,33 \\
10 & 1 & 15,96 \\
10 & 2 & 12,70 \\
19 & 4 & 15,31 \\
19,60 \\
19
\end{tabular}


Anexo 13 (cont.) - Resultados médios de quatro repetições para os genótipos (GEN.) em cada local ( amb.) para a variável produtividade de açúcar estimada para cinco cortes (TPH5), nos três grupos de ensaios avaliados.

GRUPO 1 - CARACTERIZAÇĀO/92

GRUPO 2 - CARACTERIZAÇĀO/93

\begin{tabular}{|c|c|c|}
\hline GEN. & LOCAL & TPH5 \\
\hline 23 & 5 & 13,82 \\
\hline 23 & 6 & 10,83 \\
\hline 23 & 7 & $\{4,74$ \\
\hline 23 & 8 & 14,67 \\
\hline 23 & 9 & 14,70 \\
\hline 23 & 10 & 15,48 \\
\hline 23 & 11 & 16,47 \\
\hline 23 & 12 & 12,51 \\
\hline 23 & 13 & 16,06 \\
\hline 23 & 14 & 19,89 \\
\hline 24 & 1 & 13,06 \\
\hline 24 & 2 & 16,46 \\
\hline 24 & 3 & 16,45 \\
\hline 24 & 4 & 17,18 \\
\hline 24 & 5 & 15,25 \\
\hline 24 & 6 & 13,82 \\
\hline 24 & 7 & 16,24 \\
\hline 24 & 8 & 15,33 \\
\hline 24 & 9 & 14,04 \\
\hline 24 & 10 & 16,08 \\
\hline 24 & 11 & 15,82 \\
\hline 24 & 12 & 14,49 \\
\hline 24 & 13 & 15,90 \\
\hline 24 & 14 & 20,29 \\
\hline 25 & 1 & 13,91 \\
\hline 25 & 2 & 17,21 \\
\hline 25 & 3 & 16,05 \\
\hline 25 & 4 & 15,90 \\
\hline 25 & 5 & 15,05 \\
\hline 25 & 6 & 14,87 \\
\hline 25 & 7 & 13,36 \\
\hline 25 & 8 & 14,55 \\
\hline 25 & 9 & 14,89 \\
\hline 25 & 10 & 13,91 \\
\hline 25 & 11 & 14,56 \\
\hline 25 & 12 & 13,75 \\
\hline 25 & 13 & 16,23 \\
\hline 25 & 14 & 19,33 \\
\hline
\end{tabular}

\begin{tabular}{rrr}
\hline GEN. & LOCAL & TPH5 \\
\hline 20 & 9 & 16,31 \\
20 & 10 & 18,18 \\
20 & 11 & 12,40 \\
20 & 12 & 13,85 \\
20 & 13 & 14,78 \\
20 & 14 & 14,80 \\
20 & 15 & 14,06 \\
20 & 16 & 18,26 \\
\hline
\end{tabular}

